Le Cirad en 2001 
Le Cirad, Centre de coopération internationale en recherche agronomique pour le développement, est un organisme scientifique spécialisé en agriculture des régions tropicales et subtropicales. Sous la forme d'un établissement public, il est né en 1984 de la fusion $d^{\prime}$ instituts de recherche en sciences agronomiques, vétérinaires, forestières et agroalimentaires des régions chaudes.

Sa mission : contribuer au développement de ces régions par des recherches, des réalisations expérimentales, la formation, l'information scientifique et technique.

Il emploie 1800 personnes, dont 900 cadres, qui interviennent dans une cinquantaine de pays. Son budget s'élève à 1 milliard de francs (152 millions d'euros), dont plus de la moitié provient de fonds publics.

Le Cirad comprend sept départements de recherche : cultures annuelles (Cirad-ca) ; cultures pérennes (Cirad-cp) ; productions fruitières et horticoles (Cirad-flhor) ; élevage et médecine vétérinaire (Cirad-emvt) ; forêts (Cirad-forêt) ; territoires, environnement et acteurs (Cirad-tera) ; amélioration des méthodes pour l'innovation scientifique (Cirad-amis).

Le Cirad travaille dans ses propres centres de recherche, au sein de structures nationales de recherche agronomique des pays partenaires, ou en appui à des opérations de développement. 
Le Cirad en 2001 

7. Le message du président

8 Pour une mondialisation équitable

(12) Coopération et excellence scientifique

(18) Cultures annuelles

28 Cultures pérennes

(38) Productions fruitières et horticoles

(46) Elevage et médecine vétérinaire

54. Forêts

62 Territoires, environnement et acteurs

70) Amélioration des méthodes pour l'innovation scientifique

81 Le Cirad en bref 



\section{Le message du président}

Le conseil d'administration du Cirad a adopté le projet stratégique lors de sa séance de mars 2002. Je voudrais souligner l'importance et la qualité de ce document qui fixe de grandes ambitions pour cet établissement et qui exprime, par ses choix, sa volonté de rénovation et d'ouverture.

Ce projet est le fruit d'un très important travail de préparation interne. Une réflexion en profondeur a été menée sur les atouts que le Cirad doit valoriser et sur les inflexions à engager. Ce projet tient compte des avis exprimés par son conseil scientifique et par le comité d'audit externe, consulté en avril 2001. I/ propose enfin la synthèse des nombreux débats de qualité que le conseil d'administration a eu sur les grands choix de l'établissement depuis deux ans.

Le projet stratégique montre la voie d'une approche renouvelée de la recherche pour le développement. L'accent est mis sur la production en commun de connaissances sur le développement durable, notamment dans le cadre des futurs pôles de compétence en partenariat. C'est sans doute un des grands enjeux pour la recherche pour le développement, laquelle est plus que jamais nécessaire dans ce contexte de mondialisation des échanges matériels et intellectuels.

Le projet stratégique souligne également le choix $d^{\prime}$ 'un enracinement renforcé au sein du système français de recherche et $d^{\prime}$ 'enseignement supérieur et celui de son ouverture à l'espace européen de la recherche. Le rôle reconnu aux équipes - cellules de base de la vie scientifique - , la mise en place d'une politique d'évaluation à quatre niveaux — l'établissement, les départements et les programmes, les équipes, les individus -, I'animation par projets thématiques transversaux, le développement des capacités de veille et de prospectives, tous ces éléments vont concourir à la modernisation scientifique du Cirad. Enfin, la mise en place d'un comité d'éthique permettra d'éclairer le choix de nos actions, notamment ceux en partenariat avec le secteur privé et les pays du Sud.

Le projet stratégique doit maintenant vivre. // offre un cadre ambitieux et large où les agents, individuellement et collectivement surtout, peuvent construire leur vision du devenir de leur action. I/ propose aussi à tous les partenaires du Cirad, publics comme privés, au Sud comme au Nord, les grandes lignes, sur lesquelles les convergences seront recherchées.

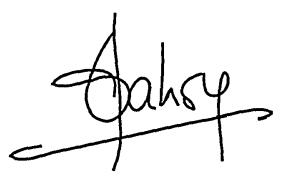

Daniel Nahon

Président du conseil d'administration du Cirad 


\section{Pour}

\section{une mondialisation équitable}

aire de la réduction des inégalités

Yun des objectifs prioritaires des rapports internationaux et fonder, par le partage et la construction des savoirs, une conception équitable de la mondialisation telles sont les ambitions qui sous-tendent le projet stratégique du Cirad pour les dix prochaines années. Fruit d'une réflexion engagée depuis la fin de 1999, ce projet, approuvé par le conseil d'administration de Vétablissement en mars 2002, va amener le Cirad à infléchir l'ensemble de ses missions : la recherche, Vappui au développement et aux politiques publiques, la formation et l' information. Pour mieux répondre aux besoins de ses partenaires du Sud. 


\section{Le projet stratégique du Cirad}

Notre monde est en mutation. La mondialisation et la libéralisation des échanges, les progrès de la biologie et de l'informatique, la fulgurante expansion des technologies de l'information et de la communication bouleversent nos repères : la planète est désormais un village qu'il faut apprendre à gérer ensemble tout en respectant la diversité. Lutte contre

I a pauvreté et la malnutrition, sécurité et qualité alimentaire, amélioration des conditions de vie des sociétés rurales les plus démunies, accès pour tous aux connaissances et aux technologies, préservation de l'environnement sont, pour tous les pays du Nord et du Sud, les grands enjeux de ce début de troisième millénaire. Etablissement public de recherche et de coopération pour le développement, au cœur des questions internationales, le Cirad est l'un des principaux acteurs de cette mutation.

Comment adapter notre action dans un monde qui change? Vers quels domaines prioritaires orienter nos recherches pour contribuer à un monde plus équitable? Sur quels atouts fonder notre évolution? C'est pour répondre à ces questions que le Cirad a engagé, dès la fin de 1999, une réflexion sur sa stratégie dans les dix années à venir.

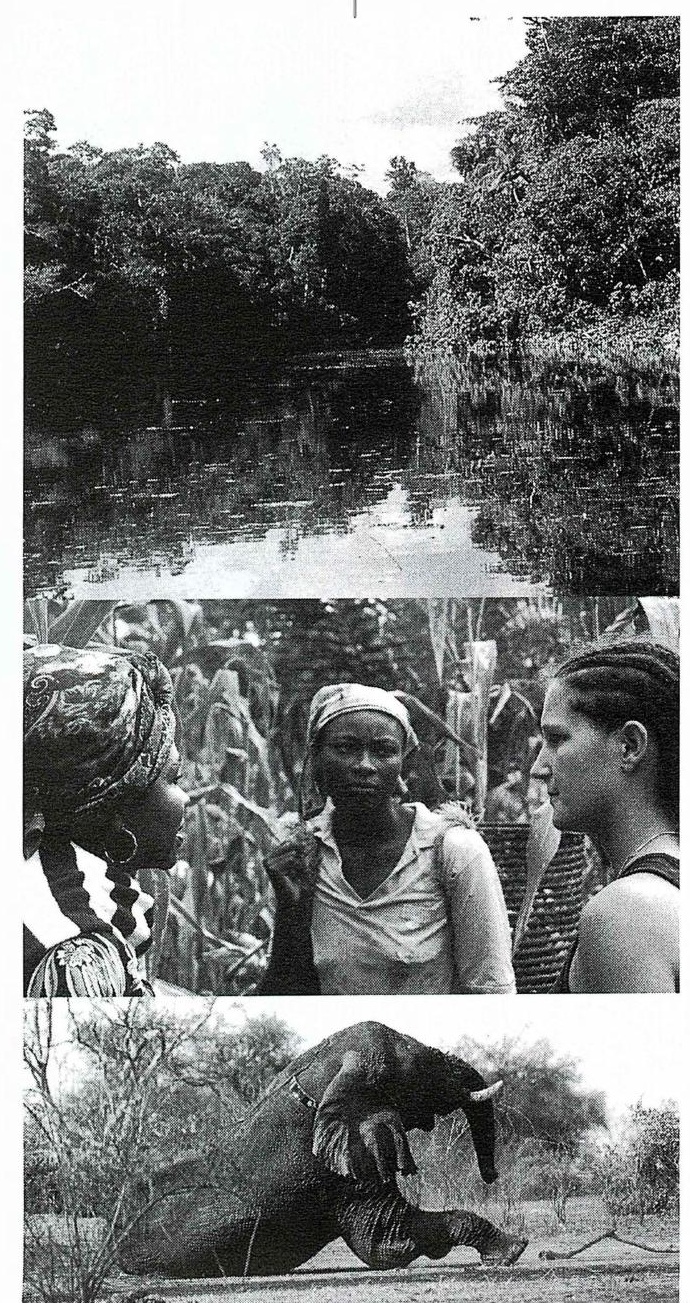

\section{Le développement durable comme ligne de force}

Aujourd'hui, dans les pays en développement, les besoins en produits agricoles ne sont pas encore satisfaits, la malnutrition demeure et les sociétés rurales aspirent à de meilleures conditions de vie. Rapidement, les agricultures de ces pays devront gagner encore en productivité - hausse des rendements, réduction des coûts de production - tout en limitant la pression sur les terres et en préservant l'environnement. Cette révolution doublement verte, le Cirad entend I'accompagner, en mettant au point avec ses partenaires une agriculture durable, tant à l'échelle du système de culture, d'élevage ou de foresterie qu'à celle du système de production et du territoire.

Face à l'ampleur de tels enjeux, il adopte résolument une approche écologique et environnementale de I'agriculture. Le développement durable des sociétés du Sud devient la ligne de force de ses actions. La dimension environnementale s'intègre à toutes ses recherches et les réoriente.

A ce titre, il inscrira plus fermement son action dans le contexte des grandes conventions internationales comme celles sur la biodiversité, la lutte contre la désertification, le changement climatique. Ce choix implique à court terme que soient renforcées ses recherches sur l'eau, l'érosion, la pollution, les maladies émergentes, les forêts et la séquestration du carbone pour ne citer que quelques exemples.

Enfin, il mettra I'accent sur la qualité des aliments et les conséquences nutritionnelles - et culturelles - des changements alimentaires dans les sociétés du Sud.

Ecologie, épidémiologie, génie technologique, sciences sociales et juridiques, sciences de la gestion et de l'information, mathématiques appliquées, autant de disciplines, complémentaires de la biologie et de I'agronomie, que le Cirad mobilisera dans les années à venir afin d'œuvrer efficacement au développement durable. 


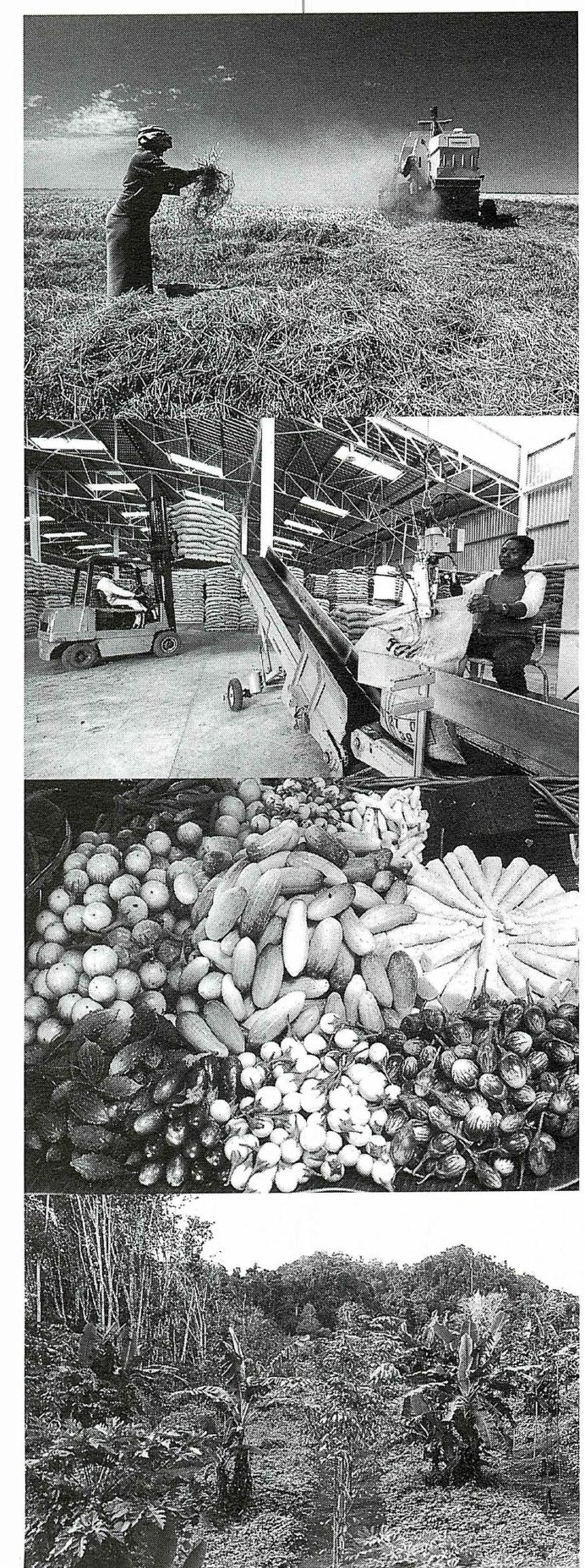

Parce qu'ils sont garants de l'excellence de ses recherches, le Cirad renforcera ses liens avec la communauté scientifique française en participant aux unités mixtes et aux instituts fédératifs de recherche qui se mettent en place.

Enfin, organisme de recherche finalisée, le Cirad applique à ses objets de recherche une approche pluridisciplinaire : du gène à la variété, de la plante ou de l'animal au produit commercialisé, de l'analyse à la décision, de la parcelle au territoire, il organise ses compétences sur le principe de continuums méthodologiques, qu'il maîtrise et promeut. Par ailleurs, il accorde une large place aux métiers de la valorisation, de l'expertise et du développement, qui favorisent l'intégration des connaissances. Cette approche, que le Cirad souhaite conforter, fait du Centre I'une des rares institutions au monde qui puissent traiter de façon intégrée les questions de recherche d'intérêt international posées par les systèmes agricoles et alimentaires des pays du Sud.

\section{De nouvelles modalités de pilotage}

Pour accompagner sa stratégie, le Cirad mettra en place de nouvelles modalités de pilotage. L'équipe verra son rôle renforcé dans la mise en œuvre des activités. Le dispositif d'évaluation sera complété ; global et cohérent, il portera sur quatre niveaux: I'établissement; le département et ses programmes; I'équipe; I'individu. Le Cirad mettra un accent particulier sur la veille scientifique, la prospective stratégique et I'analyse d'impact. Il engagera une démarche d'assurance qualité appliquée à l'ensemble des processus de recherche, de formation, d'information et de gestion. Il définira des critères d'alliance avec le secteur privé, veillant à préserver le droit de transférer les savoirs acquis aux pays du Sud. Enfin, dans un contexte de diversité culturelle et de forte disparité entre le Nord et le Sud, il prendra mieux en compte la dimension éthique de son activité de recherche en coopération. 
'ampleur des défis planétaires actuels oblige les institutions à mettre en commun leurs moyens financiers et humains tout en repensant leur mode de coopération. Le paysage scientifique national et international est ainsi en profonde évolution. Face aux risques d'exclusion et d'accroissement des inégalités, le Cirad ouvre de nouveaux espaces de coopération pour les scientifiques impliqués dans la recherche pour le développement; il s'est notamment fortement engagé avec ses partenaires dans la construction et l'animation de nouvelles formes d'organisation des activités scientifiques en coopération.

Depuis 1999, le Cirad fait principalement porter ses efforts

sur le renforcement $d^{\prime}$ un dispositif équilibré, viable

à long terme, reposant sur une présence continue

des équipes dans les régions tropicales et subtropicales.

Il a ainsi mis en place dans l'outre-mer français des dispositifs adaptés, en concertation avec les autres centres de recherche.

A l'étranger, les équipes du Cirad sont accueillies dans les structures de recherche nationales ou internationales, de plus en plus diversifiées.

Coopération et excellence scientifique
Récemment, des pôles de compétence en partenariat ont vu le jour. Le Cirad s'attache aussi à renforcer ses collaborations avec les universités et les autres établissements $d^{\prime}$ enseignement supérieur au sein d'unités mixtes de recherche et à concrétiser le projet de plate-forme internationale de recherche à Montpellier. Le paysage scientifique français ainsi restructuré en pôles de compétences offre plus de cohérence. Le Cirad améliore son potentiel de coopération avec les systèmes européens et des pays du Sud.

Ses rapprochements avec les établissements de l'enseignement supérieur tout comme la mise en place des pôles de compétence en partenariat à l'étranger bénéficieront pleinement aux chercheurs du Sud $s^{\prime}$ ils s'accompagnent $d^{\prime}$ une dynamique forte d'accueil et de formation. 


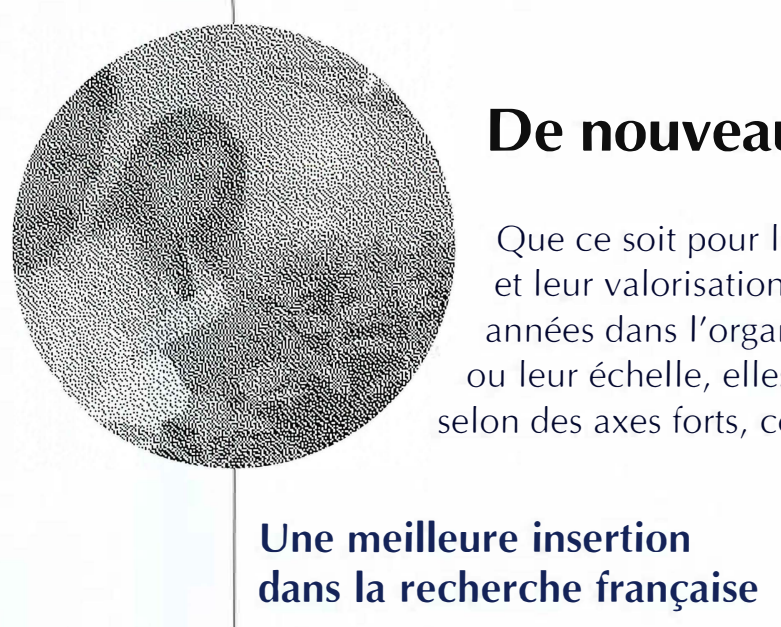

En France, le Cirad a resserré ses liens avec ses partenaires principaux - Inra, Ird et universités - , avec lesquels existe une forte complémentarité scientifique. Un système national de la recherche agricole pour le développement se met peu à peu en place et plusieurs projets, unités de recherche et laboratoires communs traduisent cette dynamique.

Un potentiel renforcé par les unités mixtes de recherche

Les unités mixtes de recherche allient des centres de recherche, des universités et des grandes écoles. Ces alliances offrent au Cirad la perspective d'améliorer son potentiel de recherche, en élaborant avec des équipes de haut niveau des concepts, des outils et des méthodes, qui répondent aux questions de développement et sont utiles à tous. Elles permettent en outre au Cirad de s'impliquer plus fortement dans I'enseignement supérieur français.

L'un des objectifs importants de la participation du Cirad aux unités mixtes de recherche est de contribuer à ouvrir le système français de recherche et d'enseignement supérieur à la coopération scientifique avec les pays du Sud. Cela se traduit par deux effets majeurs. Le premier est de mobiliser de nouvelles équipes scientifiques sur les problématiques des régions tropicales et subtropicales et $d^{\prime}$ inciter davantage les établissements de recherche à prendre en charge certaines thématiques d'intérêt planétaire. Le second est de renforcer I'accueil et l'association des étudiants et des scientifiques des pays du Sud, pour faciliter leur accès à des formations diplômantes.

Une unité mixte de recherche a pour but de mettre en commun, de façon contractuelle, pour une première durée de quatre ans, des moyens financiers et humains. Il s'agit de constituer des équipes de chercheurs d'horizons différents autour d'une même thématique afin de créer des synergies. ou l'organisation de la coopération internationale.

$C^{\prime}$ est dans ce cadre que le Cirad a entrepris de rénover son dispositif de recherche.

En France, il contribue activement à mettre en place un système national de la recherche pour le développement. Plus largement, il participe à I'ouverture d'espaces nouveaux de coopération pour les scientifiques des pays du Nord et du Sud impliqués dans la recherche pour le développement et $s^{\prime}$ est fortement engagé dans la construction et I'animation de nouvelles formes de partenariat. En parallèle, il souhaite recentrer ses activités et développer ses collaborations afin de s'appuyer sur un dispositif équilibré, tant du point de vue scientifique que géographique.

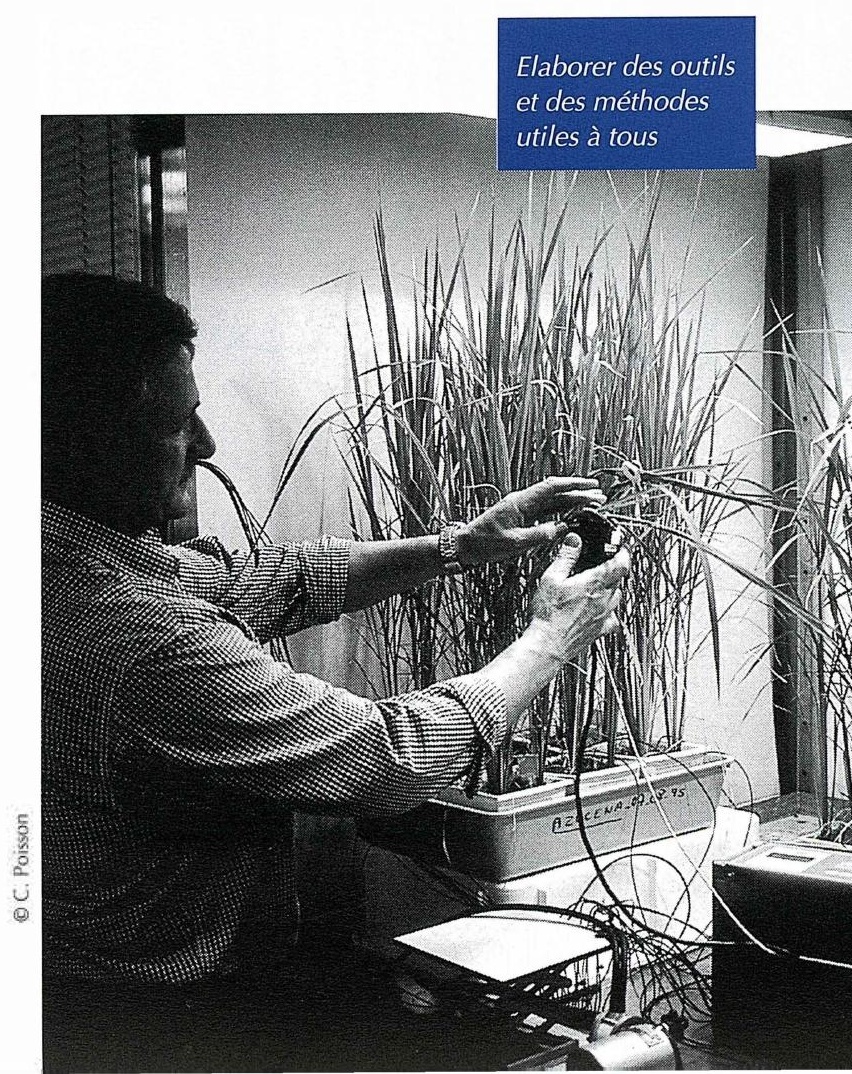




\section{Les unités mixtes de recherche auxquelles participe le Cirad}

- Biologie du développement des plantes pérennes cultivées. Organismes signataires : Agro Montpellier, Cirad, Inra, Ird. Directrice : Françoise Dosba (Agro Montpellier)

- Biologie et génétique des interactions plante-parasite pour la production intégrée. Organismes signataires : Agro Montpellier, Cirad, Inra. Directeur Jean-Loup Notteghem (Agro Montpellier)

- Botanique et bio-informatique de I'architecture des plantes. Organismes signataires : Cirad, Cnrs, Inra, Ird, université Montpellier II. Directeur François Houllier (Inra)

- Centre de biologie et de gestion des populations. Organismes signataires Agro Montpellier, Cirad, Inra, Ird. Directeur : Yves Gillon (Ird)

- Centre d'écologie fonctionnelle et évolutive. Organismes signataires Agro Montpellier, Cirad, Cnrs, Ird, universités Montpellier I, Montpellier II Montpellier III. Directeur : Bernard Delay (Cnrs)

- Diversité et génome des plantes cultivées. Organismes signataires Agro Montpellier, Cirad, Inra, Ird. Directeur : Serge Hamon (Ird)

- Ecologie des forêts de Guyane. Organismes signataires : Cirad, Engref, Inra. Directrice : Meriem Fournier (Inra)

- Elevage des ruminants en région chaude. Organismes signataires : Agro Montpellier, Cirad, Inra. Directeur : François Bocquier (Agro Montpellier)

- Fonctionnement et conduite des systèmes de culture tropicaux et méditerranéens. Organismes signataires : Agro Montpellier, Cirad, Inra. Directeur : Jacques Wéry (Agro Montpellier)

- Génie des procédés, élaboration des bioproduits. Organismes signataires : Cirad, Ensia, universités Montpellier I et Montpellier II. Directeur : Alain Grasmick (université)

- Génomique appliquée aux caractères agronomiques. Organismes signataires Agro Montpellier, Cirad, Inra. Directeur : Jean-Christophe Glaszmann (Cirad)

- Ingénierie des agropolymères et technologies émergentes. Organismes signataires : Agro Montpellier, Cirad, Ensia, Inra, université Montpellier II. Directeur : Stéphane Guilbert (université)

- Innovation, changement technique, apprentissage et coordination dans I'agriculture et I'agroalimentaire. Organismes signataires : Agro Montpellier, Cirad, Cnearc, lam, Inra. Directeur : Fabrice Dreyfus (Agro Montpellier)

- Laboratoire de rhéologie du bois. Organismes signataires : Cirad, Cnrs, Inra, université de Bordeaux. Directeur : Patrick Castera (Inra)

- Laboratoire des symbioses méditerranéennes et tropicales. Organismes signataires : Agro Montpellier, Cirad, Inra, Ird. Directeur : Bernard Dreyfus (Ird)

- Peuplements végétaux et bioagresseurs en milieu tropical. Organismes signataires : Cirad, université de la Réunion. Directeur : Jacques Figier (université)

- Systèmes agraires, gestion durable des ressources et des territoires tropicaux et méditerranéens. Organismes signataires : Cirad, Cnearc, Engref. Directeur Philippe Jouve (Cnearc)

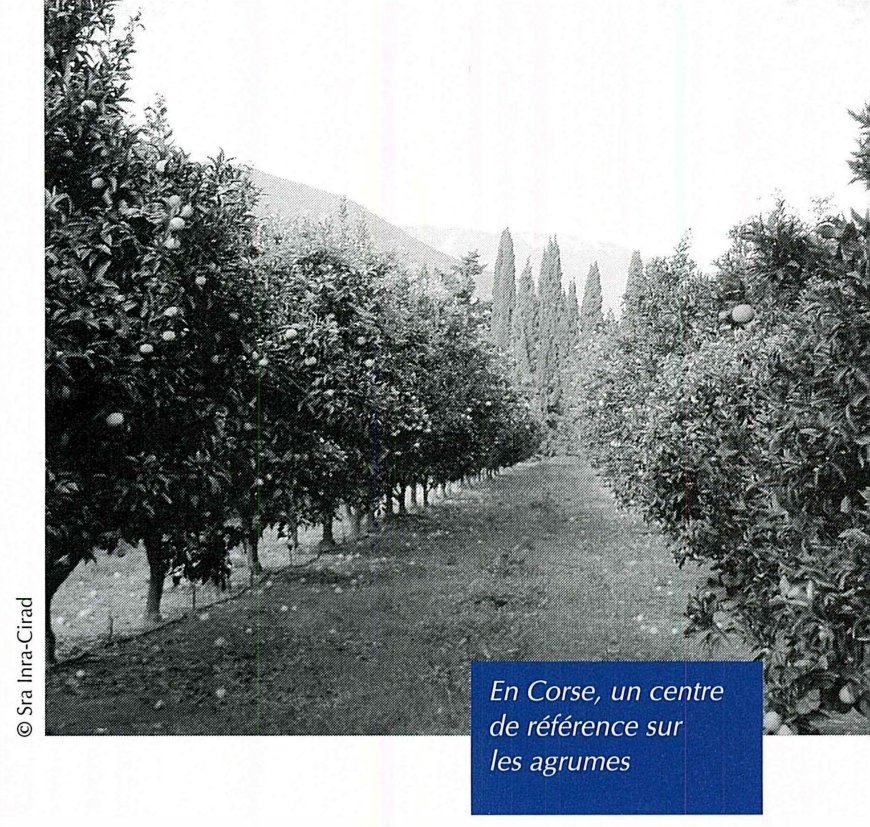

\section{Des centres de référence}

D'autres formes d'association visent à renforcer les pôles existants ou à en créer de nouveaux. Unités communes, instituts fédératifs de recherche et groupements $d^{\prime}$ intérêt scientifique constituent des lieux de coordination et d'échange entre des réseaux de chercheurs et deviennent ainsi des centres de référence.

Une unité commune interdisciplinaire entre I'Inra et le Cirad a été créée à la station de San Giuliano, en Corse. Les chercheurs des deux institutions y mènent des recherches sur les agrumes et les espèces fruitières méditerranéennes. Cette unité est aujourd'hui un pôle de référence international sur les ressources génétiques des agrumes. Elle a pour mission d'élaborer des référentiels scientifiques et techniques dans les domaines de la création variétale, du contrôle de la qualité sanitaire, de l'amélioration de la qualité et de la maîtrise des coûts de production. Le Jardin tropical de Paris associe aux chercheurs du Cirad des universitaires et des scientifiques du Cedimes, du Cired (unité mixte de recherche du Cnrs et de l'Ehess), de I'ledes (université Paris I), de Solagral et de I'Inra. Son ambition est de devenir un centre international sur la mondialisation et l'économie du développement durable, largement ouvert aux chercheurs des pays du Sud. Par ailleurs, le Cirad héberge et gère I'Institut fédératif de recherche pour le développement durable, auquel sont associés I'Ademe, le Cirad, le Cnrs, I'Ifen, I'Inra et I'Ird. Ce groupement d'intérêt scientifique a pour objectif de renforcer les échanges et la concertation entre scientifiques, décideurs, secteur privé et organisations non gouvernementales, afin d'identifier les enjeux du développement durable, de construire les problématiques qui en découlent et d'orienter les travaux de recherche. 


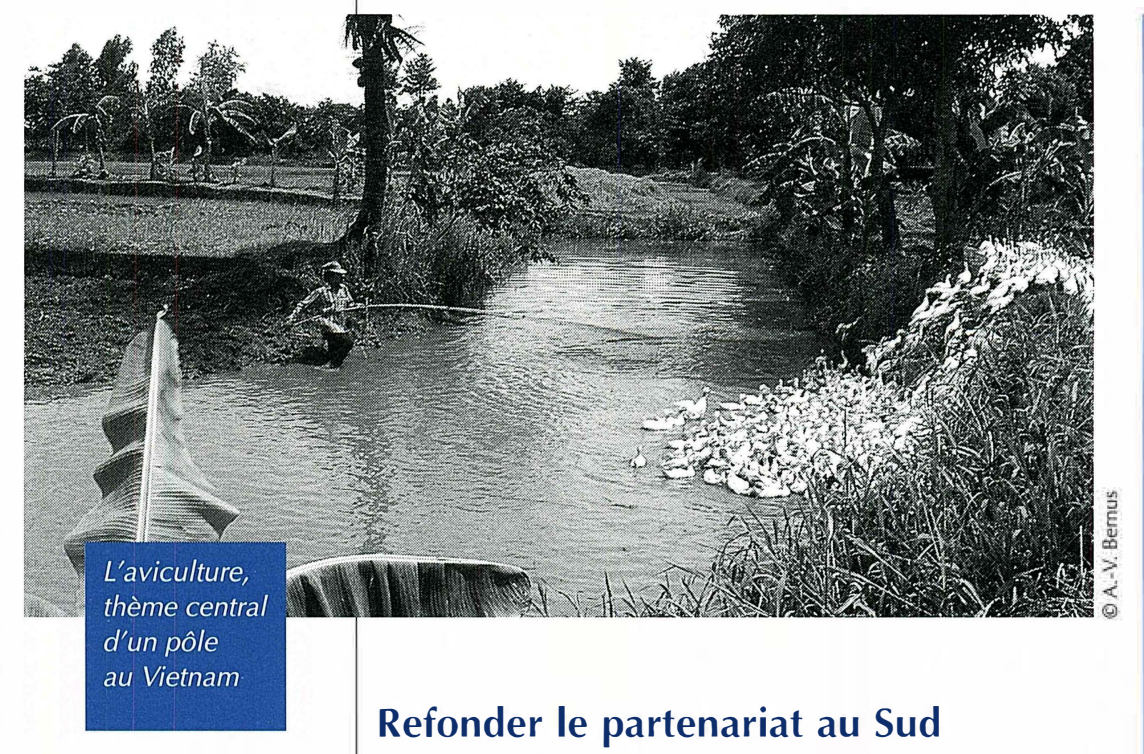

La politique des pôles de compétence en partenariat est l'axe majeur de la refondation de la politique de coopération du Cirad avec les pays du Sud. Réunissant les conditions d'une production scientifique de haut niveau, les pôles de compétence en partenariat privilégient la recherche en commun et la formation des partenaires. Ils répondent à une problématique de développement identifiée avec les partenaires locaux et traitent d'une ou de plusieurs thématiques scientifiques cohérentes. Ils associent à leur initiative des instituts de recherche, des universités, des organismes locaux - groupements de producteurs, organisations non gouvernementales -, et favorisent le regroupement de scientifiques en équipes mixtes dans un lieu unique, à l'étranger. Les recherches menées doivent avoir un véritable impact sur les conditions de vie des populations des pays du Sud : améliorer I'approvisionnement en produits agricoles et accroître le revenu des agriculteurs.

Les activités des pôles de compétence en partenariat seront prises en charge par une équipe pluridisciplinaire et pluri-institutionnelle contractuellement constituée et organisée dans une perspective de long terme, avec des évaluations périodiques. L'évaluation des résultats sera complétée par celle du partenariat, qui portera sur la consolidation des capacités scientifiques des partenaires, la diffusion des produits de recherche dans les sociétés rurales ou dans les filières agricoles et agro-industrielles concernées. Leur impact économique, social et écologique sera également pris en compte.

Huit pôles de compétence en partenariat ont été créés ou sont en cours de validation. En 2003, des pôles sur les problématiques des cultures pérennes, de l'agroforesterie et de la gestion des
Pôles de compétence en partenariat créés ou en cours de validation en 2001-2002

- Economie de la consommation et alimentation des villes. Au Vietnam, un pôle est en cours de création à partir des activités de recherche et de formation engagées par le Cirad (Cirad-flhor, Cirad-emvt, Cirad-amis) avec ses partenaires (Rifav, Vasi, los) sur la problématique de l'alimentation des villes.

- Génomique des plantes tropicales et agroalimentaire. Au Brésil, un pôle est en cours de création à partir des accords-cadres signés par le Cirad avec deux universités de l'Etat de São Paulo, Unicamp et Usp.

- Gestion durable des écosystèmes de savanes d'Afrique de l'Ouest. Au Mali, ce pôle associe I'ler, I'Institut polytechnique de Katibougou, I'université de Bamako et le Cirad (Cirad-ca, Cirad-emvt, Cirad-forêt, Cirad-tera).

- Gestion durable des forêts et protection de la biodiversité. A Madagascar, ce pôle rassemblera le Fofifa, I'université d'Antananarivo (Essa et faculté de droit), le Cnre, le Cirad (Cirad-forêt, Cirad-tera).

- Intensification de l'élevage. Au Vietnam, un pôle de recherche a été créé en 2002. II associe le Cirad (Cirad-emvt) et des partenaires vietnamiens (Niah).

- Lutte contre la désertification et agrosylvopastoralisme. Au Sénégal, le pôle agrosylvopastoral en zones sèches d'Afrique de l'Ouest associe I'Isra, les universités de Dakar et de SaintLouis, le Cirad (Cirad-emvt, Cirad-forêt, Cirad-tera).

- Mécanismes physiologiques et génétiques d'adaptation à la sécheresse. Au Sénégal, un pôle associe l'Isra, l'Ensa de Thiès, I'Ucad, les universités de Paris-Créteil, de Hohenheim en Allemagne et de Greenwich en Angleterre, le Cirad (Cirad-ca, Ciradamis).

- Systèmes de culture et rizicultures durables. A Madagascar, le pôle sur la problématique d'une gestion écologiquement, économiquement et socialement durable des rizicultures paysannes engage le Fofifa, I'université d'Antananarivo (Essa), le Cirad (Cirad-ca, Cirad-tera).

écosystèmes devraient se mettre en place en zone tropicale humide. Ces pôles permettront au Cirad de participer, dans le cadre de partenariats, à la compréhension et à l'analyse des défis environnementaux, économiques et sociaux des régions tropicales et subtropicales.

La mutation complète du dispositif de recherche en coopération demandera plusieurs années. Elle exige en effet que chaque pôle soit conçu avec chacun des partenaires locaux et suppose un redéploiement progressif des moyens humains et financiers. 


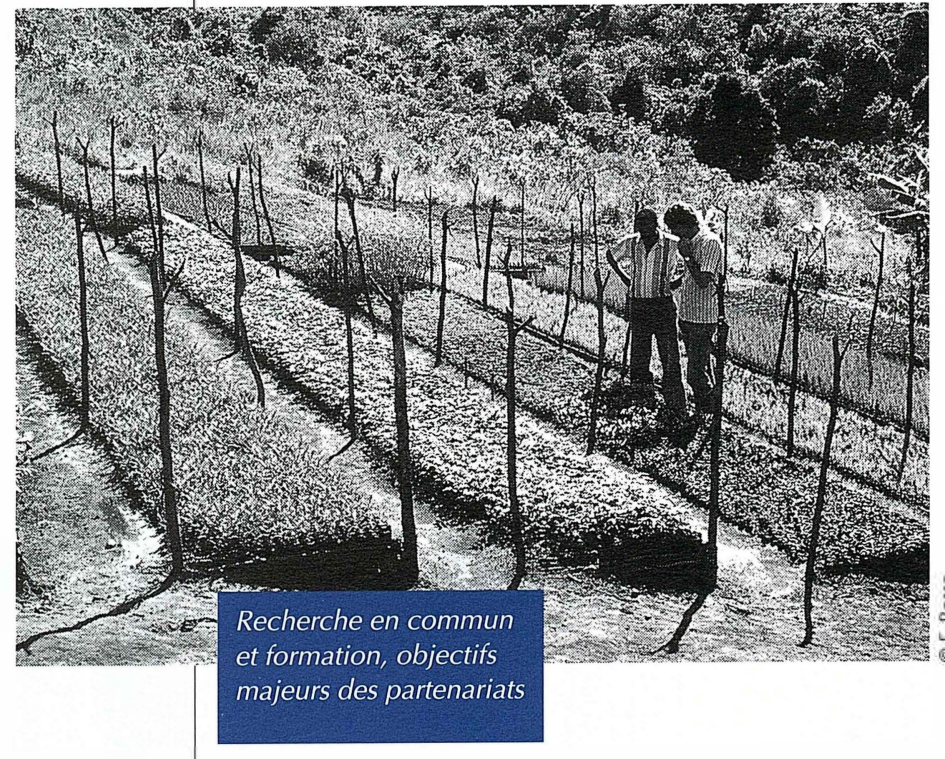

Ces nouveaux modes de coopération viennent compléter des dispositifs de recherche très divers, locaux ou régionaux. Ceux-ci fédèrent, autour des acteurs de la production et du développement, des instituts nationaux, des centres internationaux et des équipes du Nord. Le Cirad participe à des regroupements $\mathrm{n}^{\prime}$ ayant pas, à ce stade, de statut de pôle de compétence en partenariat mais qui réunissent les mêmes conditions de production scientifique et de partenariat. Par exemple, il est associé au Pôle régional de recherche appliquée au développement des savanes d'Afrique centrale, au Centre international de recherche-développement sur l'élevage en zone subhumide au Burkina, ou encore, dans le domaine forestier, à I'unité de recherche sur la productivité des plantations industrielles en République du Congo. Il est aussi présent aux côtés du Catie, centre régional de recherche et $d$ 'enseignement en agronomie tropicale au Costa Rica et au sein du laboratoire franco-chinois d'informatique et de mathématiques appliquées en Chine.

\section{Vers une plate-forme mondiale de recherche}

Aujourd'hui, l'objectif de positionner le centre de recherche de Montpellier comme I'une platesformes mondiales en recherche agricole pour le développement est atteint.
De plus, par le renforcement de la plate-forme d'Agropolis, le Cirad avec d'autres partenaires notamment une vingtaine $d^{\prime}$ 'instituts de recherche et d'enseignement, des collectivités locales, des entreprises privées - a contribué à ouvrir la communauté scientifique à l'international dans le champ de l'agronomie tropicale. Des programmes conjoints avec les centres du Groupe consultatif de la recherche agricole internationale ont été mis en œuvre, et les chercheurs de ces centres travaillent à Montpellier. Un accord avec l'Embrapa, l'institut fédéral brésilien de recherche agronomique, a été signé et un laboratoire de cet institut, Labex, a été créé à Montpellier. Des négociations sont en cours pour ouvrir Agropolis à d'autres partenaires du Sud, notamment l'Icar en Inde et des consortiums d'universités thaïlandaises et sud-africaines.

Grâce à ces nouveaux outils, au renforcement de la plate-forme $\mathrm{d}^{\prime}$ Agropolis, à la coordination des recherches par des unités mixtes de recherche et à la création des pôles de compétence en partenariat, le Cirad poursuit sa mission de recherche pour le développement et de formation des communautés scientifiques du Sud.

Aujourd'hui, près d'un tiers des chercheurs du Cirad travaillent au sein de ces nouveaux dispositifs.

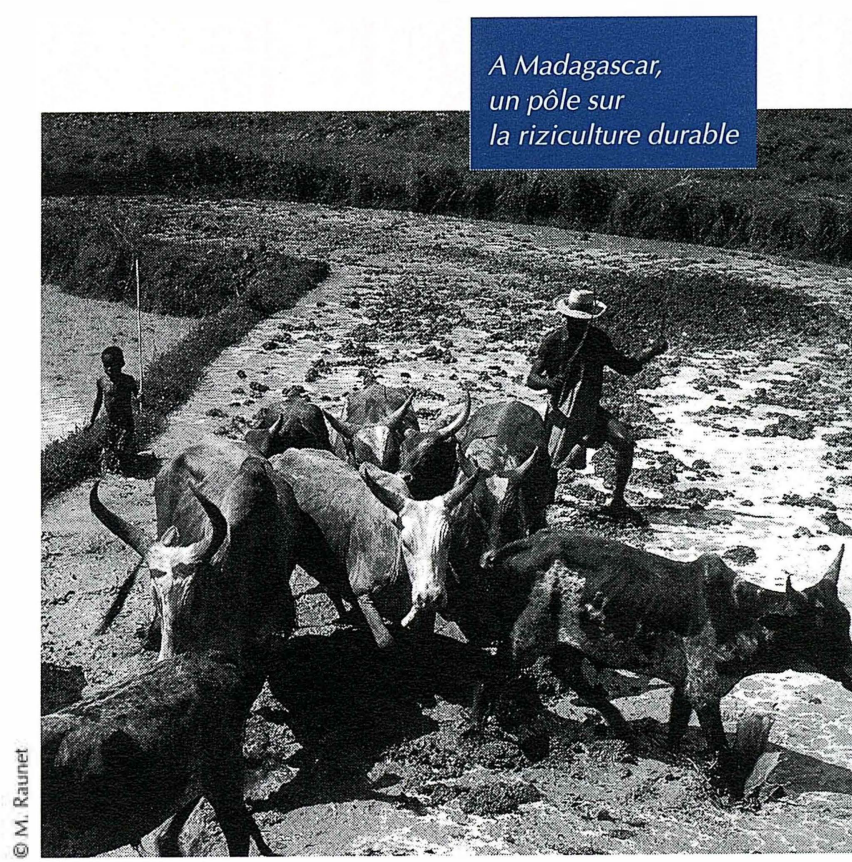




\section{Cultures}

\section{annuelles}

'année 2001 a vu la mise en place de dispositifs de recherche intégrant diverses disciplines pour améliorer les systèmes de culture. Ainsi, les équipes de recherche sur la nouvelle culture du cotonnier ont été confortées au Bénin, au Cameroun et au Mali. Le projet de préservation des sorghos paysans a été lancé au Mali et au Burkina. A Madagascar, l'équipe sur le riz a rejoint celle qui élabore des systèmes de culture sur couverture végétale. Au Sénégal, les dispositifs d'étude de la qualité de l'arachide de bouche sont implantés au sein des systèmes de culture.

Dans toutes ces recherches, I'approche agronomique classique du rendement, de la qualité des végétaux et de la fertilité du milieu a évolué vers une démarche écologique appliquée aux systèmes de culture ou approche

"écosystémique ». Ainsi, la biodiversité des espèces cultivées, la biologie des sols, l'érosion, les flux

hydriques sont pris en compte de même que l'effet des successions de culture et de la sélection variétale sur le parasitisme et sur l'environnement, et la réceptivité des milieux cultivés vis-à-vis de l'apport de déchets pour leur recyclage.

Ces approches écosystémiques requièrent le regroupement de chercheurs de disciplines variées autour d'une thématique, d'objets d'étude et de projets de développement partagés. La création des pôles de compétence en partenariat avec les chercheurs et les universitaires du Mali, sur la gestion des écosystèmes de savane, et de Madagascar, sur les systèmes de culture et les rizicultures durables, a permis de concevoir des programmes nouveaux en coopération. Ces pôles sont désormais, avec les Dom et le Brésil, des lieux privilégiés de recherche et d'innovation. 


\section{Canne à sucre}

Afin d'accroître la productivité et d'abaisser les coûts de production de la canne à sucre, des réflexions se sont engagées pour mieux orienter les recherches. Ainsi, I'amélioration variétale, la conduite de la culture à moindre coût et une utilisation raisonnée de la ressource en eau font l'objet de recherches plus approfondies. Les actions auprès des partenaires étrangers sont consolidées et reposent sur de nouveaux

\section{Modélisation du couvert végétal}

Un modèle de croissance de la canne, Mosicas, de type dynamique et fonctionnel, a été construit à la Réunion. Son domaine de validité concerne actuellement les repousses de la variété R570 pour des cycles de douze à quatorze mois en conditions limitantes d'alimentation hydrique et non limitantes d'alimentation azotée. II permet de simuler toutes les composantes de la biomasse et celles du bilan hydrique. Les expérimentations en cours depuis 2000 à la Réunion et à la Guadeloupe doivent permettre $d^{\prime}$ intégrer au modèle les cannes vierges et six autres variétés commerciales et d'adapter le bilan hydrique aux vertisols.

De nombreuses applications d'aide à la décision sont déjà disponibles : les estimations de production à l'échelle du bassin de collecte, l'optimisation de l'utilisation de la ressource en eau, le calage des cycles pour la Guadeloupe et les Hauts de la Réunion.

Le modèle pourrait aussi assister les sélectionneurs dans la caractérisation des environnements cibles, I'analyse des essais multilocaux et le choix des variétés pour un environnement donné. Des systèmes d'information géographique - Cassis, base de données géoréférencées de la sole cannière à la Guadeloupe, Maplrric, représentation géoréférencée des paramètres parcellaires concernant la gestion de l'eau, et Mapcanne, cartographie des potentialités - associés au modèle de croissance fournissent des informations sur les potentialités et sur la gestion du parcellaire.

\section{Protection de I'environnement}

La monoculture intensive mécanisée de banane dans la région de Capesterre, à la Guadeloupe, est à I'origine d'une dégradation physico-chimique du sol (semelle de labour, compaction, anoxie) et de l'émergence de parasites telluriques (nématodes, charançons) dont l'activité fait baisser les rendements et la longévité des bananeraies. Or, les pressions environnementales fortes obligent à réduire I'utilisation des pesticides usuels. engagements : I'accompagnement des producteurs sucriers d'Afrique de l'Ouest et du Centre, la productivité des petites exploitations en Afrique du Sud, I'utilisation de nouveaux outils de génotypage au Brésil et les effets des agents telluriques en Louisiane.

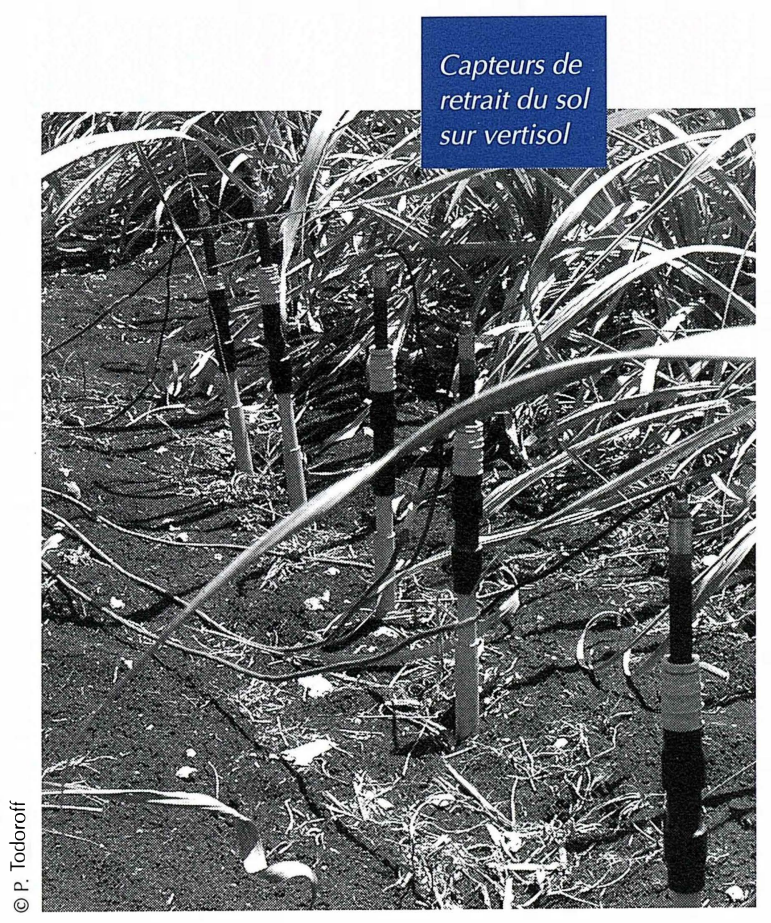

Dans une conjoncture de concurrence peu propice aux investissements, la filière de la banane guadeloupéenne est fragilisée.

L'introduction de la culture de la canne dans le système de production bananier guadeloupéen semble être une solution intéressante tant sur le plan agronomique qu'économique. Depuis 1998, près de 200 hectares de banane sont concernés par ce schéma de rotation et les premiers résultats sont encourageants. 


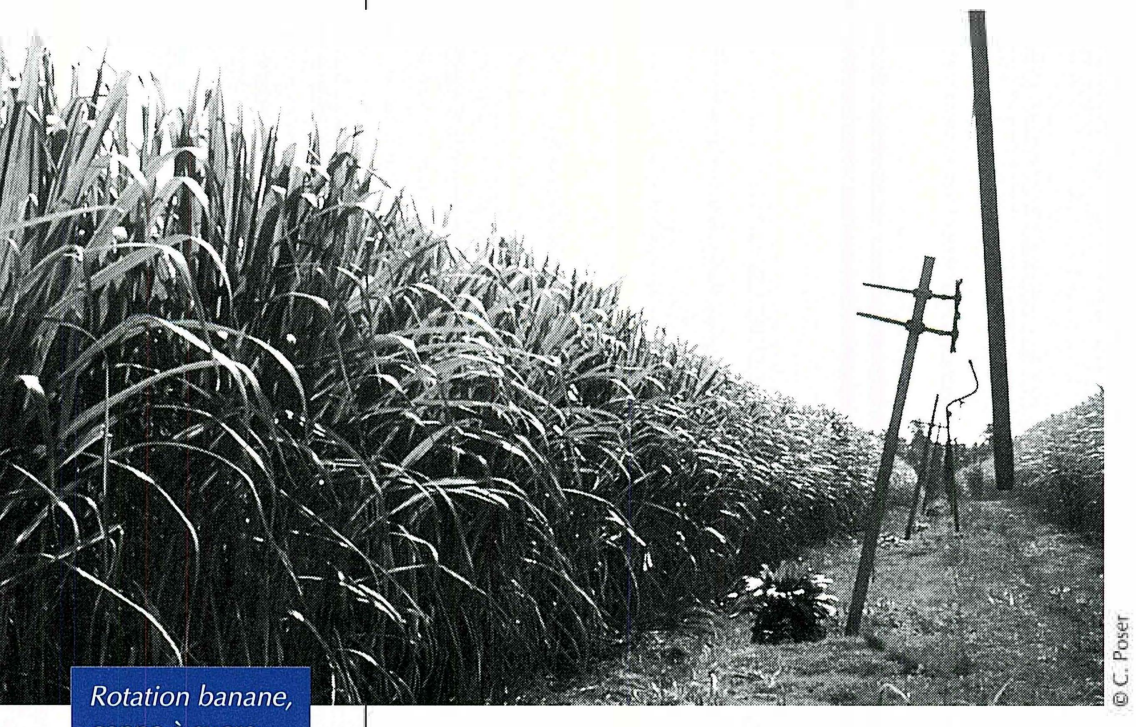

canne à sucre

\section{Approvisionnement des sucreries}

La centralisation des unités de broyage, le maintien ou non de certains centres de réception de canne à sucre ou de certaines usines et la modernisation des équipements industriels sont les préoccupations premières des usiniers pour réduire les coûts de production. Dans cette optique, la réorientation des flux de cannes et le redimensionnement des équipements restants sont des questions importantes.

Un projet s'orientant vers la réorganisation structurelle et fonctionnelle du système global d'approvisionnement a été réalisé en collaboration avec I'Inra, la Mauritius Sugar Producers' Association et trois groupes sucriers à Maurice. Deux modèles informatiques ont été développés pour fournir des éléments de réorganisation des approvisionnements. Un modèle global donne une représentation à l'échelle du bassin d'approvisionnement d'une ou de plusieurs sucreries. Un modèle logistique évalue l'impact des différents scénarios de dimensionnement des équipements agro-industriels.

L'objectif à moyen terme est de fournir des éléments sur l'impact des différents scénarios proposés, associant des aspects logistiques et des aspects plus stratégiques. Les nouveaux modes d'attribution des quotas de livraison pourront être testés tant en terme d'exploitation de la richesse des cannes qu'en terme d'utilisation des équipements agro-industriels.

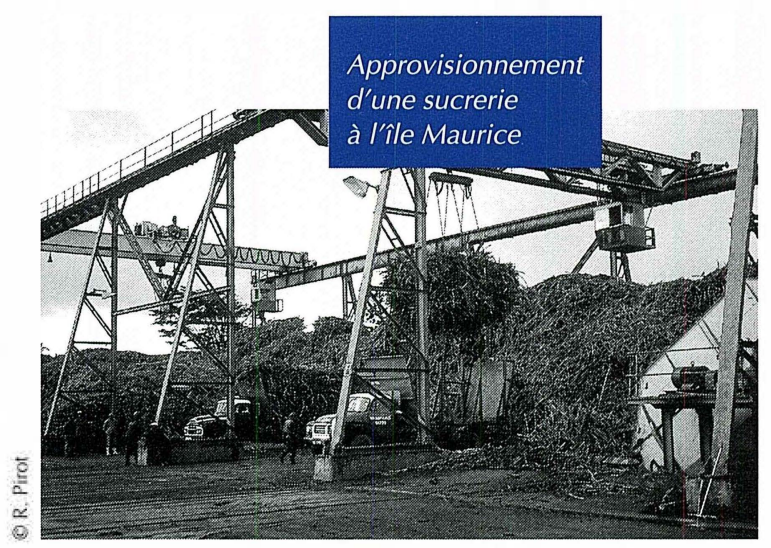

\section{Syndrome de la feuille jaune}

Une étude a été menée sur le syndrome de la feuille jaune causé par le Sugarcane yellow leaf virus pour déterminer l'impact du virus sur les principaux cultivars de canne à sucre à la Réunion et étudier la maladie dans l'île. La présence du virus fait diminuer de $23 \%$ la production en tonnage et de $11 \%$ la teneur en sucre chez le détecter. 
le cultivar R577, mais n'a pas d'effet chez les cultivars R570 et R579. Une enquête épidémiologique indique que la résistance diffère selon les cultivars, que les souches de canne à sucre infectées restent malades après la récolte et que le virus est principalement, mais non exclusivement, propagé par la plantation de boutures infectées et non par l'intermédiaire d'insectes vecteurs. Si la majorité des isolats viraux de la Réunion se différencie de ceux d'autres origines, quatre sont cependant proches. Cela suggère que le virus a été introduit d'un pays tiers et qu'un génotype particulier s'est développé et installé

\section{dans l'île.}

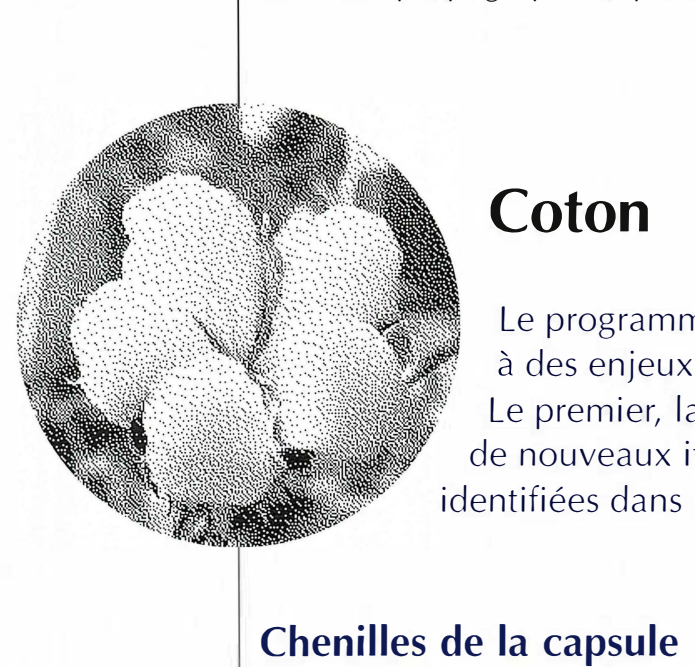

Actuellement, la protection de la culture cotonnière contre les chenilles de la capsule repose essentiellement sur l'application d'insecticides selon un calendrier d'intervention à dates fixes. Afin de rationaliser les traitements insecticides, les stratégies de protection doiventévoluer vers la lutte intégrée et n'utiliser de pesticides que lorsque les ravageurs ont un impact économique réel sur la culture. Cette approche repose sur le seuil de tolérance économique, ou effectif limite, au-delà duquel une population de ravageurs cause des dégâts plus importants que le coût d'un traitement insecticide.

Le cotonnier est une plante à croissance indéterminée qui possède une aptitude à compenser des pertes d'organes fructifères. La détermination d'un seuil de tolérance économique est donc complexe. En effet, à une même population d'insectes peuvent correspondre des pertes de production variables suivant que la culture pourra ou non compenser les dégâts. Les progrès récents dans la modélisation du développement du cotonnier par le modèle Cotons ${ }^{\circledR}$, en association avec la modélisation du développement des populations d'insectes, ont ouvert une nouvelle voie d'approche des seuils de tolérance.

Dans cette optique, le modèle Simbad a été développé en collaboration avec I'Irad au Cameroun, dans le cadre du Prasac. Simbad modélise la démographie et le comportement alimentaire des quatre principales espèces africaines de chenilles de la capsule du cotonnier: Helicoverpa armigera, Diparopsis watersi, Earias spp. et 
Spodoptera littoralis. Le couplage des modèles Cotons $^{\circledR}$ et Simbad permet d'évaluer les pertes de production occasionnées par une population de chenilles en fonction de paramètres tels que l'effectif de la population, sa composition faunistique, la date de l'attaque, le potentiel de production de la culture, etc. L'objectif final est de mettre au point des grilles de décision pour déclencher les traitements insecticides en fonction du rendement visé, d'un potentiel de production ou d'un scénario climatique. Ces grilles de décision devront ensuite être validées en milieu paysan.

\section{Résistance aux insecticides}

Le succès de la culture cotonnière en Afrique de I'Ouest est aujourd'hui sérieusement remis en

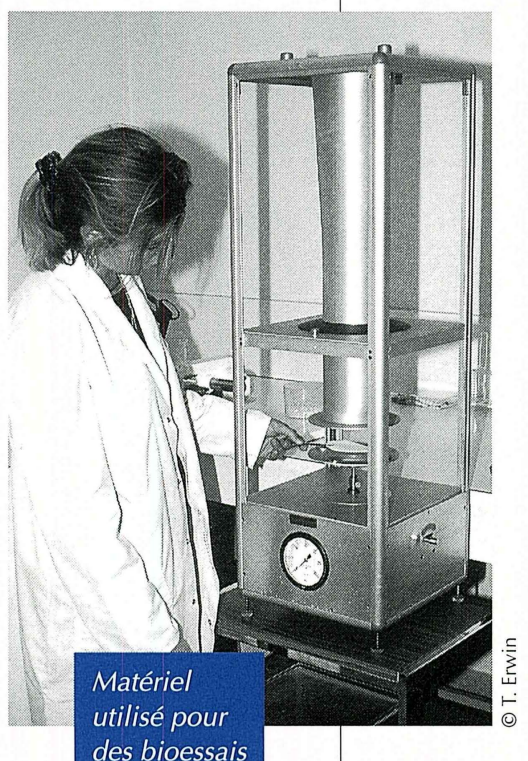
question par une dégradation de la situation phytosanitaire, liée au développement de phénomènes de résistance aux insecticides chez certains ravageurs polyphages, comme la noctuelle Helicoverpa armigera. A partir de 1994, on a observé lors de suivis au laboratoire une forte réduction de la sensibilité aux pyréthrinoïdes, qui s'est manifestée dès 1996 au Bénin et au Burkina par l'échec des traitements au champ. Les sociétés cotonnières et les structures nationales de recherche agronomique ont réagi très rapidement en mettant en place dès 1998 un projet régional pour prévenir l'extension du phénomène. Les trois points clés du projet ont été la réduction de la pression de sélection en excluant les pyréthrinoïdes du début de la campagne, le retour à leur utilisation sous forme d'associations binaires et le suivi régulier des populations de la noctuelle. Les deux dernières campagnes n'ont subi qu'une faible pression parasitaire, laissant penser que les mesures prises avaient eu un effet immédiat sur les populations de la noctuelle. Cependant, la proportion d'individus résistants n'a pas diminué. L'exploration des mécanismes de résistance a été entreprise sur des populations du Bénin et de Côte d'Ivoire : la résistance semble surtout provenir d'une métabolisation de la matière active de l'insecticide par des oxydases.

Une évolution similaire est soupçonnée chez le puceron Aphis gossypii et I'aleurode Bemisia tabaci. Le Cirad a donc engagé plusieurs actions de recherche. Parmi les résultats les plus significatifs, une résistance au diméthoate a été mise en évidence chez des souches camerounaises du puceron.
Un autre projet, Gerico, financé par le ministère français des affaires étrangères, a démarré à la fin de 2001. Il vise à mieux connaître les flux de gènes entre populations $d^{\prime}$ insectes, en particulier ceux liés à la résistance, et à comprendre le mode de diffusion de la résistance à l'échelle de I'Afrique de l'Ouest. Son objectif est à la fois scientifique et pédagogique : caractériser les populations et étudier les mécanismes de résistance, mais aussi former les scientifiques du Sud aux techniques de biochimie et de biologie moléculaire que requièrent ces recherches.

\section{La recherche au Bénin}

Le volet coton du projet d'appui à la recherche agricole du Bénin (Parab) s'est terminé en 2000. Avec la collaboration de I'Inrab et du Cirad, un programme de création variétale du cotonnier a été lancé sur l'amélioration du rendement à l'égrenage et de la qualité technologique de la fibre. Une équipe de sélection est maintenant constituée. Elle a créé du matériel génétique nouveau et prometteur de plusieurs centaines de lignées et mis en place, en partenariat avec les organisations de producteurs du Bénin, un dispositif de sélection participative.

L'objectif du nouveau projet Parcob (2002-2005) est de consolider les résultats du Parab et de permettre à la recherche de s'adapter aux évolutions institutionnelles et techniques en cours : comment rendre le coton béninois plus compétitif sur le marché mondial et assurer la durabilité des systèmes de culture incluant le coton ?

La mise en place d'un observatoire de la filière vise à comprendre les stratégies paysannes et les

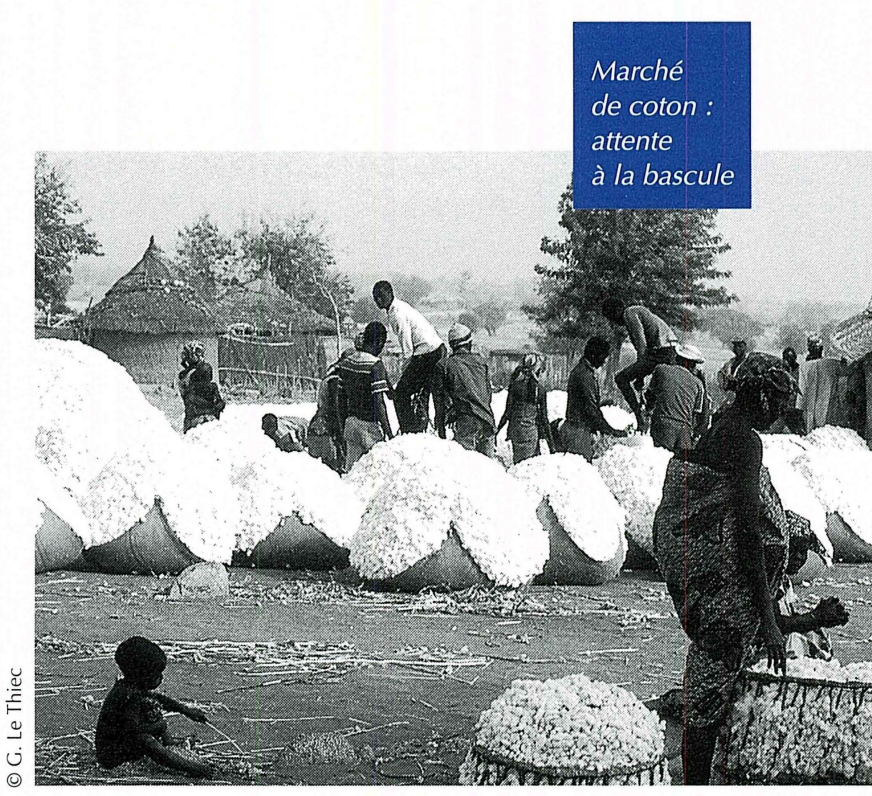


jeux d'acteurs dans leur diversité face aux changements de leur environnement, pour mieux les traduire en problématiques de recherche.

Les éléments de diagnostic déjà disponibles attribuent la baisse des rendements au champ à plusieurs facteurs : productivité insuffisante des variétés importées, baisse d'efficacité des matières actives insecticides, semis plus tardifs, épandage $d^{\prime}$ 'engrais et désherbages retardés. Des recherches utilisant une approche participative porteront en priorité sur ces facteurs et les innovations résultantes devront s'intégrer dans des systèmes de culture globalement cohérents.

Pour créer dans la filière un environnement favorable à la diffusion des innovations, la recherche devra s'impliquer dans le contrôle de la qualité des produits, dans la formation des responsables et plus particulièrement des représentants du monde paysan, dans l'information des acteurs et dans la mise en place de structures d'expérimentation et d'outils d'aide à la décision au sein des organisations paysannes.

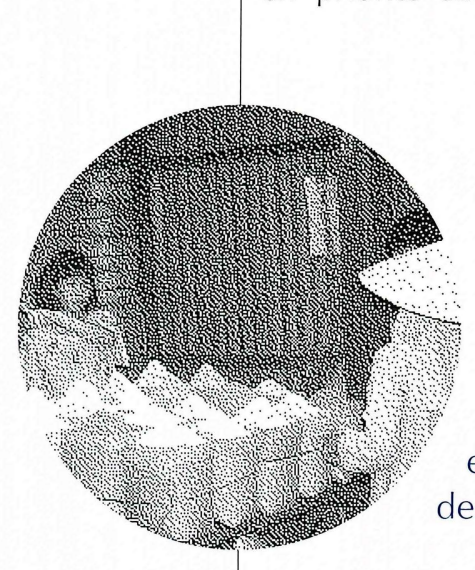

\section{Aklui sec}

L'aklui est une bouillie traditionnelle béninoise, préparée à base d'une farine de maïs fermentée, très appréciée des consommateurs urbains. II est fabriqué artisanalement tous les jours, vendu à l'état frais et consommé directement sur le lieu de vente. Ce produit ne se conserve pas. Un produit de longue conservation prêt à l'emploi pour la confection de la bouillie matinale familiale, des granules séchés prêts à cuire, a été développé par le Cerna, au Bénin, avec l'appui du Cirad.

Un atelier de production semi-industrielle d'aklui stabilisé séché a été installé au Cerna. II a permis de mettre sur le marché ce nouveau produit, plus cher que le produit traditionnel, mais correspondant à la demande urbaine actuelle. Les conditions de production dans I'atelier ont été récemment améliorées et standardisées grâce à un financement du ministère français des affaires étrangères. En particulier, la farine de maïs est maintenant produite mécaniquement à l'aide d'un dégermeur et des bacs de fermentation, achetés localement, facilitent cette opération. L'aklui séché est ensuite conditionné en sachets. Ce produit a été bien accepté par les consommateurs, qui l'achètent volontiers malgré son prix élevé.

L'atelier de fabrication semi-mécanisée produit et commercialise depuis plus de six ans l'aklui séché à Cotonou. Sa rentabilité économique est quasiment acquise. Depuis, six unités concurrentes se la compétitivité et la durabilité des filières rizicoles, liées au marché mondial et reposant sur de grandes unités mécanisées ou de nombreuses petites exploitations implantées dans une même région.

Pour cela, il met en œuvre des recherches sur la connaissance de la plante et ses interactions avec I'environnement cultivé, ainsi que sur l'amélioration des variétés et des itinéraires techniques.

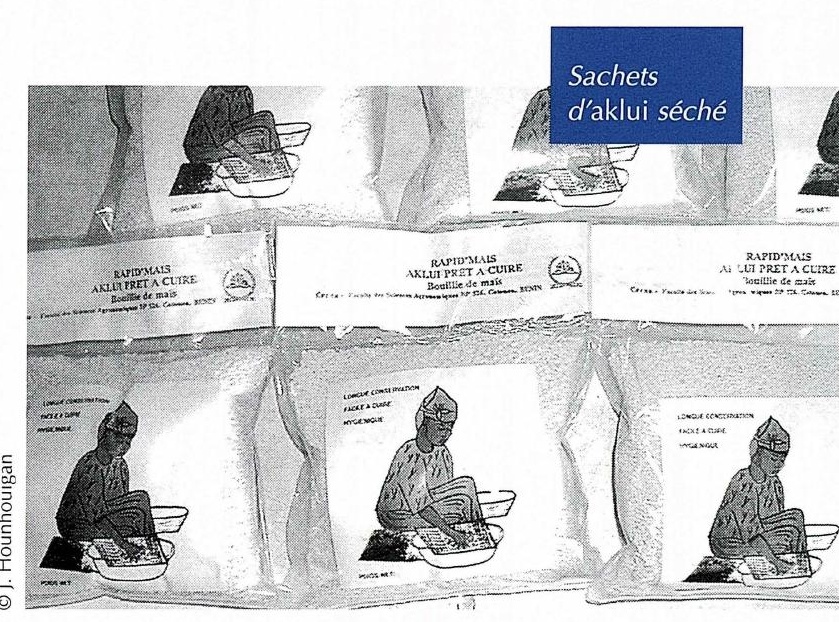

sont montées pour occuper ce nouveau marché. Certaines ont bénéficié d'un appui technique de I'atelier pilote pour la mise au point de leur procédé. 


\section{Pyriculariose du riz}

Ayant rassemblé une collection unique au monde de 1800 souches de Magnaporthe grisea provenant de cinquante-cinq pays, le Cirad a identifié des souches fertiles de ce champignon responsable de la pyriculariose du riz et a étudié les bases génétiques de l'interaction hôte-pathogène.

Trois gènes d'avirulence du champignon ont été cartographiés en collaboration avec le Cnrs. L'un d'entre eux, Ace1, a été cloné et séquencé. II est de grande taille et de nature très différente des autres gènes $d^{\prime}$ avirulence clonés jusqu'à maintenant. L'analyse de ce gène montre une expression précoce et très localisée de son activité.

Le gène de résistance du riz $\mathrm{Pi}-33$ correspondant à $A c e 1$ a été cartographié sur le chromosome 8 . Des marqueurs proches encadrant le gène ont été obtenus. La cartographie physique du locus $\mathrm{Pi}-33$ a été réalisée dans la variété Nipponbare, dont le génome est connu mais qui ne possède pas I'allèle du gène $P i-33$ conférant la résistance. La cartographie physique dans une variété possédant le gène de résistance est en cours et devrait permettre son clonage.

Ces travaux permettent de mieux comprendre les problèmes de durabilité de la résistance et d'évolution des populations de I'agent pathogène. Ils pourront, en particulier, s'appliquer à la sélection assistée par marqueur. En effet, le gène Pi-33 est présent dans plusieurs variétés cultivées sur des surfaces importantes et, combiné à un autre gène de résistance, $P i-1$, il semble conférer une résistance efficace et durable vis-àvis d'une gamme large de souches de M. grisea.

\section{Diversité génétique du taro}

Le taro, Colocasia esculenta, est cultivé sur près de deux millions d'hectares en zone tropicale humide. Malgré son importance pour les agriculteurs les plus pauvres, aucun centre de recherche international $\mathrm{n}^{\prime}$ a pour mandat de conserver ou d'améliorer les cultivars locaux. Grâce à un financement européen, le Tansao, réseau régional d'amélioration du taro pour I'Asie du Sud-Est et I'Océanie, composé de chercheurs du Vietnam, de Thaïlande, de Malaisie, d'Indonésie, des Philippines et de PapouasieNouvelle-Guinée, a pu être mis en place avec le Cirad. De 1998 à 2001, le réseau a collecté et

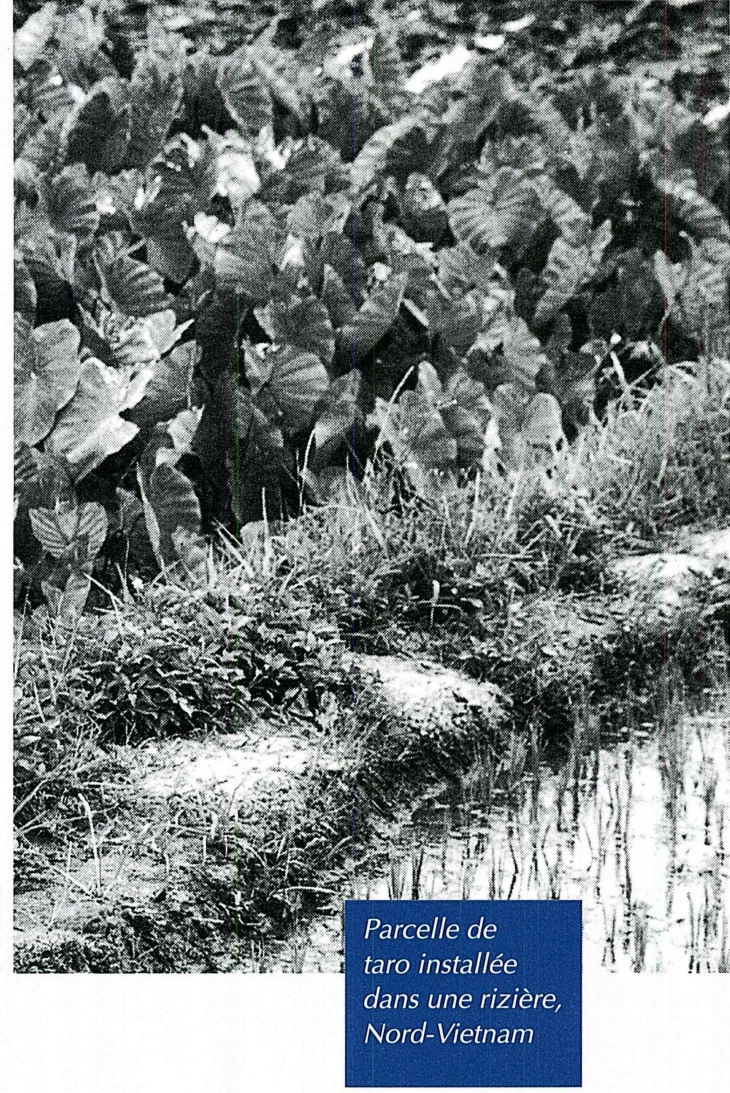

caractérisé près de 2300 variétés locales et criblé plus de 2000 d'entre elles avec six systèmes enzymatiques pour avoir une image de la diversité génétique sur cette vaste zone. Une sélection de 170 cultivars d'élite a été placée in vitro puis distribuée aux pays participants pour multiplication. Une étude à l'aide de marqueurs Aflp sur 235 accessions a permis de confirmer la présence de deux pools génétiques distincts en Asie du SudEst et dans le Pacifique, correspondant à des aires de domestication indépendantes ; la base génétique à l'intérieur de chaque pays est très étroite. Ces résultats, associés à la grande variabilité génétique du principal agent pathogène Phytophthora colocasiae, confirment l'intérêt d'échanger des géniteurs via un centre de transit pour élargir en toute sécurité les bases génétiques des programmes d'amélioration. L'importance du choix variétal est également renforcée par la grande variabilité qui existe pour les teneurs en matière sèche et en amidon.

\section{Arachide de bouche}

Pour relancer la production d'arachide de bouche à l'exportation, le Sénégal doit garantir la qualité physique et sanitaire des graines, notamment en matière de contamination par les aflatoxines, composés toxiques pour la santé humaine. Un projet franco-sénégalais met au point une stratégie intégrée pour améliorer la qualité à chaque étape, de la production à la consommation. 
La première année de recherche a été orientée vers le développement d'outils de gestion de l'alimentation hydrique et l'étude de l'impact des pratiques paysannes et des maladies foliaires sur la qualité des graines $d^{\prime}$ arachide de bouche.

En 2001, les premiers résultats ont été transférés en milieu paysan et l'outil de gestion de l'alimentation hydrique a été validé avec de nouvelles variétés et sous divers modes d'irrigation. L'impact des étapes de postrécolte sur la qualité des arachides de bouche a été étudié pour optimiser les outils et les pratiques. La concertation nationale pour l'amendement de la réglementation sur I'arachide de bouche au Sénégal s'est poursuivie. Les contraintes qualitatives liées à chaque étape de la filière de production et de transformation des arachides de bouche sont maintenant identifiées et quantifiées en terme de risque potentiel de dégradation de la qualité. Des mesures préventives et correctives sont proposées et une filière pilote doit mettre en œuvre l'ensemble de ces recommandations afin d'évaluer la faisabilité technicoéconomique de la production d'arachide de bouche pour l'exportation.

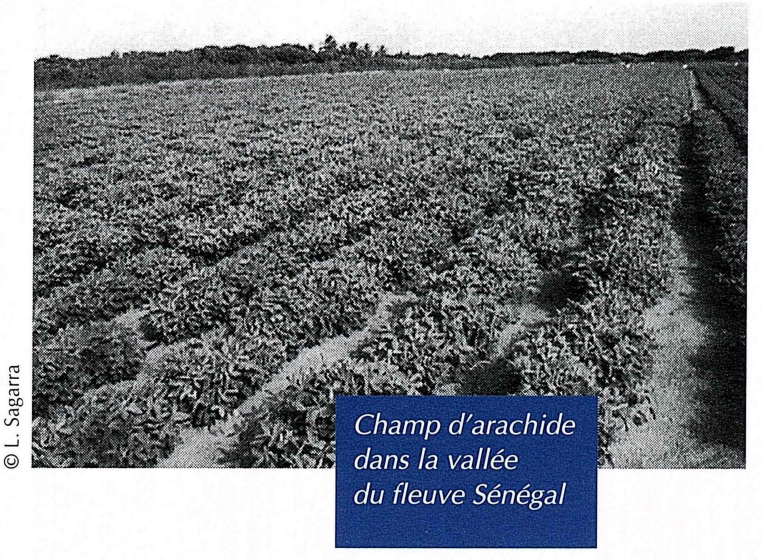

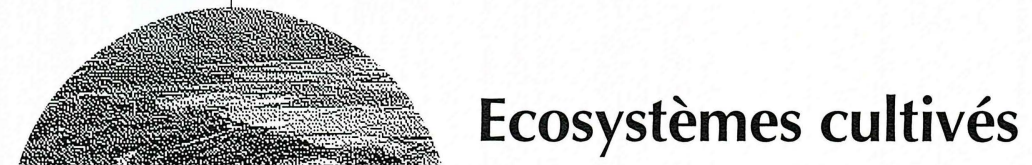

Le programme écosystèmes cultivés a fédéré des recherches explicatives en génétique, en écophysiologie et en géochimie. Il s'est également engagé dans les domaines de la géographie, de la sociologie, de l'économie et du génie des procédés. L'équipe qui étudie les systèmes de culture sur couverture végétale a formé les quatre agronomes récemment recrutés, organisé un atelier de formation

\section{Laboratoire de biologie des sols}

La macrofaune du sol et plus précisément les vers de terre, les fourmis et les termites interviennent dans l'écologie du sol. Leur rôle dans les processus pédologiques tels que la régulation de la dynamique de la matière organique, la libération d'éléments assimilables par les plantes, le maintien de la structure physique du sol et la pédogenèse de certains sols a été largement illustré. Leur implication dans la régulation de l'activité microbienne du sol est maintenant reconnue et ils sont également capables d'influencer l'abondance et la structure des peuplements d'autres invertébrés. Des travaux récents montrent une relation étroite entre l'activité des vers de terre et la croissance végétale. De même, la présence de vers de terre influe sur les niveaux de population des parasites et des ravageurs des plantes.

Cette importance de l'activité de la faune du sol a conduit le Cirad, avec l'aide financière de l'Europe et du Conseil régional de la Réunion, à créer un laboratoire de biologie des sols tropicaux à la Réunion. à Madagascar et entrepris des actions nouvelles au Cameroun et en Tunisie. L'équipe qui traite de la valorisation des déchets a rédigé sa programmation autour du concept d'observatoire, à la Réunion, et deux biogéochimistes ont été recrutés. Une première réflexion sur les hydrosystèmes cultivés a montré le besoin de relancer l'innovation agronomique en agriculture irriguée.

Ce laboratoire étudie quantitativement l'activité de la faune et son influence sur le fonctionnement du sol dans les écosystèmes cultivés. II a également pour objectif $d^{\prime}$ améliorer la compréhension des mécanismes mis en œuvre, qui reste encore très insuffisante, et de former des étudiants de tous niveaux. Enfin, le laboratoire est à la disposition des chercheurs des pays de la zone (Afrique du Sud, Comores, Madagascar, Mayotte, Zimbabwe) dans le cadre de la coopération régionale. 


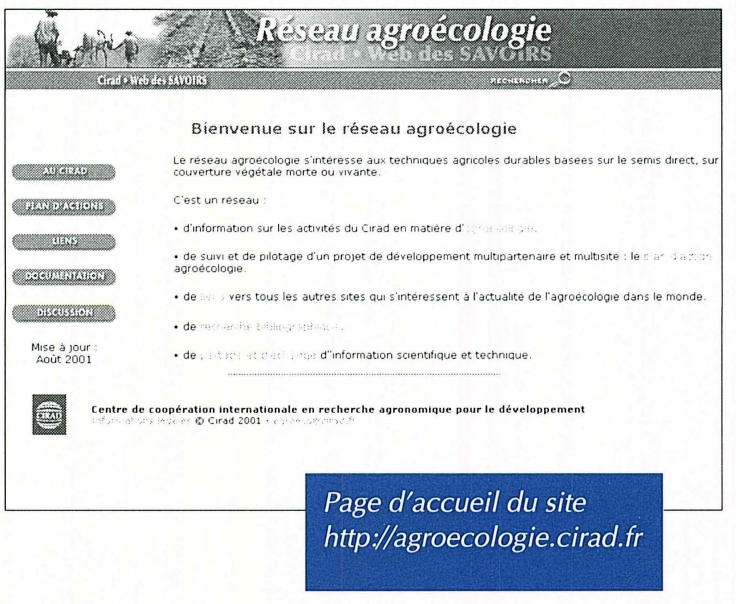

\section{Site web agroécologie}

Le Cirad a développé un site Internet sur les activités du réseau agroécologie, accessible à I'adresse: http://agroecologie.cirad.fr.

Le réseau agroécologie s'intéresse aux techniques agricoles durables fondées sur le semis direct sur couverture végétale morte, vivante ou mixte. C'est un réseau d'information sur les activités du Cirad en matière d'agroécologie. II sert aussi à piloter un projet de développement multipartenaire et multisite, le plan d'action agroécologie. Ce plan est une initiative fédératrice des compétences et des moyens d'action des principaux acteurs de I'aide française. Son objectif est de mettre au point les modes de transfert et de développement des techniques agroécologiques dans cinq pays de la zone prioritaire de solidarité présentant un éventail de zones agroclimatiques (Cameroun, Laos, Madagascar, Mali et Tunisie).

Des liens existent vers les autres sites qui s'intéressent à l'actualité de I'agroécologie dans le monde, réseaux, organisations non gouvernementales, sites thématiques, etc.

Une compilation de données bibliographiques regroupe des références d'ouvrages traitant des techniques culturales de semis direct sur couverture végétale, de l'écologie du profil cultural et du continuum air-plante-sol.

Un espace de discussion est accessible à tous. Cet outil doit permettre à ses utilisateurs de discuter des aspects techniques de l'agroécologie, de faire part de leur savoir-faire, d'échanger des contacts et des références bibliographiques et de s'informer sur l'actualité de l'agroécologie dans le monde.

\section{Agriculture de conservation}

Le Cirad a organisé un atelier international sur les systèmes de culture sur couverture végétale à Madagascar, en mars 2001. La formation d'une cinquantaine de chercheurs et de praticiens des systèmes sur couverture végétale venant d'horizons divers a conduit à un débat scientifique interdisciplinaire et à des perspectives de coopération dans le cadre de réseaux.

Les participants ont échangé leurs expériences, nombreuses et variées, puisqu'ils venaient de pays et de régions aussi différents que I'Afrique du Sud, le Bénin, le Brésil, le Cameroun, I'Ethiopie, la France, I'Indonésie, le Laos, le Mali,

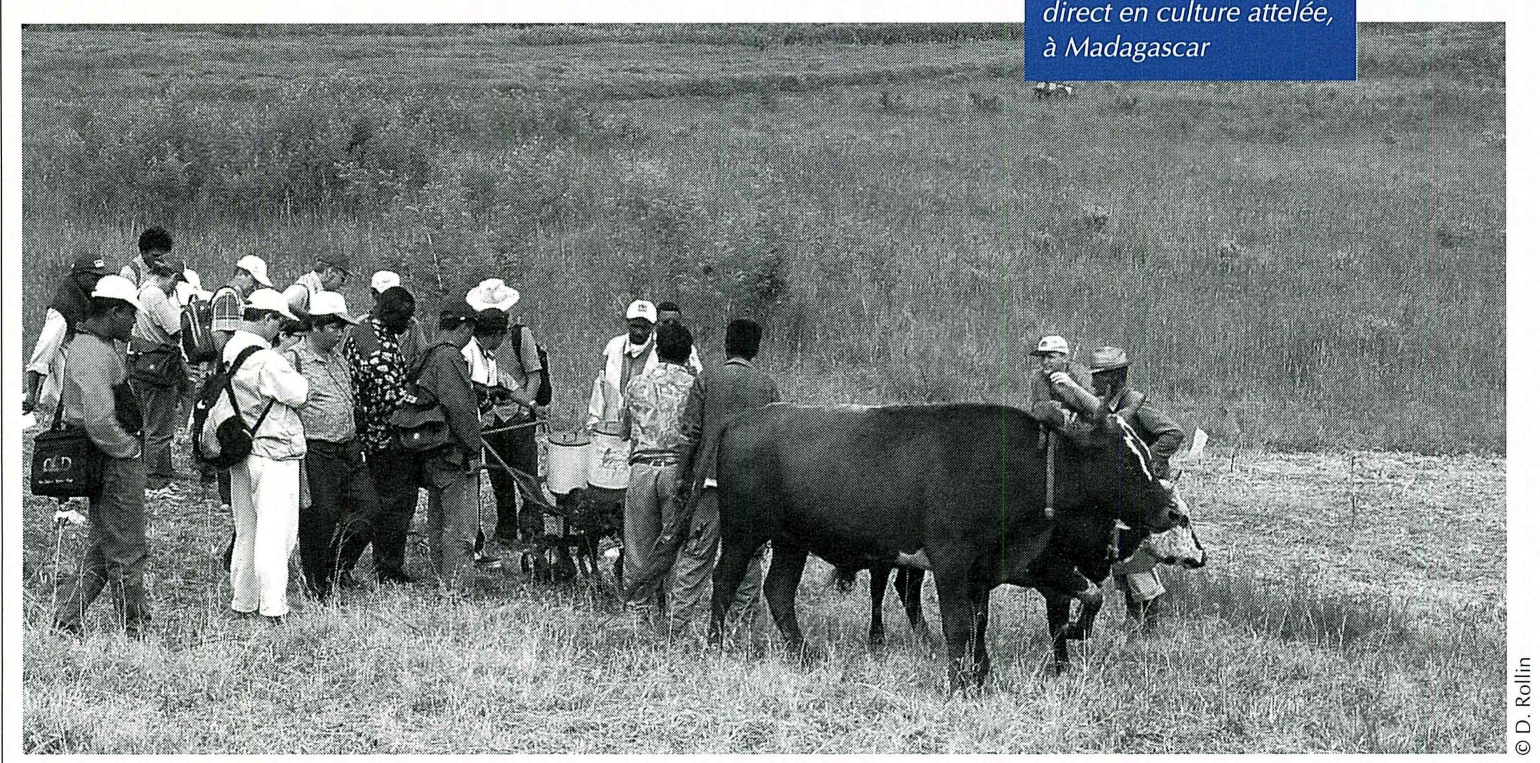


Mayotte, le Mexique, le Mozambique, la Réunion, la Tunisie, le Vietnam, et bien sûr, Madagascar. Des questions comme I'association de l'agriculture et de l'élevage ou la gestion et I'allocation des ressources végétales ont été abordées. La rencontre de paysans et de techniciens sur le terrain n'a fait que confirmer la nécessité de les approfondir.

Avec une forte participation du Cirad, le premier congrès mondial sur "I'agriculture de conservation "s'est déroulé à Madrid en octobre 2001. Huit cents personnes, de cinquante nationalités du Nord et du Sud, y ont participé. Le nombre et la diversité géographique et institutionnelle des participants montrent à quel point la préoccupation de concilier productivité, durabilité et protection de l'environnement est partagée. Ce congrès a contribué à sensibiliser la société civile sur la nécessité d'une agriculture de conservation.

\section{Séquestration du carbone}

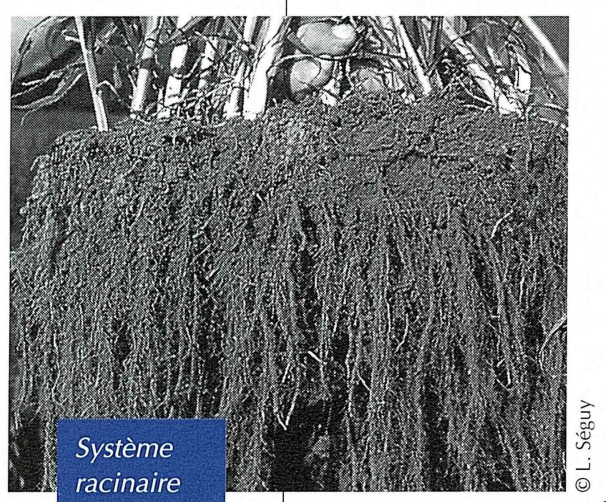

Le plan d'action agroécologie est un ensemble de projets de développement mis en œuvre de façon conjointe par I'Agence française de développement, le ministère français des affaires étrangères, le Fonds français pour I'environnement mondial et le Cirad. Dans ce cadre, le conseil scientifique des projets et les principaux acteurs scientifiques (Cirad, Inra, Ird) ont travaillé à $d^{\prime}$ Eleusine coracana plante de couverture Montpellier en octobre 2001 sur les méthodes de comparaison des émissions ou des séquestrations des gaz à effet de serre dans les systèmes de culture avec semis direct sur couverture végétale et dans les systèmes de culture traditionnels.

Ce travail a permis de retenir quatre zones expérimentales pour financer les recherches - le Laos, le Mali et Madagascar, pays accueillant les projets pilotes du plan d'action agroécologie, ainsi que le Brésil, pays tropical le plus avancé sur le semis direct sous couverture végétale - et de présenter leurs activités futures d'expérimentation.

Des exposés ont présenté les aspects scientifiques et économiques de la séquestration du carbone intéressant potentiellement les différentes zones expérimentales. Les acteurs du projet ont défini une plate-forme méthodologique commune sur la mise en place des dispositifs agronomiques contrôlés, les modes de prélèvement et d'analyse des sols. La nécessité de bien cerner les problèmes d'échantillonnage et de mesure des stocks de carbone dans les sols, selon les types de situations étudiées, a été soulignée. La possibilité de prendre en compte les flux d'oxyde d'azote a également été étudiée.

\section{Diagnostic agronomique régional}

Une thèse intitulée "Modélisation de culture et diagnostic agronomique régional - Mise au point d'une méthode et application au cas du maïs chez les petits producteurs du Brésil central » a développé une méthode fondée sur une enquête de terrain et sur la construction, puis l'exploitation d'un modèle de simulation de culture. Cette approche facilite la détection des contraintes et les hiérarchise de manière objective. Elle permet de vérifier, pour une série de saisons agricoles représentatives du climat local, le diagnostic élaboré pour l'enquête.

Dans l'étude de cas, la modélisation a consisté à adapter le modèle Stics pour améliorer la simulation du bilan hydrique et introduire les effets de la toxicité aluminique, de l'excès d'eau et de la compétition entre culture et adventices pour la lumière, l'eau et l'azote. Le diagnostic a montré l'importance des problèmes de gestion des tracteurs et des semoirs par les associations de producteurs. 
$\mathrm{D}$ ans un contexte de politiques libéralisées et mondialisées ainsi que d'émergence de questions nouvelles sur la gestion durable des territoires et des ressources naturelles, le Cirad s'interroge sur le maintien à moyen et long terme des fonctions économiques, sociales et environnementales assurées aujourd'hui par les cultures pérennes dans les zones tropicales humides. Cette réflexion l'a conduit à s'associer au bureau d'études Bnetd de Côte d'lvoire et à l'université libre d'Amsterdam pour organiser la conférence internationale « L'avenir des cultures pérennes : investissement et durabilité en zones tropicales humides $»$ qui s'est tenue à Yamoussoukro, en novembre 2001. Acteurs du développement, décideurs nationaux et internationaux, organisations non gouvernementales et chercheurs ont conduit leurs réflexions sur les perspectives de la demande,

l'évolution des marchés, les risques et les modèles de prise de décision pour investir, le changement des contextes politique et institutionnel, l'impact environnemental, le rôle de la recherche. Au-delà du constat de crise,

l'enjeu était d'inventorier les voies politiques, économiques, sociales et techniques qui permettront de proposer des fonctionnements de marchés qui soient plus favorables aux investissements, qui assurent des répartitions plus équitables entre les différents acteurs et, enfin, qui tiennent pérennes compte des contraintes environnementales.

Les participants des vingt-six pays représentés ont tenu à exprimer leurs préoccupations aux opinions publiques mondiales et aux responsables politiques dans une déclaration. Elle confirme le rôle des cultures pérennes dans les équilibres économiques, sociaux et environnementaux des pays tropicaux.

Elle affirme la nécessité de faire bénéficier les petits planteurs des programmes de lutte contre la pauvreté. Enfin, elle appelle à une construction renouvelée des échanges internationaux, fondée sur la solidarité entre les acteurs économiques et politiques. 


\section{Cacao}

Outre l'obtention de résultats scientifiques provenant de collaborations avec les chercheurs et les professionnels de la filière du cacao en France et dans les pays producteurs, les activités du programme ont été marquées par le démarrage de deux importants projets pluriannuels portant sur la durabilité de la cacaoculture ouest-africaine. Le premier, conduit par le Cirad et le Cnra de Côte d'Ivoire, sur la réhabilitation et la replantation des cacaoyères sénescentes, a reçu l'appui financier de l'ambassade de France à Abidjan et a conduit à l'affectation

\section{Cartographie de QtI}

Les programmes d'amélioration génétique du cacaoyer cherchent à cumuler dans un même génotype des allèles favorables à la productivité et à la qualité.

La première carte génétique a été obtenue par le Cirad, puis plusieurs études de cartographie ont permis d'identifier des Qtl liés aux composantes du rendement, à la résistance au Phytophthora et aux caractéristiques des fèves. Ces Qtl se répartissent sur les dix chromosomes du cacaoyer, plus particulièrement sur le chromosome 4 .

Parmi les populations étudiées, trois, implantées au Cnra en Côte d'Ivoire, ont été analysées durant une dizaine d'années. Des Qtl ont été identifiés dans deux groupes de cacaoyers : Trinitario et Forastero haut-amazonien.

Pour des génotypes issus d'un même groupe ou des deux groupes, il existe des colocalisations de Qtl liés à un même ensemble de caractères, comme ceux impliqués dans la taille des fèves. Des colocalisations de Qtl de caractères différents ont aussi été identifiées dans une même région du génome, par exemple celle mise en évidence sur le chromosome 4 et impliquant des Qtl liés au poids de la cabosse, à la vigueur et à la résistance au Phytophthora.

Ces résultats permettent d'envisager des stratégies de sélection à l'aide des marqueurs moléculaires.

\section{L'ochratoxine A des fèves}

L'étude sur l'origine et le développement des ochratoxines sur les fèves de cacao, menée en partenariat avec les industriels européens de la filière (Caobisco), a pour objectif d'identifier les points critiques qui favorisent le développement des moisissures et la production d'ochratoxine A (Ota). Les résultats obtenus la première année montrent que l'utilisation de bonnes pratiques de postrécolte - délai d'écabossage court, fermentation en caisse, séchage sur claies ou séchage artificiel avec de nombreuses retournes - permet d'obtenir à Gagnoa d'un agronome système.

Le second, régional - Cameroun, Côte d'Ivoire, Ghana et Nigeria - et soutenu par le ministère français des affaires étrangères, vise à définir des systèmes de cacaoculture compétitifs et durables en Afrique. Sa coordination scientifique est assurée par un agronome installé au Ghana. Les deux projets contribuent au programme mondial cacao en cours de constitution dans le cadre du Forum mondial de la recherche agricole.

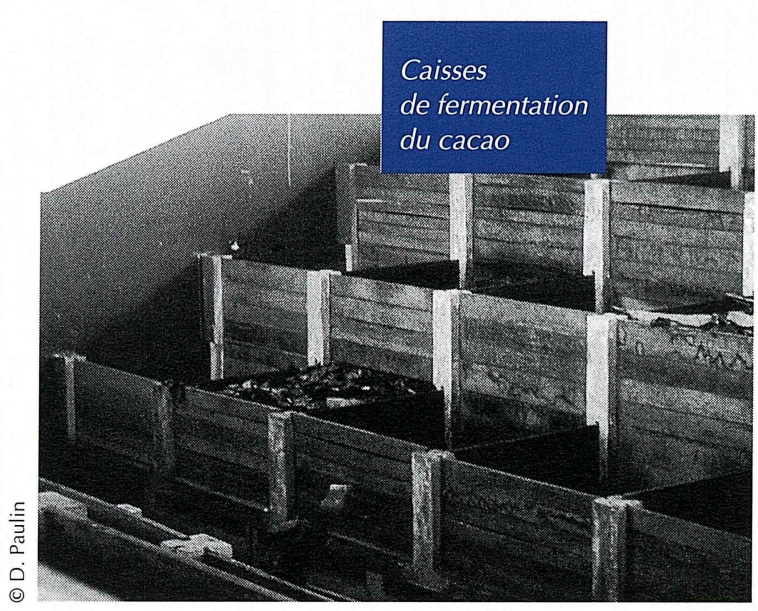

des fèves de cacao exemptes d'Ota ou en présentant seulement des traces, mais ces techniques sont peu utilisées par les petits producteurs. Par ailleurs, la teneur en Ota augmente à la fin de la récolte principale, en février-mars.

Les objectifs de ce programme pour la deuxième année sont de comprendre les liens entre la formation d'Ota et, d'une part les pratiques de postrécolte des petits planteurs, d'autre part, le comportement des acheteurs. Après l'analyse des résultats, il faudra aussi confirmer les méthodes de postrécolte à recommander aux planteurs. 


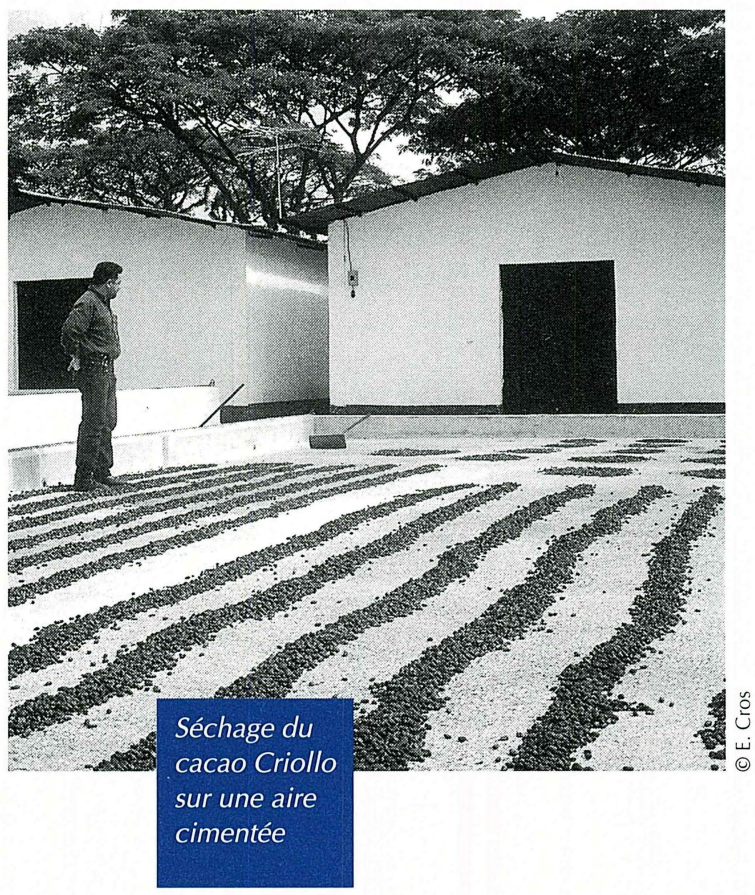

\section{Le cacao Criollo du Venezuela}

Le Venezuela est un pays producteur de cacaos fins, notamment de type Criollo, qui présentent des particularités aromatiques très prononcées. Or, les producteurs de ces cacaos emploient des méthodes de traitement de postrécolte très variables qui ne lui sont pas forcément adaptées. Un programme de recherche quadriennal est conduit par le Cirad et le Conicit, avec la participation de quatre doctorants. Son premier objectif est de proposer des conditions de traitement de postrécolte du cacao Criollo acceptables par le producteur et qui garantissent une bonne qualité du cacao marchand, et d'établir le schéma général du développement de l'arôme de ce type de cacao. Le second est de connaître les structures génétiques les plus favorables à l'expression de certains caractères de qualité. A cette fin, une étude systématique de l'influence des conditions de fermentation - délai d'écabossage, durée de fermentation et rythme des brassages - sur la qualité aromatique a été entreprise. Cette qualité est déterminée par I'analyse organoleptique et chimique des composés volatils, ainsi que des composés impliqués dans le développement de l'arôme.

Les facteurs étudiés ont un effet significatif sur les caractéristiques organoleptiques du cacao. Les interactions entre ces facteurs influencent également les notes d'acidité et d'intensité aromatique. Cependant, quelles que soient les conditions de traitement, les cacaos fermentés trois ou quatre jours sont les plus aromatiques.

\section{Epidémiologie de la pourriture brune}

Parmi les espèces de Phytophthora pathogènes du cacaoyer, P. megakarya est considérée comme la plus agressive au champ. Au Cameroun, les pertes de production potentielle peuvent atteindre $80 \%$. La méthode prioritaire de lutte a été la sélection de cacaoyers possédant une résistance partielle à cette maladie. Les programmes d'amélioration génétique ont toutefois été limités par un manque de connaissances sur la structuration génétique et le niveau d'agressivité de P. megakarya lors de l'évaluation du matériel végétal. Afin de mieux contrôler l'effet des souches lors de ces évaluations, des travaux sur la diversité génétique et sur les différences d'agressivité entre souches ont été menés au Cameroun, en collaboration avec I'Irad. L'objectif de ces travaux est d'évaluer l'efficacité d'une stratégie d'utilisation des résistances du cacaoyer vis-à-vis de $P$. megakarya et de prédire la durabilité de ces résistances en fonction de la diversité et des possibilités d'adaptation de ce pathogène. Afin de mieux comprendre le rôle adaptatif des différents facteurs évolutifs - mutation, recombinaison, dérive génétique, migration et sélection par I'hôte - la diversité spatio-temporelle et génétique des souches provenant d'une parcelle expérimentale a été étudiée ainsi que la variabilité de leur pouvoir pathogène. L'originalité de cette étude repose sur un couplage des analyses épidémiologiques et des recherches sur la structuration des populations pathogènes.

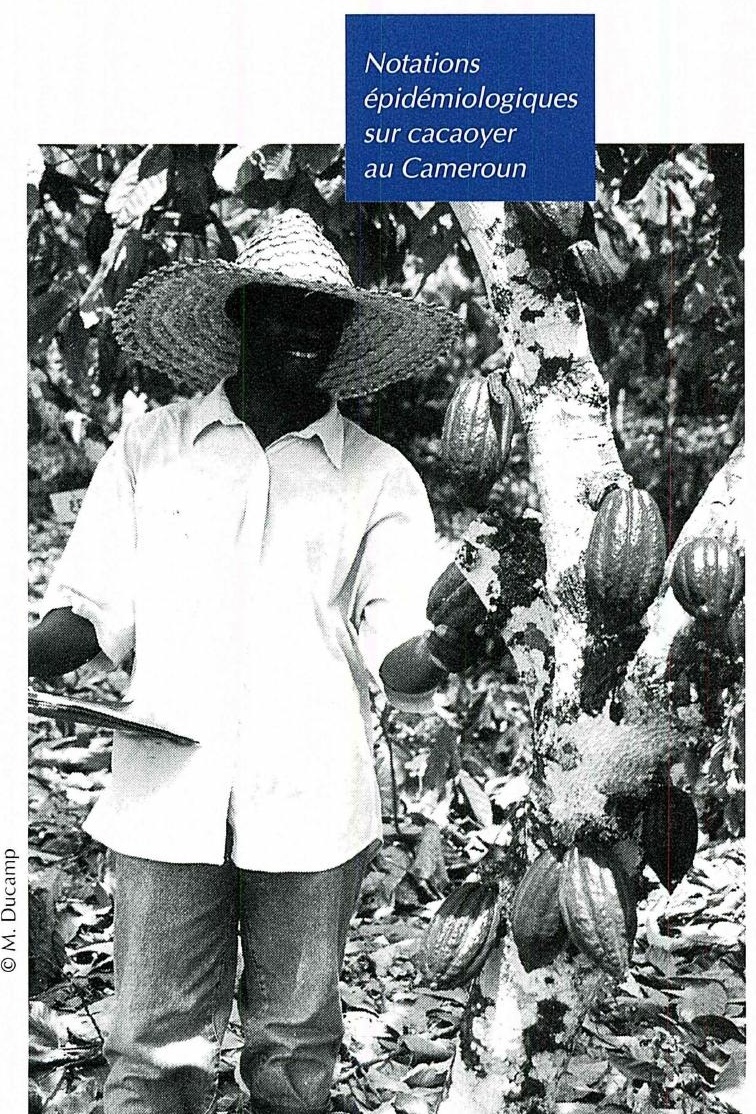




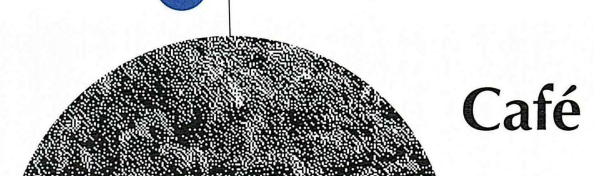

La notion de qualité des cafés se réfère à un ensemble de caractéristiques physiques, biochimiques, organoleptiques et sanitaires qui dépendent de facteurs génétiques, écologiques, culturaux et technologiques tels que les traitements de postrécolte, la torréfaction et la préparation de la boisson. La recherche a ainsi longtemps étudié chacun de ces facteurs sans prendre réellement en compte leur interdépendance. Du fait de l'actuelle conjoncture très préoccupante des cours des cafés sur les marchés mondiaux, les caféiculteurs ne parviennent plus à couvrir leurs

\section{Ochratoxines du café}

Le Cirad s'est impliqué dans un projet de prévention du développement des moisissures responsables des ochratoxines. En 2001, I'omniprésence des champignons du genre Aspergillus sur les cafés a été mise en évidence. L'évaluation in vitro du pouvoir toxinogène de ces souches a révélé une grande variation dans la production $d^{\prime}$ 'ochratoxines. Les corrélations entre les teneurs en ochratoxines de lots de café et le potentiel toxinogène des souches prélevées restent à établir. L'origine des contaminations par les moisissures dues aux Aspergillus entre la récolte et le traitement de postrécolte doit être précisée. Les observations préliminaires montrent que le séchage sur des aires aménagées limiterait la contamination par les moisissures et que les teneurs en toxines sont généralement élevées dans les cafés insuffisamment séchés. Les conditions de stockage en magasin pendant plusieurs semaines semblent aussi avoir une incidence significative sur la production d'ochratoxines.

L'analyse des filières nationales montre que $c^{\prime}$ est vraisemblablement chez les intermédiaires et les acheteurs que se situe un des points critiques. En achetant du café insuffisamment sec, ils ne prennent pas la précaution de terminer le séchage rapidement, avant de le stocker et de I'usiner. Une meilleure rémunération des cafés bien séchés devrait permettre de limiter la contamination, plus particulièrement en période de prix très bas.

\section{Embryogenèse somatique}

L'amélioration variétale du caféier s'oriente vers la sélection d'hybrides vigoureux, productifs, donnant un produit de qualité et possédant des résistances aux principales maladies et aux ravageurs. Pour propager à grande échelle ces hybrides, le Cirad a développé un procédé performant et original de multiplication in vitro par embryogenèse somatique. II consiste à produire en masse des embryons en bioréacteurs, puis à coûts de production. Face à cette situation de crise, s'insérer dans le marché des cafés haut de gamme par la promotion d'origines géographiques spécifiques semble une voie prometteuse pour les pays producteurs.

Toutefois, seule une approche pluridisciplinaire de la qualité, prenant en compte l'ensemble des facteurs, permettra de répondre aux nombreux pays producteurs qui souhaitent de plus en plus développer ces filières.

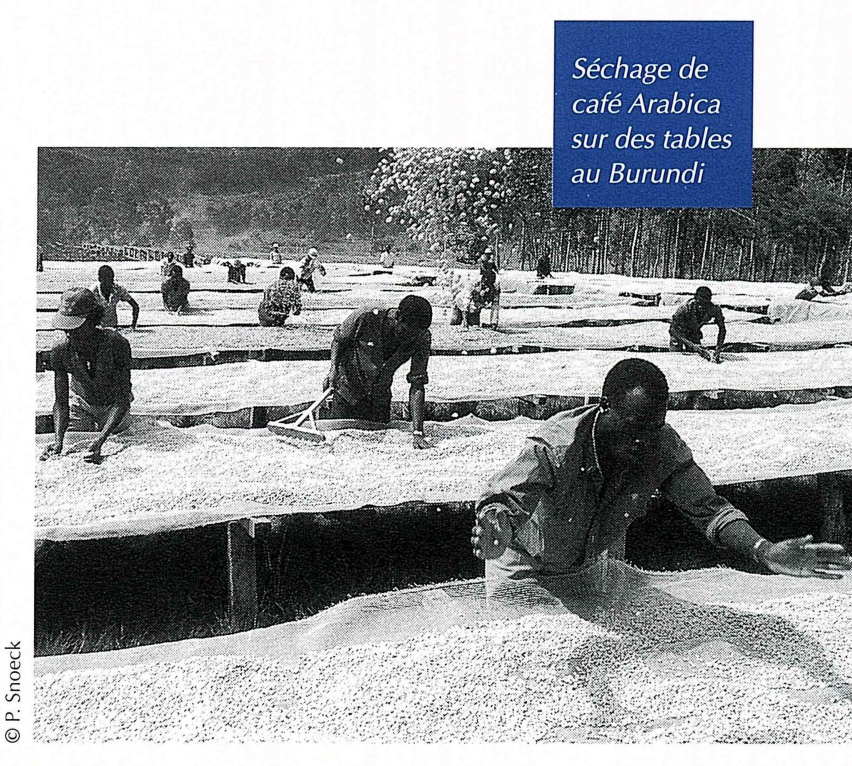

les semer directement. Ce procédé associe I'automatisation de la production d'embryons en laboratoire et la simplicité d'une étape de régénération de plantes intégralement réalisée en pépinière. Environ 100000 plants ont été installés en Amérique centrale et en Tanzanie pour évaluer le comportement agronomique et la conformité génétique du matériel régénéré par cette technique. Les faibles coûts de production et les premières données agronomiques très encourageantes ont permis d'envisager le passage à une étape d'industrialisation. 
Pour mieux répondre à la demande de nouvelles variétés et promouvoir cette technique dans les pays producteurs, le Cirad s'est associé à Vitropic, laboratoire privé spécialisé dans la propagation de vitroplants de bananier, afin d'adapter cette technique à l'échelle industrielle. L'étape de transfert technologique à Vitropic est sur le point de se terminer. La multiplication de variétés sélectionnées par le Cirad est en cours.

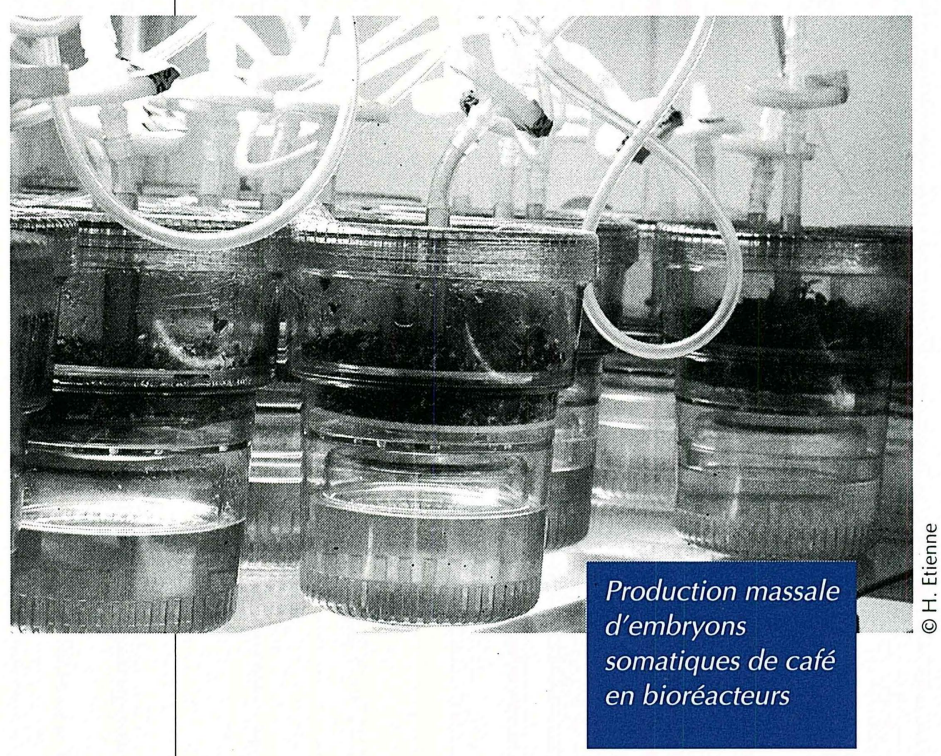

\section{Ecophysiologie}

Depuis 1999, le Cirad, le Catie et l'Institut du café du Costa Rica mènent des études sur les réponses physiologiques - photosynthèse et transpiration - des feuilles de caféier dans divers systèmes de production et sous différentes conditions microclimatiques. De plus, des mesures de flux de sève et $d^{\prime}$ interception de la lumière ont conduit à mieux caractériser la répartition des ressources en eau et en lumière entre les caféiers et les arbres d'ombrage. Ces mesures ont confirmé l'importance de la position du rameau dans l'arbre, de sa charge en fruits, du statut hydrique du caféier et de l'intensité de l'ombrage sur sa productivité et sur les propriétés physiques, biochimiques et organoleptiques du café.

En 2001, une version préliminaire d'un modèle d'allocation de carbone au sein d'un rameau de caféier a été développée en collaboration avec I'Inra, à Avignon. Ce modèle simule les effets de I'ombrage, de la charge en fruits et du statut hydrique du caféier sur la production d'assimilats et leur répartition entre les baies de café et la partie végétative du rameau en croissance. Au cours des quatre prochaines années, ces travaux écophysiologiques vont $s^{\prime}$ intensifier grâce à un projet européen lancé en fin d'année.

\section{Qualité au Laos}

Dans le sud du Laos, sur le plateau des Bolovens situé dans les provinces de Champassak et Saravane, entre 800 et 1200 mètres d'altitude, 30000 hectares de beaux sols volcaniques sont cultivés en caféiers Robusta, Arabica et Excelsa, essentiellement par des petits planteurs. Les conditions agronomiques favorables du plateau des Bolovens permettent de produire un café Arabica de haute qualité. Pour cette raison, une opération de recherche et développement vise à montrer que des planteurs peuvent s'organiser et produire un café à haute valeur ajoutée. Cette opération $s^{\prime}$ inscrit dans la perspective de création de filières combinant équité et qualité, associant les opérateurs et la recherche, dont le rôle est de mobiliser les méthodes nécessaires en génétique, écologie, technologie et organisation.

Ce projet, financé par l'Afd et mis en œuvre en 1999, a permis aux petits planteurs de préparer, en association avec un exportateur, 9200 kilos de café parche qui ont été exportés sous forme de café vert en Malaisie. Dès 2000, des échantillons ont été présentés à un acheteur français offrant l'accès à un marché de niche. De nombreux planteurs ont ainsi manifesté leur intérêt pour cette opération et ses débouchés.

En 2001, 16200 kilos de café vert ont été achetés à 12000 kips le kilo, soit 1,90 dollar, bord champ. Le maintien d'un effort soutenu des petits planteurs permettra à I'Arabica du Laos de retrouver ses lettres de noblesse.

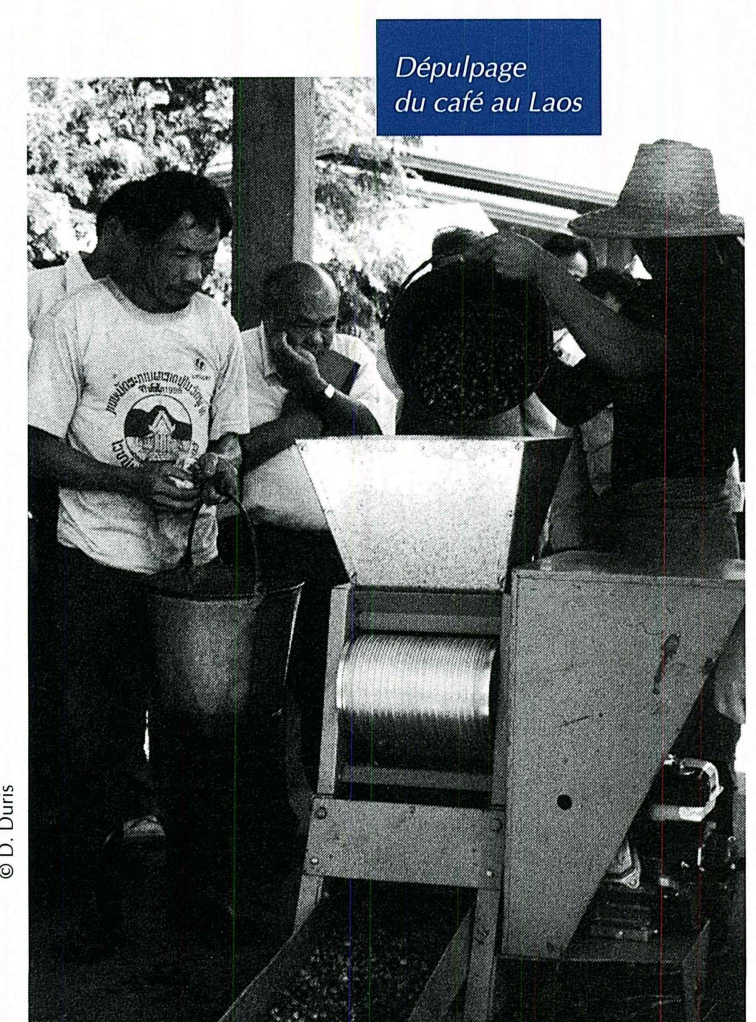




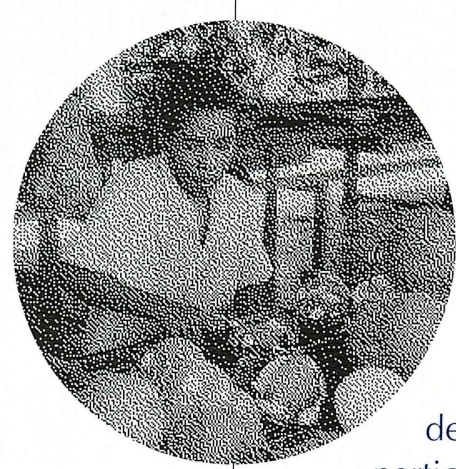

\section{Cocotier}

Les principaux partenaires de la filière du cocotier préparent le lancement d'un programme mondial de recherche pour le développement du cocotier. Cinq axes prioritaires de recherche ont été retenus : ressources génétiques et amélioration ; contrôle des maladies et des ravageurs ; productivité et durabilité des agrosystèmes à base de cocotier ; utilisation et valorisation des produits; enjeux socio-économiques. Dès I'origine, le Cirad a activement participé à cette initiative qui s'inscrit dans la démarche du Forum mondial

\section{Séquestration de carbone}

La séquestration de carbone par une plantation de cocotiers est étudiée au Vanuatu dans le cadre d'un projet auquel participent le Cirad, I'Inra, I'Ird, le Cnrs et l'université de Franche-Comté. Les flux totaux d'énergie, d'eau et de carbone de la plantation sont mesurés en continu par la méthode des fluctuations turbulentes. La somme annuelle des flux de carbone est comparée aux variations de stocks d'une succession de classes d'âges.

Les premiers résultats montrent une croissance très rapide, une photosynthèse importante mais une respiration de l'écosystème élevée. La séquestration journalière de carbone est donc modérée. Cumulée à l'échelle annuelle, elle pourrait pourtant atteindre la valeur exceptionnelle de sept tonnes de carbone par hectare et par an grâce à des conditions climatiques peu contrastées, à un stress hydrique limité et à la croissance continue du cocotier.

Dans l'hypothèse d'une tonne de carbone négociée à 10 dollars, d'un rendement moyen d'une tonne de coprah par hectare et par an, et d'un prix au planteur de 171 dollars par tonne de coprah, le revenu de la séquestration de carbone pourrait représenter une plus-value de $40 \%$ par rapport au coprah. Ce chiffre serait inférieur si on ne prenait en compte que la part réellement certifiable de la séquestration.

L'usage de l'huile comme carburant est également une alternative au diesel : il faut environ cinq hectares de cocotiers pour faire rouler une voiture 20000 kilomètres par an.

\section{Micropropagation du cocotier}

Le Cirad est engagé dans des recherches sur la multiplication végétative in vitro du cocotier, en collaboration avec I'Ird. Le clonage doit permettre la diffusion de génotypes performants, tolérants aux principales maladies.

Malgré les progrès réalisés, les applications de la culture in vitro nécessitent de mieux maîtriser la germination des embryons somatiques et la de la recherche agricole. II apporte à la fois une vision à long terme de la filière, une connaissance approfondie des hommes et du terrain et une expertise scientifique et technique de haut niveau. Sa contribution est importante dans plusieurs domaines : bilan carboné de l'agrosystème, lutte intégrée pour la protection des plantations, gestion des ressources génétiques, culture in vitro du cocotier. Un premier programme mondial de recherche sur le jaunissement mortel du cocotier, qui devrait recevoir le soutien du Fonds commun pour les produits de base, vient d'être proposé.

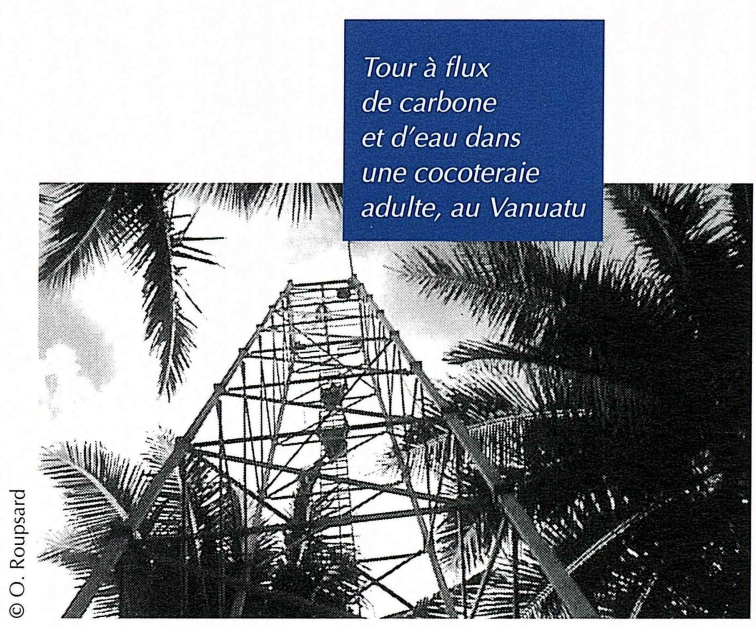

vigueur des vitroplants. Pour tenter de résoudre ces difficultés, le Cirad a fait appel aux données récemment acquises sur des plantes modèles. Des gènes connus pour contrôler la division des cellules, la mise en place et le fonctionnement du méristème caulinaire chez Arabidopsis ont été isolés chez le cocotier. L'étude de leur expression en fonction des conditions de culture est en cours. En 2001, ce programme a fait l'objet d'une collaboration avec le Cicy, sous la forme de l'accueil $d^{\prime}$ un postdoctorant et d'un chercheur. 


\section{Cryoconservation des ressources génétiques}

Le cocotier, essentiellement conservé en champ dans des collections régionales, est soumis à de forts risques d'érosion génétique. Ce mode de conservation rend difficile l'échange de ressources génétiques entre les pays producteurs. La cryoconservation, sur laquelle l'équipe mixte Ird-Cirad travaille en collaboration avec le Cnra de Côte d'Ivoire, permet de contourner ces difficultés. Les travaux portent actuellement sur l'optimisation du protocole par encapsulation et déshydratation des plumules isolées de l'embryon. Pour répondre à la menace croissante d'un anéantissement de collections régionales, comme celle de Côte d'Ivoire, une évaluation des risques de transmission,

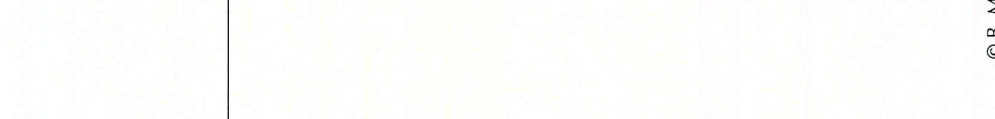

par l'embryon, du phytoplasme responsable du jaunissement mortel sera effectuée. Ce programme a reçu le soutien financier du Bureau des ressources génétiques.

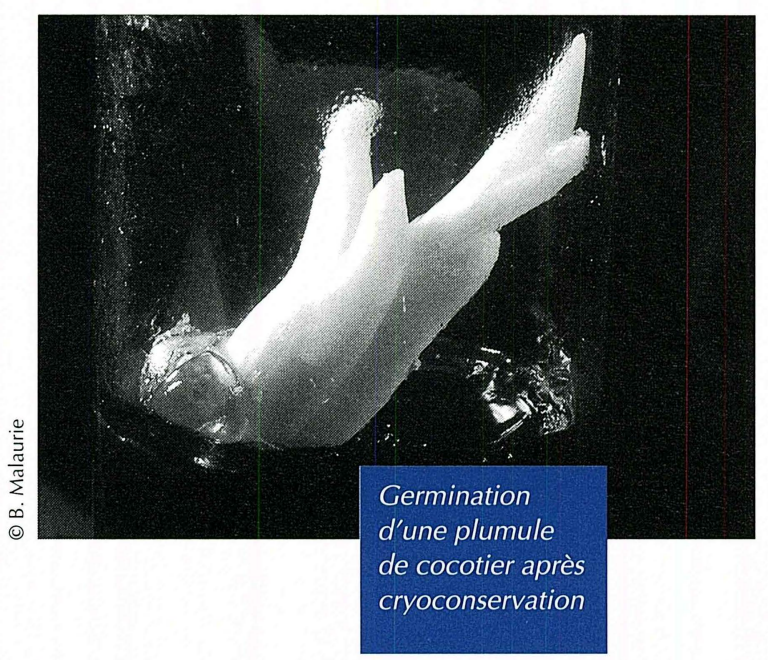

\section{4.}

Dans un contexte de crise de l'hévéa, le Cirad a organisé un séminaire sur l'apport des biotechnologies à cette culture, à l'occasion de la réunion annuelle de I'Irrdb. Quatre-vingts personnes venant de dix pays producteurs y ont participé. Les vingt-trois conférences présentées ont donné une vision globale de la recherche mondiale sur les biotechnologies appliquées à l'hévéaculture. La mise au point d'outils dans les domaines de l'embryogenèse somatique et de la génomique a beaucoup avancé. Plusieurs sujets de collaboration ont été évoqués, en particulier avec la Malaisie.

\section{Fonctionnement hydrique et carboné}

Les composants des systèmes cultivés à base d'hévéa stockent et recyclent le carbone, l'eau et les éléments minéraux. Pour optimiser l'utilisation de ces ressources, éviter des concurrences et augmenter la rentabilité des systèmes d'exploitation, une approche écophysiologique globale est nécessaire. La valorisation du bois d'hévéa impose des itinéraires techniques permettant un meilleur équilibre entre croissance et production de latex. Or l'exploitation de l'hévéa par la saignée crée un nouveau puits métabolique et provoque une compétition pour I'utilisation des assimilats hydrocarbonés et de l'eau, qui se traduit par un ralentissement de la croissance.

La première étape de la recherche lancée en Thaïlande en 1999, avec I'Inra, le Rrit et I'université de Kasetsart, et avec I'appui du ministère français des affaires étrangères, vise à quantifier les flux de carbone et d'eau dans I'arbre pour aboutir à un modèle explicatif de fonctionnement des hévéas saignés.
Un groupe de biotechnologie a été créé au sein de l'Irrdb, dont la coordination a été confiée au Cirad. Le dispositif du programme hévéa en Thaïlande s'est encore renforcé par l'affectation d'un troisième chercheur en physiologie et biochimie à l'université de Kasetsart, où il travaillera en collaboration avec le Rrit sur les problèmes de variabilité de la qualité du caoutchouc.

Sur jeunes plants en pots, un dispositif de contrôle des apports d'eau permet d'aborder I'influence du stress hydrique sur l'assimilation carbonée et d'estimer les conséquences sur la croissance en phase initiale non saignée, avec deux clones dotés d'architectures contrastées.

Sur arbres adultes, pour mieux comprendre la relation entre la saignée et le fonctionnement global, on mesure la consommation de carbone par respiration au niveau des troncs grâce à un appareillage spécifique conçu par I'Inra. En 
parallèle, I'activité métabolique et la mobilisation du saccharose dans les vaisseaux laticifères, ainsi que la dynamique de stockage et de mobilisation des réserves en amidon du bois, sont
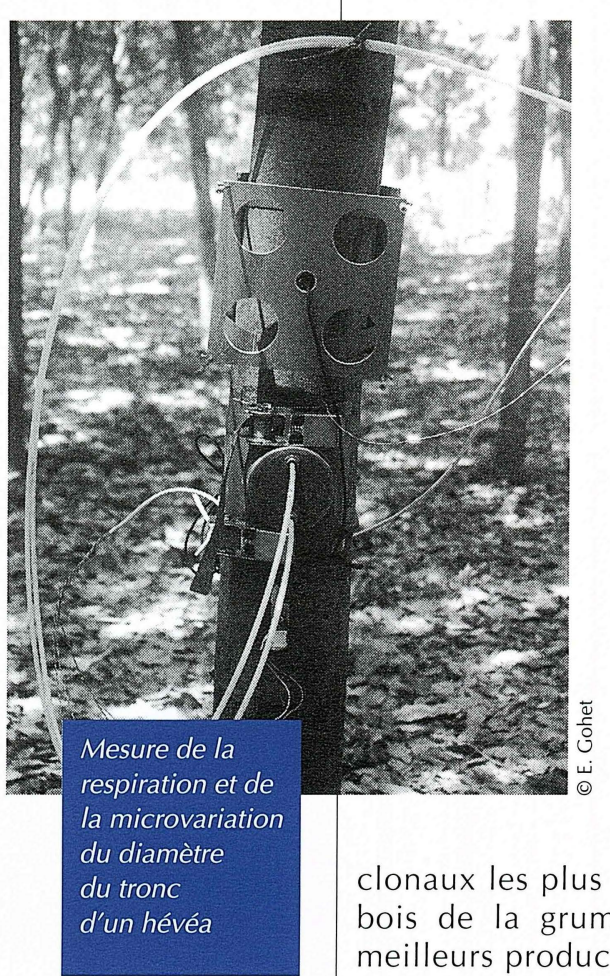

suivies en fonction d'un gradient d'intensité d'exploitation du latex sur une station du Rrit. Les premiers résultats indiquent que le saccharose s'accumule en dehors de l'aire directement drainée par la saignée et que le métabolisme du tissu laticifère est actif sur une large partie du tronc. Ces données devraient permettre d'analyser les variations de production liées à la gestion des panneaux de saignée. Des extractions d'arbres entiers, destinées à quantifier la dynamique d'accroissement de la biomasse totale dans les différents étages de l'arbre, ont montré que les méthodes usuelles sous-estimaient la biomasse du clone le plus planté en Thaïlande et que les types clonaux les plus favorables à la valorisation en bois de la grume ne sont pas forcément les meilleurs producteurs de biomasse.

\section{Promoteurs spécifiques}

Le clonage de promoteurs spécifiques des tissus laticifères ou inductibles par les stress biotiques et abiotiques a été entrepris en vue d'optimiser l'expression des gènes qui seront introduits chez I'hévéa par transformation génétique. Les promoteurs spécifiques, adaptés à l'application recherchée, permettent une maîtrise plus fine de l'expression spatio-temporelle des transgènes que les promoteurs constitutifs, souvent décriés. Deux types de promoteurs ont été clonés, à partir de gènes exprimés dans les cellules laticifères des arbres en production : des gènes de glutamine synthétase, induits de manière précoce par l'éthylène, et des gènes d'hévéine, potentiellement spécifiques des cellules laticifères et surexprimés par la blessure et l'éthylène. Un promoteur spécifique des cellules laticifères aurait pour intérêt d'optimiser l'expression des transgènes dans le latex, sans perturber l'ensemble de la plante. L'inductibilité par l'éthylène est intéressante pour optimiser l'expression de transgènes en condition d'exploitation intense, sachant que la stimulation de la production de latex par traitement éthylénique est une pratique courante en hévéaculture.
Les promoteurs isolés et clonés en amont du gène rapporteur gus seront analysés dans I'hévéa, dans des lignées de cals transgéniques tout d'abord, en attendant la régénération de plantules transformées. Ils sont actuellement analysés dans des plantes modèles _ riz et Arabidopsis. Les premiers résultats confirment la fonctionnalité de ces promoteurs dans le riz, ce qui pourrait permettre d'élargir leur champ d'application à d'autres plantes que l'hévéa.

\section{Lignées de cals transformés}

Afin de disposer d'un outil pour l'étude du fonctionnement des cellules laticifères par modification de l'expression de gènes impliqués dans la production de latex, une méthode de transformation génétique d'Hevea brasiliensis est développée. Ces connaissances permettront d'identifier des gènes cibles pour l'amélioration des clones industriels par modification génétique.

Le procédé de transformation génétique consiste en une première étape conduisant à l'établissement de lignées de cals friables transformés, suivie d'une phase de régénération de plantes transgéniques via le processus d'embryogenèse somatique. Les travaux menés avec l'université de Kasetsart et I'Institut de recherche sur le caoutchouc en Thaïlande ont conduit à la définition des conditions d'obtention de lignées de cals friables transformés par Agrobacterium tumefaciens. Cette technique est en cours de validation au Cirad. L'obtention régulière de lignées qui serviront à la régénération des plantes transgéniques est recherchée. Par ailleurs, de nouveaux vecteurs de transformation sont utilisés. Ils comportent des promoteurs d'intérêt permettant une expression soit spécifique au niveau des tissus laticifères, soit inductible par de l'éthylène. En outre, des lignées de cals entretenus transformés avec divers gènes candidats sont créées pour étudier précocement la régulation de l'expression

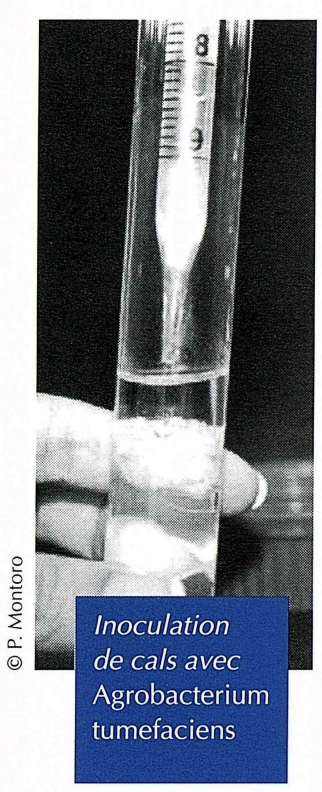
génique et l'impact de ces modifications sur le métabolisme. Ainsi, des gènes cibles pour l'amélioration de la productivité de l'hévéa pourront être plus aisément identifiés. 


\section{(Y) Palmier à huile}

La dynamique de contractualisation engagée aujourd'hui par le programme concerne l'ensemble des partenaires publics et privés de la filière. Tout en améliorant la lisibilité des actions à l'extérieur, elle stabilise son partenariat en l'engageant sur vingt ou trente ans. Les programmes de recherche peuvent alors bénéficier de réseaux expérimentaux à grande échelle, sécurisés sur le long terme. Ce renouvellement du partenariat s'appuie sur des outils de contractualisation indispensables à une activité commerciale compétitive.

\section{Libéralisation de la filière}

En Côte d'Ivoire, la privatisation de la filière du palmier à huile est intervenue en 1997, après trente ans de gestion étatique. Elle s'est traduite par le rachat de la société d'Etat par trois groupes privés, et par une volonté publique de promouvoir les organisations professionnelles de planteurs. Aujourd'hui, cette rupture forte dans les modes de coordination des acteurs, qui s'ajoute à la chute des cours internationaux, a conduit à un climat de tension entre planteurs et usiniers. Les différends portent sur le mécanisme de fixation des prix de régimes de palme et sur le transfert des prestations aux planteurs, qu'assurent encore les agroindustries. La clarification des nouvelles règles de gestion de la filière et la mise en place d'instances de concertation pour l'élaboration de nouveaux compromis deviennent des outils indispensables. Le Cirad et I'université de Bouaké travaillent sur I'organisation de la filière dans un contexte de postprivatisation, afin de proposer aux acteurs des thèmes de recherche : conséquences des nouvelles formes de contractualisation sur l'organisation de la production villageoise, articulation entre marchés locaux et filières de transformation, dynamique de l'action coopérative, analyse économique et sociologique des mécanismes de négociation, de construction des règles et de régulation de la filière.

\section{Piégeage d'Oryctes rhinoceros}

pour capturer Oryctes rhinoceros
Oryctes rhinoceros est le ravageur le plus redoutable des replantations de palmier à huile et de cocotier. L'adulte creuse une galerie à la base des feuilles centrales, provoquant un retard de croissance et parfois la mort du jeune palmier. En vue de réduire les populations du ravageur, des recherches sur le piégeage olfactif de masse à partir d'une phéromone et d'odeurs de plantes ont été menées dans le cadre d'un projet européen.
Pour ce qui concerne l'activité semencière, ces accords reconnaissent au Cirad un rôle de coobtenteur, justifié par un investissement intellectuel et financier important. Ces accords définissent également de manière précise les modalités de rémunération équitables des partenaires, par un système de royalties dues aux obtenteurs et de répartition des marges bénéficiaires sur les activités de commercialisation du matériel végétal amélioré.

Les arbres attaqués sont colonisés isolément aussi bien par les mâles que par les femelles. Les investigations réalisées dans les vieux bois et les déchets végétaux en décomposition ont confirmé une arrivée et un regroupement des insectes pour l'accouplement et la ponte. La phéromone émise par les mâles favorise la colonisation de ces milieux.

Ces observations ont été mises à profit pour améliorer le piégeage du ravageur en associant la phéromone et les rafles en décomposition provenant d'usines d'huile de palme. L'effet synergique se traduit par une multiplication par deux ou trois des captures par rapport à celles obtenues avec la phéromone seule. En attendant de disposer d'un attractif entièrement synthétique, actuellement à l'étude, ce résultat relance I'intérêt du piégeage de masse. Des études spatiotemporelles seront réalisées pour comprendre I'effet des attractifs sur la colonisation d'une parcelle et évaluer l'efficacité du piégeage dans la réduction des attaques de jeunes palmiers.

\section{Résistance à Ganoderma}

La pourriture basale du stipe du palmier à huile, provoquée par Ganoderma sp., entraîne, dans les palmeraies d'Asie du Sud-Est, des pertes d'autant plus sévères que se succèdent les cycles de culture. Les résultats obtenus sur le terrain montrent des différences significatives de comportement d'une 
origine à l'autre. La sensibilité générale du matériel Deli s'oppose à une certaine résistance des origines La Mé ou Yangambi. Les hybrides interspécifiques Elaeis oleifera x E. guineensis expriment peu de symptômes en zone fortement contaminée. Ces résultats vont être exploités pour écarter les sources de forte sensibilité, élaborer une stratégie de sélection et fournir une gamme de croisements de référence nécessaire au développement d'un test précoce de sensibilité. Le Cirad s'est donc engagé dans un programme de recherche avec deux sociétés de plantation privées de Sumatra. Socfindo aborde désormais le quatrième cycle de culture et doit faire face à des problèmes sanitaires qui préfigurent la situation de la culture des palmacées du Sud-Est asiatique dans les dix à vingt années à venir. atteint pourriture basale H. La société de plantation London Sumatra, avec sa station de Bah Lias, participe déjà largement aux recherches sur Ganoderma.

\section{Conformité clonale}

Actuellement, I'utilisation de la micropropagation par embryogenèse somatique est limitée par l'induction, lors de la culture in vitro, d'un variant somaclonal, dit mantled. Ce dernier présente une architecture florale anormale, qui peut perturber le rendement en huile du palmier. Le caractère mantled étant réversible et hérité de façon non mendélienne, des études moléculaires de l'expression du génome des cellules cultivées in vitro ont été conduites afin d'identifier des marqueurs des tissus conformes ou variants. Dans le cadre d'un projet cofinancé par le Mpob, la technique du differential display RT-PCR a été utilisée pour identifier plusieurs gènes dont l'expression est modifiée en relation avec l'état de conformité clonale. L'un de ces gènes, EGAD1, code une protéine appartenant à la famille des défensines végétales. Une suraccumulation des Arn transcrits du gène EGAD1 a été observée dans des cultures in vitro variantes au stade du cal, par rapport à des cultures conformes. Ces résultats prometteurs, qui ont récemment fait l'objet d'un dépôt de brevet commun Cirad-Mpob, serviront à mettre au point un test précoce de conformité clonale, pour éliminer les plantes non conformes avant leur plantation au champ et perfectionner le procédé de micropropagation.

\section{Compostage des sous-produits}

L'usinage des régimes de palme produit une quantité très importante de sous-produits, dont une tonne de rafles et trois tonnes d'effluent par tonne d'huile.

Le Cirad travaille depuis plusieurs années, en partenariat avec PT Smart en Indonésie, à la valorisation agricole de ces sous-produits organiques riches en éléments minéraux, pour une culture des palmacées plus performante et respectueuse de l'environnement.

Le compostage est une alternative séduisante lorsque les conditions ne permettent pas une application en champ des produits frais. II réduit le volume des rafles de $80 \%$ et leur poids initial de $55 \%$, facilitant ainsi transport et manutention. Les expérimentations conduites à diverses échelles ont permis de déterminer les conditions optimales du compostage : ensemencement initial avec un compost mûr et arrosage régulier d'effluent pour maintenir I'humidité à $60 \%$. Ces deux composés apportent aussi des matières azotées favorables à l'activité des micro-organismes responsables du compostage. Les doses et les fréquences d'application ont été précisées pour chaque phase du procédé. Par ailleurs, les arrosages agissent en complément des retournements réguliers pour le contrôle de la température des andains.

Le compost se substitue favorablement aux fertilisants minéraux habituellement utilisés à tous les stades de la plantation. La durée de compostage se traduit par un produit final plus ou moins décomposé, qui peut être ainsi adapté à l'utilisation envisagée : bien mûr en pépinière pour une valorisation immédiate, moins décomposé pour un épandage en palmeraie où une action plus lente, mais plus durable, est préférable.

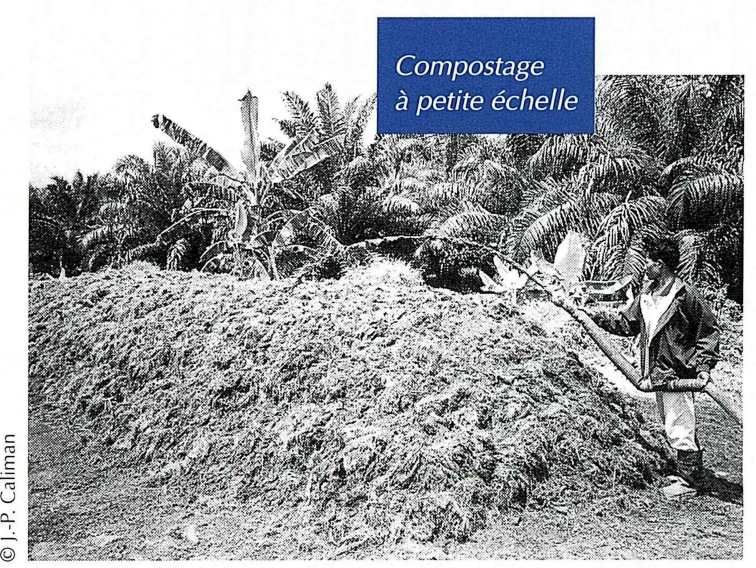


F ace aux évolutions de la demande du marché et des consommateurs, des questions environnementales et du contexte général du secteur des fruits et légumes tant au Nord qu'au Sud, le département prend des options nouvelles ou renforcées dans plusieurs domaines prioritaires.

Ainsi, une priorité accrue est donnée à la caractérisation de la valeur nutritionnelle et des propriétés organoleptiques et aromatiques des fruits et légumes, ainsi qu'à la préservation de leur qualité par des procédés de conservation et de transformation.

Il s'agit de répondre aux préoccupations croissantes des consommateurs des pays du Nord, comme du Sud, à la recherche d'une alimentation saine et équilibrée. A côté des macronutriments essentiels, les micronutriments sont de plus en plus mis en avant, alors que les fruits et légumes, qui les contiennent, jouent encore un rôle nettement insuffisant dans la sécurité alimentaire des pays du Sud.

Une deuxième évolution importante concerne la génomique structurelle et la génomique fonctionnelle, notamment dans la recherche de résistances aux maladies, dans l'élaboration de la qualité des fruits et dans la compréhension des problèmes de virus intégré dans le génome des bananiers. Les équipes

Productions fruitières et horticoles du département sont bien placées dans ce domaine sur la scène internationale.

En outre, la promotion d'une agriculture raisonnée, qui permette de concilier des mesures agri-environnementales avec les exigences du marché en termes de qualité et de compétitivité, reste l'objectif dominant de plusieurs équipes sur le terrain.

Enfin, un point essentiel est de veiller à ce que les utilisateurs $\mathrm{s}^{\prime}$ approprient les résultats de la recherche, qui ne deviennent de véritables produits que lorsqu'ils sont intégrés et utilisés durablement. C'est dans cette optique que sont organisées des rencontres régulières avec les acteurs des filières, telles que

la journée professionnelle de septembre 2001 ,

qui a permis de promouvoir les résultats du département auprès de ses partenaires agro-industriels et d'instaurer un dialogue entre scientifiques et utilisateurs de la recherche. 


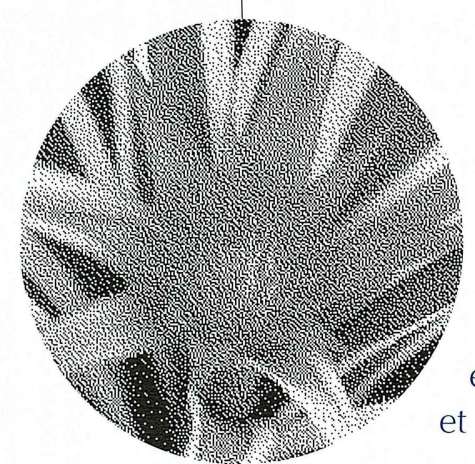

\section{Vallorisation des hybrides d'ananas}

La valorisation des hybrides d'ananas auprès d'opérateurs privés a débuté. Elle concerne actuellement plusieurs variétés ornementales et une variété fruitière. Cette dernière a un fruit attractif avec une chair ferme, très sucrée et riche en vitamine $C$, sa maturité est homogène et sa saveur originale très agréable. Les premières productions pourront être trouvées sur le marché en 2003. Les variétés ornementales cultivées pour la beauté de leur inflorescence sont elles déjà commercialisées essentiellement en Europe du Nord.

\section{Sûreté alimentaire et production d'ananas}

Les crises graves qui ont affecté différents secteurs de l'agriculture ont fait émerger une demande forte des consommateurs en matière de sûreté alimentaire, que I'Union européenne a traduite par des lois strictes sur les limites de résidus de pesticides. Pour de nombreux produits tropicaux, les données scientifiques n'existant pas, la plupart des limites de résidus ont été fixées, par facilité et de façon hâtive, au seuil de détection.

Cette décision menace les possibilités d'exportation de nombreux fruits et légumes. Cette situation est particulièrement grave pour l'ananas traité à l'étéphon qui améliore la coloration des fruits. Un travail de recherche est mis en place sur ce thème et bénéficie d'un soutien financier de l'Organisation centrale des producteurs-exportateurs d'ananas et de banane de Côte d'Ivoire. Les expérimentations ont montré la complexité du problème posé. Alors que la climatologie, les techniques $\mathrm{d}^{\prime}$ apport, la fumure et le poids de chaque fruit déterminent la réussite du traitement, il faut concilier l'efficacité de celui-ci avec la qualité gustative et le respect de résidus minimaux. D'importantes difficultés, ignorées par le législateur, sont apparues en particulier dans la validité des dosages, la variabilité des individus et les méthodes d'analyse.

Les résultats serviront à établir un code de bonnes pratiques agricoles et de nouvelles normes

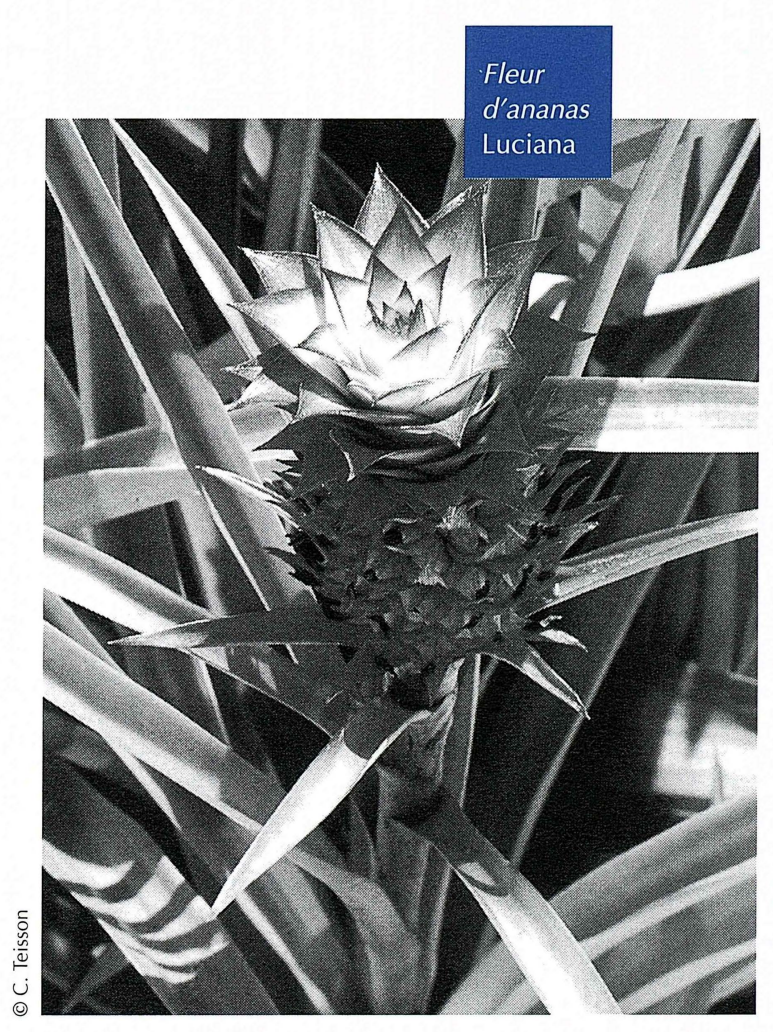

européennes répondant aux intérêts des producteurs et des consommateurs. L'expérience acquise sur ce thème précis pourra être valorisée pour d'autres produits. 


\section{Ressources génétiques de l'ananas}

Implantée à la Martinique en 1985, la collection d'ananas du Cirad comprend aujourd'hui plus de six cents accessions. Les données collectées sont considérables mais, enregistrées sous des formes diverses, elles restent sous-utilisées. Le Cirad a donc développé une base de données, dont une version d'évaluation a été diffusée à la fin de 2001. Chaque accession est identifiée par son passeport (origine, lieu de collecte), par un numéro unique, par son nom et par sa classification botanique. Les caractères qualitatifs, hautement héritables, facilement observables et peu sensibles à l'environnement font l'objet d'un enregistrement unique. Les caractères quantitatifs, relatifs au rendement et à la caractérisation biochimique des fruits, sont sensibles au milieu. De ce fait, chaque cycle de mesures donne lieu à une série d'enregistrements. Un indicateur de fiabilité de I'observation est associé à chaque caractère et peut être utilisé comme filtre lors des interrogations. Pour les travaux de génétique, de sélection et de développement, mais aussi pour la formation, les utilisateurs disposent de diverses formes de restitution : un inventaire succinct ou étendu, des fiches descriptives par accession, des photographies. En outre, le logiciel utilisé offre de multiples possibilités d'interrogation.

Simultanément, I'Ipgri intègre dans une base de données l'ensemble des collections d'ananas dans le monde. Les informations standardisées seront échangeables entre les bases.

\section{Diffusion de variétés indemnes de badnavirus}

Le Banana streak virus, badnavirus agent de la maladie de la mosaïque en tirets du bananier, provoque de graves symptômes pouvant aller jusqu'au dépérissement complet. Il est naturellement transmis par une cochenille du genre Planoccocus. Plusieurs équipes, dont celles du Cirad (équipe de virologie du Cirad-amis et Cirad-flhor) ont récemment découvert que les bananiers possédant des chromosomes de l'espèce balbisiana contiennent des séquences du virus dans leur génome. Ces bananiers ont la capacité de développer la maladie à la faveur d'un stress, en l'absence de contamination directe par le virus. Afin d'éviter tout risque de dissémination importante de la maladie, le Cirad a décidé de suspendre la diffusion des hybrides issus de croisements entre les espèces Musa acuminata et Musa balbisiana contenant des séquences intégrées du virus. Simultanément, un programme de recherche pluridisciplinaire a été mis en place. Il vise à étudier le déterminisme génétique et

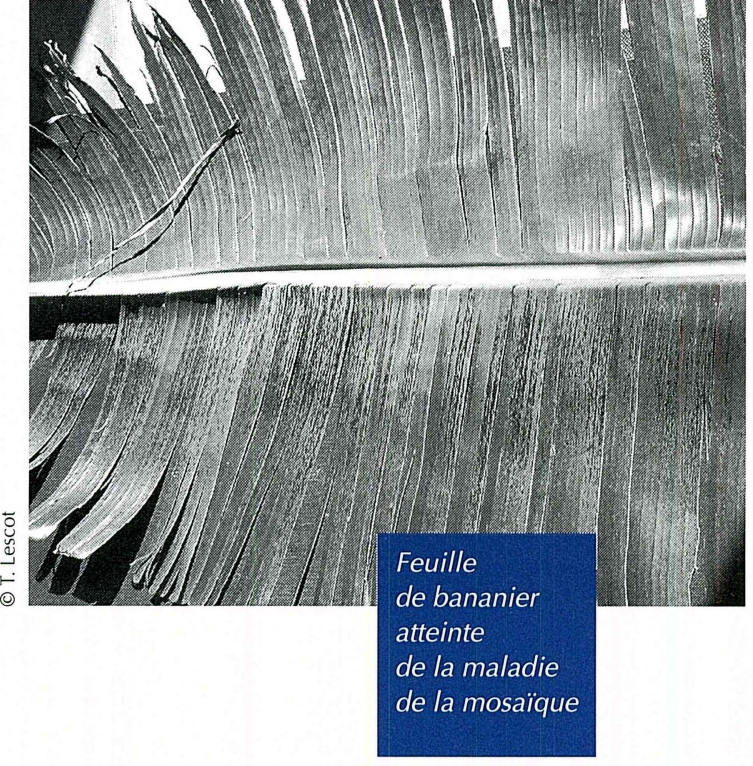

moléculaire de l'activation de ces séquences intégrées et à évaluer les risques associés à la diffusion de plants renfermant ces séquences. En outre, de nouveaux schémas de croisement sont explorés à partir de géniteurs diploïdes de la seule espèce acuminata $\mathrm{n}^{\prime}$ ayant pas de séquences du virus. Les résultats de ce programme devraient permettre au Cirad de garantir la diffusion de ses hybrides ayant par ailleurs montré leur résistance aux cercosporioses, leur aptitude agronomique et une bonne qualité après récolte.

Il s'agit là d'une opération exemplaire pour le Cirad. Pour répondre à un besoin de diffuser de nouveaux hybrides, il s'engage dans des recherches fondamentales de tout premier plan.

\section{Qualité de la banane}

Commencée à la Guadeloupe, au début de l'an 2000, une étude de la physiologie moléculaire de la banane a pour but de comprendre les mécanismes moléculaires de la maturation du fruit en liaison avec la qualité.

Les Adnc correspondent à des protéines impliquées dans les processus clés de la maturation. Ils sont recherchés et caractérisés grâce à l'étude de l'expression et à l'analyse de la complexité génique. Ils sont ensuite validés comme candidats pour la recherche de marqueurs moléculaires de la qualité du fruit. Ces marqueurs "plus ciblés" viennent compléter les marqueurs aléatoires déjà existants. Les travaux en cours ont porté sur I'aspect de la biosynthèse et de la transduction du signal de l'éthylène, hormone qui initie et contrôle certains mécanismes de la maturation et de la qualité de la banane. Les Adnc codant pour les deux enzymes clés de la biosynthèse de I'éthylène ainsi que deux Adnc nouveaux codant les récepteurs de l'éthylène ont été isolés et enregistrés dans la banque de données Gennak sous les numéros AF445195 et AF445196. 


\section{Protection de I'environnement}

Mieux répondre aux défis économiques et environnementaux est un objectif majeur des professionnels de la filière de la banane. Chercheurs et producteurs déterminent ensemble les solutions techniques les mieux adaptées au milieu.

Sont à l'étude la réduction du travail du sol pour limiter l'érosion, le recours à des indicateurs de production et de pollution pour optimiser I'application des engrais et des produits phytosanitaires et gérer les ressources en eau, I'appui aux producteurs pour promouvoir une lutte par avertissement contre les maladies fongiques des feuilles du bananier. Par ailleurs, l'intérêt des rotations ananas-bananier et canne à sucre-bananier est évalué, notamment leur capacité d'assainissement des sols vis-à-vis des nématodes du bananier et leur impact sur la restauration de la fertilité biologique des sols. La lutte chimique est ajustée à l'état d'infection des bananeraies, grâce à la capture des charançons par des pièges à phéromone. De nouvelles voies de lutte biologique, qui associent le piégeage et l'application de nématodes et de champignons entomopathogènes, sont explorées.

Les pratiques raisonnées sont incluses dans les projets de mise en œuvre des mesures agrienvironnementales : élaboration et suivi des contrats territoriaux d'exploitation pour la banane de montagne à la Guadeloupe, cahier des charges de I'agriculture biologique, labellisation des productions issues du commerce équitable, etc. L'ensemble des acteurs de la filière s'engage à promouvoir ces nouvelles pratiques et à valoriser ces innovations sur le plan commercial.

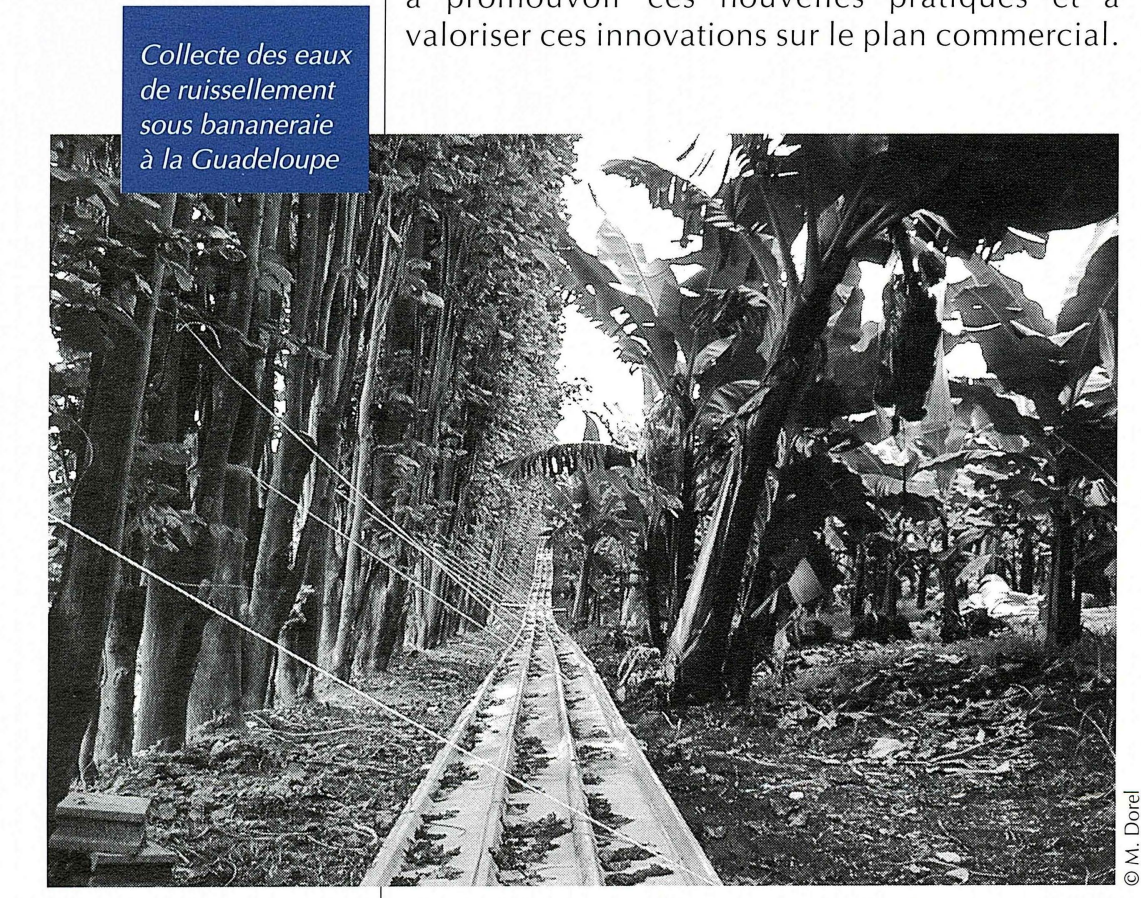

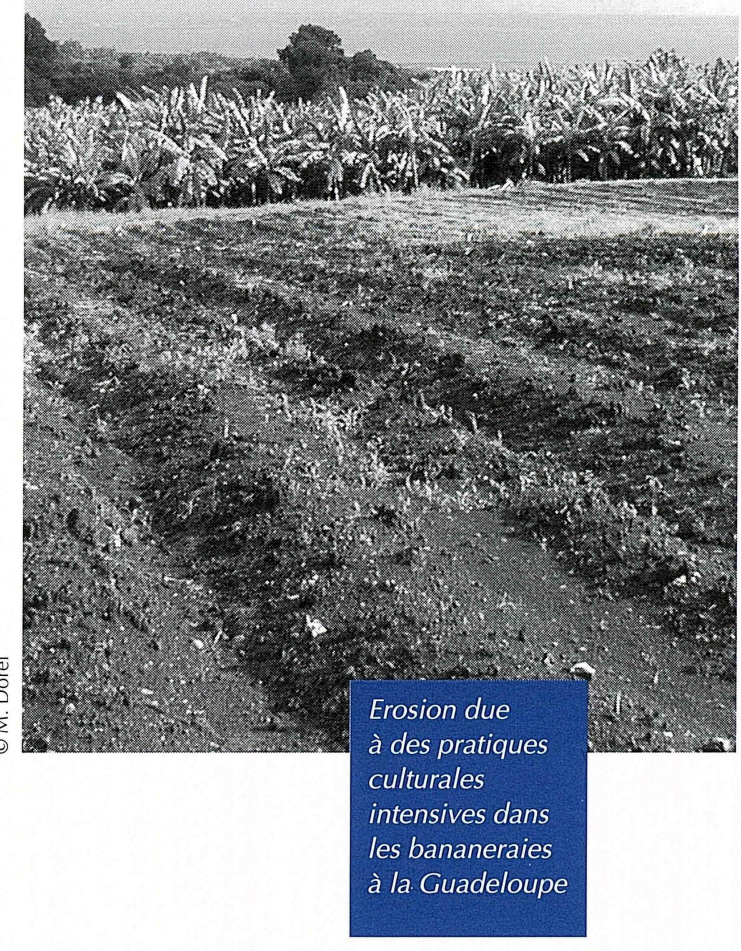

\section{Travail du sol}

A la Guadeloupe, les pratiques culturales intensives dégradent la structure des sols dans les bananeraies. L'effet de la mécanisation sur les propriétés physiques des sols issus d'un matériau volcanique récent a été évalué. Le profil cultural présente des zones contrastées : des structures compactes à faible macroporosité et à conductivité hydraulique réduite et des structures fragmentaires à forte conductivité.

Dans le cas de culture pérenne non mécanisée, le profil cultural apparaît favorable à l'enracinement latéral, sans discontinuité structurale nette. Le passage d'engins au cours de la culture entraîne le compactage des interlignes, obstacle au développement latéral des racines. Mesurée en conditions contrôlées, la compacité du sol réduit fortement la biomasse et la densité racinaire du bananier, ainsi que la longueur des racines primaires. La répartition des racines et I'exploitation des réserves hydriques du sol ont été étudiées pour deux profondeurs de travail du sol. Renseigné à partir des résultats des essais, un modèle de simulation fournit une estimation de l'effet de l'état physique du sol sur le fonctionnement d'une culture de bananier.

Les recommandations techniques prennent en compte la variabilité des conditions pédoclimatiques dans la bananeraie guadeloupéenne. Elles proposent de restreindre le travail du sol, voire de le supprimer, notamment sur les sols andiques d'altitude. Elles visent à garantir un fonctionnement optimal du système racinaire et une conservation à long terme de la fertilité du sol. 


\section{Arboriculture fruitière}

Les fruits jouent un rôle nutritionnel fondamental dans les pays du Nord comme du Sud. S'appuyant sur une bonne connaissance des systèmes de culture, des marchés et des consommateurs, le programme arboriculture fruitière oriente ses recherches sur les agrumes, la mangue et la diversification fruitière. Avec 80 \% de la production fruitière des régions chaudes, les agrumes et la mangue occupent une place essentielle

\section{Huanglongbing au Vietnam}

Maladie de dégénérescence des agrumes, le huanglongbing est d'origine bactérienne, transmis par greffage ou par des psylles vecteurs. En Asie, la longévité des agrumes chute fortement et ne dépasse guère six à huit ans, autorisant seulement deux récoltes normales et parfois une troisième. La lutte contre le huanglongbing est complexe. Des méthodes préventives sont proposées : isoler les zones de développement ou de réhabilitation de la culture des agrumes et éradiquer le plus tôt possible les arbres contaminés. En outre, il est recommandé de planter exclusivement du matériel végétal sain et de lutter efficacement contre les psylles vecteurs.

Le Vietnam est directement concerné par ces travaux avec l'engagement des instituts de recherche en agriculture (Vasi) et de protection des plantes (Nipp), qui collaborent avec le Cirad. Le centre australien de recherche en agriculture Aciar est également impliqué.

La lutte contre le huanglongbing recouvre trois stratégies. La première - la plus importante actuellement - est la mise en valeur agrumicole des régions moins favorables à la maladie. Elle repose essentiellement sur des actions de prévention, notamment par la fourniture de matériel végétal sain et l'accompagnement de la production par des mesures prophylactiques. La lutte contre le vecteur et la recherche de résistance variétale constituent les deux autres axes majeurs d'étude.

\section{Recherches au Brésil}

La demande $d^{\prime}$ une plus grande sûreté alimentaire est une préoccupation essentielle des consommateurs. Au Brésil, différents aspects de cette question sont abordés : améliorer les technologies de transformation des fruits, garantir leur qualité organoleptique et nutritionnelle et connaître les effets des procédés employés sur la qualité des produits transformés. Un vaste projet associe plusieurs institutions de recherche et de développement et des universités brésiliennes et dans le secteur des fruits frais et transformés. Dans le domaine de la diversification fruitière, les recherches portent sur le remplacement des grandes cultures pivots et sur la valorisation de nouveaux produits. Le programme s'appuie sur des pôles de compétence et des réseaux et s'intéresse au développement intégré des filières fruitières, à l'adéquation de l'offre à la demande et à l'obtention de produits finis innovants et faciles à mettre en œuvre par les professionnels.

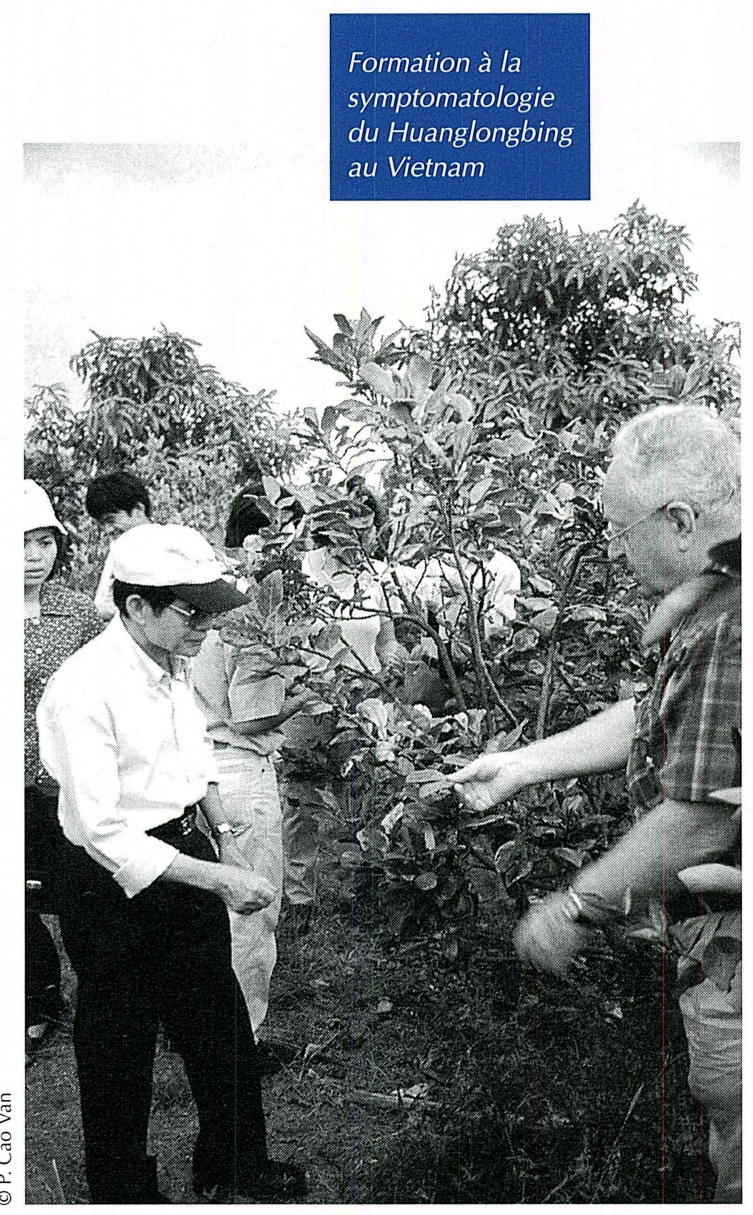


françaises (Cnrs, Cta, Embrapa, Fruthotec, lem, Unicamp) ainsi que des opérateurs privés.

La conservation de la qualité des mangues est le thème d'une recherche conduite depuis 2001, dans I'Etat du Nordeste, en partenariat avec I'Embrapa. La physiologie de la mangue après récolte est étudiée, en particulier dans le cadre de travaux sur les atmosphères modifiées.

Mieux valoriser les ressources génétiques fruitières du bassin amazonien tout en respectant le milieu naturel et promouvoir des systèmes agricoles familiaux durables sont les objectifs d'une étude qui regroupe I'Embrapa (Cenargen, Cpaaf), I'Inpa, le Funai, les universités brésiliennes et I'Ipgri. Dans un premier temps, sont inventoriés les fruits et leur mode de consommation local. Ensuite les espèces seront collectées et leur diversité morphologique et moléculaire analysée. Elles seront évaluées du point de vue agronomique et technologique, puis dans le but d'une dynamique de conservation in situ et de valorisation locale des produits frais et transformés.

Le chancre citrique, causé par Xanthomonas axonopodis pv. citri, est une maladie bactérienne présente dans la majorité des régions agrumicoles du monde. Une collaboration avec Fundecitrus, centre privé de recherche brésilien, est engagée depuis I'année 2000. Les souches présentes dans I'Etat de São Paulo sont caractérisées. Ces résultats serviront à élaborer des outils de diagnostic précoce et contribueront à adapter les méthodes de lutte.

\section{Production de noix de cajou}

Premier produit d'exportation du Mozambique - $16 \%$ des recettes d'exportation en 1998 contre $22 \%$ en 1996 - I'anacarde, ou noix de cajou, représente 4 à $5 \%$ du produit intérieur brut. La production nationale a chuté de 216000 tonnes en 1971-1972, à moins de 50000 tonnes. Plus de 400000 producteurs, 2000 commerçants et 8000 artisans sont concernés.

Afin de doubler les exportations, les autorités mozambicaines ont décidé de stimuler la production de noix de cajou grâce à un projet d'envergure soutenu financièrement par I'Agence française de développement et mis en place par l'institut de recherche agronomique du Mozambique (Inia). Accroître la productivité et améliorer la qualité sont les deux objectifs majeurs d'une recherche appliquée confiée au Cirad sur cinq ans. Des progrès sont attendus dans la sélection du matériel végétal et dans l'optimisation des systèmes de culture insérés dans des exploitations de polyculture familiale capables de conserver la fertilité des sols. Une réflexion est engagée sur l'évolution du cadre réglementaire régissant la filière de l'anacarde dans le pays.

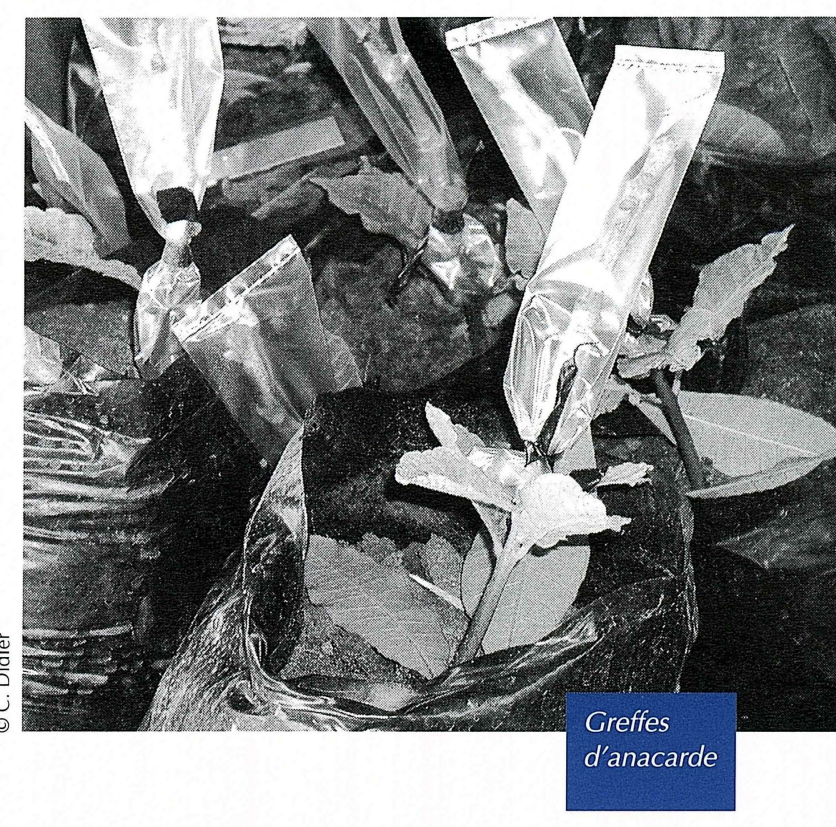

\section{Transformation des fruits}

Concurrent des procédés traditionnels de blanchiment-broyage, le procédé de flash-détente ${ }^{\circledR}$ sous vide consiste à étuver le matériel végétal (fruits, légumes) à $60-90^{\circ} \mathrm{C}$ puis à l'introduire brutalement dans une chambre sous vide poussé (30-50 millibars). Lors de la détente sous vide, l'évaporation instantanée d'une fraction de l'eau de constitution (environ 10 \%) entraîne une désagrégation du matériel végétal résultant de I'expansion, avec la formation de microcanaux intercellulaires.

Les purées et les jus de fruit de la passion pourpre, de mangue et de citron présentent, après raffinage, de nouvelles propriétés par rapport aux produits issus des méthodes traditionnelles. La consistance et la viscosité sont très nettement supérieures. En effet, une partie de l'enveloppe externe des fruits est incorporée, les teneurs en parois cellulaires sont donc plus élevées. L'accroissement de l'espace intercellulaire augmente aussi la viscosité. Les colorations sont plus claires et plus intenses car des molécules colorées (anthocyanes) ou des tissus blanchâtres (albedo) de l'enveloppe des fruits sont conservés. En outre, dans le cas du citron, la purée obtenue est plus amère.

Par ailleurs, le procédé de flash-détente ${ }^{\circledR}$ a été appliqué à des écorces d'agrumes (citron, orange douce, mandarine et pomelo) pour extraire des huiles essentielles. Le rendement de ce procédé est analogue à celui des procédés traditionnels. Par rapport à des huiles pressées à froid, les huiles extraites par le procédé de flash-détente ${ }^{\circledR}$ sont plus riches en hydrocarbures terpéniques et appauvries en composés oxygénés. Ce procédé prometteur est testé en partenariat avec des opérateurs industriels, afin de poursuivre son évaluation et d'améliorer l'extraction de molécules actives. 


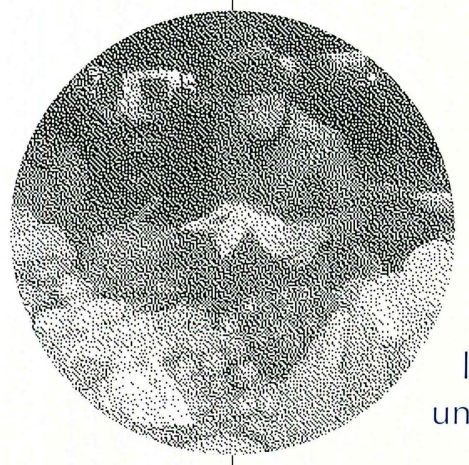

\section{Qualité des légumes en Asie}

Dans les grandes villes d'Asie du Sud-Est, la qualité des légumes est une préoccupation croissante des consommateurs. Au Vietnam, les légumes-feuilles, le choysum (Brassica rapa cv. Choysum) et la moutarde (Brassica juncea), sont les plus consommés. A cause de leur faible durée de conservation, ils sont produits près des villes, toute l'année, sur des périodes courtes qui requièrent engrais et pesticides. Cependant, les consommateurs exigent une garantie de fraîcheur et d'innocuité. Comment diminuer les risques de pollution? Les agronomes de l'institut de recherche des fruits et légumes (Rifav), en collaboration avec les chercheurs du Cirad et du centre de recherche et de développement des légumes en Asie (Avrdc), sont chargés de répondre à cette question complexe. La fertilisation azotée et l'emploi des insecticides sont au centre du diagnostic des pratiques culturales. Des expérimentations seront menées en station et chez les agriculteurs afin de proposer des conseils techniques tenant compte de la variation saisonnière des populations de ravageurs et des conditions antérieures de culture (techniques traditionnelles, état des sols...). Pour étudier la gestion de l'azote dans les systèmes maraîchers tropicaux, le Cirad a développé un partenariat avec l'Inra et avec le réseau Initiative stratégique pour I'agriculture urbaine et périurbaine (Siupa) - regroupant plusieurs instituts sous la direction du Cip - qui s'intéresse à tous les travaux dans ce domaine.

\section{Embryogenèse somatique de l'ail}

Dans le cadre du projet européen Ail et santé, le Cirad est chargé de développer de nouvelles techniques de multiplication rapide et à grande échelle de plants sains d'ail. Un protocole d'embryogenèse somatique et de conversion des embryons en plantules a été mis au point.

Quatre cultivars d'ail, qui représentent la diversité des groupes physiologiques utilisés en Europe et sous les tropiques, sont testés. Des embryons pluridisciplinaires, illustrant la complexité des problématiques de sécurité alimentaire et de durabilité des exploitations. Ainsi, en zone tropicale humide sont abordés les aspects de gestion de l'azote et de la matière organique, de lutte intégrée contre les pathogènes bactériens, fongiques ou viraux, mais aussi les filières

de commercialisation et le transfert des innovations techniques. Par ailleurs, le programme s'investit dans la recherche de systèmes de culture durables et diversifiés dans les Dom-Tom et dans le développement des productions horticoles d'exportation.

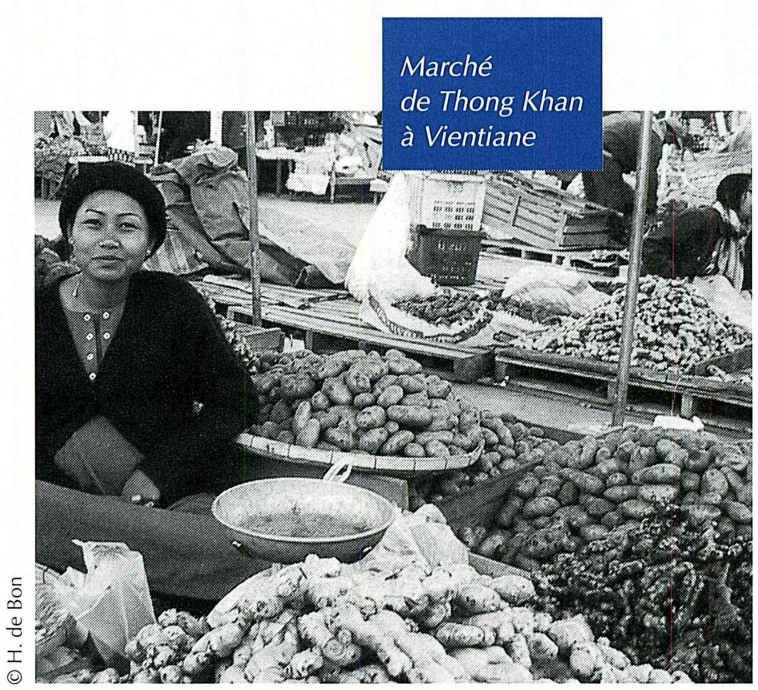

somatiques de chaque cultivar ont été régénérés à partir de cals embryogènes sur un milieu gélifié, avec un taux de conversion en plantules de $40 \%$.

Des améliorations techniques ont été apportées à chaque étape du protocole. La méthode perfectionnée consiste à établir des cultures cellulaires en suspension de chaque cultivar à partir de cals nodulaires embryogènes ou de cals friables. Les embryons obtenus par cette méthode, observés sur un milieu de régénération gélifié, ont 
un comportement similaire à celui des embryons issus de cals. De plus, le taux de conversion en plantules provenant de cals nodulaires ou de cals friables est supérieur à celui de la régénération des cals embryogènes. Par ailleurs, des études histologiques ont démontré l'origine unicellulaire des embryons somatiques. La conformité des plantes régénérées a été évaluée par rapport à celle des plantes multipliées selon la méthode classique par cayeux. La caractérisation par cytométrie de flux a montré que les 265 plantules dérivées d'embryons, après application du nouveau protocole, sont diploïdes comme les quatre témoins multipliés in situ.

Cette méthode aboutit à une grande fiabilité dans la conformité des plantules obtenues. Parallèlement, des tests au champ sont conduits par l'Inra.

\section{Flétrissement bactérien}

Le flétrissement bactérien, causé par Rastolnia solanacearum, est un facteur limitant un grand nombre de cultures, en particulier maraîchères (solanacées) dans les zones tropicales et tempérées. La recherche de méthodes de lutte intégrée exige de bien connaître le complexe plante-bactérie. Ainsi, la diversité génétique de $R$. solanacearum a été examinée à l'aide d'outils moléculaires par exploration de plusieurs régions du génome.

La séparation de l'espèce en deux divisions, R. s. asiaticum, R. s. americanum, fondée sur l'origine géographique des souches est confirmée. Cependant, des études récentes à la Réunion et en collaboration avec I'Australie montrent l'existence de souches africaines et indonésiennes séparées des souches connues. Les classifications en cinq races et six biovars subsistent, mais ne recoupent que partiellement la division en grands groupes. La Réunion a la particularité d'héberger trois populations appartenant aux deux principales races et aux trois biovars majoritaires. Un outil efficace de détection de la bactérie dans les différents supports (eau, sol, plante) et d'identification des variants (biovars 1, 2, 3 de la Réunion) a été mis au point. Cette étape constitue une condition préalable essentielle pour améliorer la prophylaxie et trouver des variétés résistantes.

Par ailleurs, I'interaction entre populations observées deux à deux a été mesurée. Pour des températures d'incubation supérieures à $25^{\circ} \mathrm{C}$, le biovar 1, comme le biovar 2, n'est pas compétitif face au biovar 3 . En revanche, pour des températures fraîches, le biovar 2 apparaît le plus efficace. Des essais de comportement menés sur des hybrides de Solanum tuberosum et de l'espèce sauvage S. stenotonum - obtenus par électrofusion de protoplastes — acclimatés puis installés sous abri ont confirmé la résistance des hybrides à la souche de race 1 . En revanche, ils se sont montrés plutôt sensibles à la souche de race 3 , tout comme le parent sauvage.

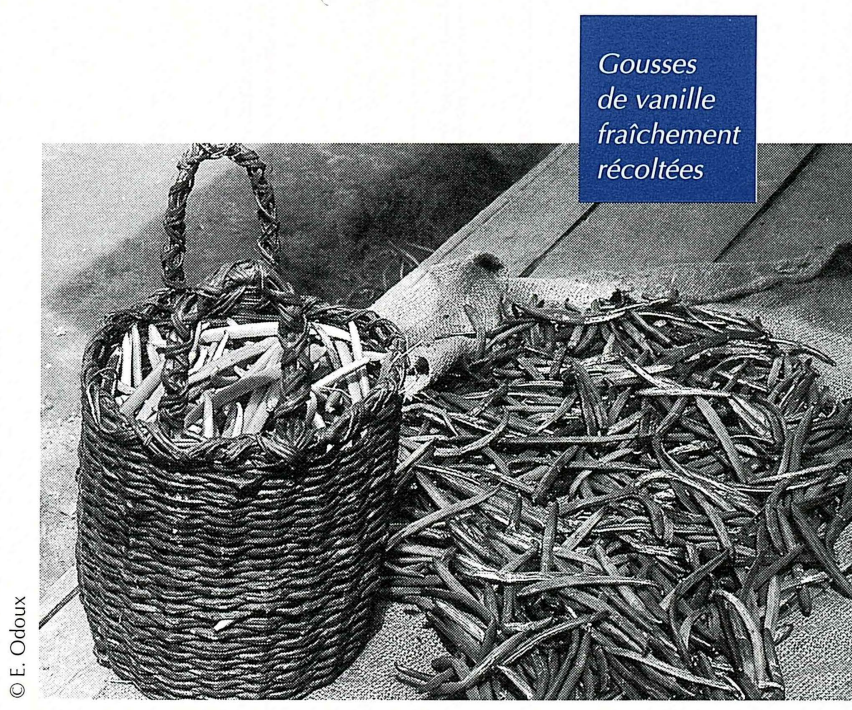

\section{Transformation de la vanille}

La vanilline est, quantitativement et qualitativement, le composé le plus important de l'arôme vanille. A la récolte de la gousse, ce composé existe principalement sous la forme de son précurseur glycosilé, la glucovanilline. Cette dernière ne possède aucune propriété olfactive et doit être hydrolysée enzymatiquement par une $\beta$-glucosidase endogène pour donner la vanilline.

L'hydrolyse de la glucovanilline au cours du procédé traditionnel a un rendement final en vanilline relativement faible, de l'ordre de $40 \%$ du potentiel de la gousse verte. Afin d'accroître le rendement de ce procédé, le Cirad, en partenariat avec une société privée française productrice d'arôme, engage à Madagascar des recherches sur la biosynthèse de la vanilline. Conduite pendant deux ans, l'étude du précurseur de la vanilline et du système enzymatique associé a mis en évidence, à l'échelle du laboratoire, des possibilités d'augmentation importante du rendement en vanilline des gousses au cours de l'hydrolyse. Plusieurs procédés de transformation de la vanille ont été expérimentés à l'échelle d'un site pilote à Madagascar en 2001. 
'augmentation des productions animales doit répondre à celle des besoins.

Elle passe, dans la plupart des cas, par l' intensification des systèmes d'élevage et par une meilleure synergie avec I'agriculture.

Intensifier, c'est aussi prendre en compte les risques d'impacts négatifs sur l'environnement, les risques de marginalisation des petits éleveurs et les exigences de plus en plus marquées des consommateurs pour une qualité et une sûreté sanitaire des aliments.

En 2001, un projet d'intensification des productions animales a pris de l'ampleur au Vietnam, dans le cadre d'un nouveau pôle de compétence, et le groupe de recherches sur la production laitière a multiplié ses terrains d'intervention.

En santé animale, les thèmes forts pour lesquels le Cirad est reconnu comme centre de référence ou collaborateur de la Fao et de l'Oie restent dans les priorités de recherche : trypanosomoses, maladies transmises par les tiques, maladies épizootiques transfrontalières, épidémiologie.

De façon transversale au département, dans les programmes écosystèmes naturels et pastoraux et santé animale, l'étude des interactions de la santé et de l'environnement, en particulier les maladies vectorielles émergentes, fait l'objet d'un investissement important. Avec les recherches sur les cycles épidémiologiques des maladies, le risque d'extension de ces maladies émergentes, autant pour les pays du Sud que pour les pays du Nord, est étudié.

et médecine Les recherches du département ont fortement progressé dans le domaine de la gestion des ressources naturelles pastorales et de la biodiversité animale. La conservation, la gestion et la valorisation de la faune font l'objet de programmes régionaux ; plusieurs pôles de concentration de compétences se sont constitués, comme au Sénégal ou au Burkina, et d'autres se mettent en place, comme en Asie du Sud-Est.

Enfin, le département a poursuivi sa politique d'enseignement et de formation en organisant de nouveaux modules, dans le cadre de partenariats toujours plus nombreux, avec par exemple I'université de Montpellier et les écoles nationales vétérinaires. 


\section{Ecosystèmes naturels et pastoraux}

La conservation des milieux, la gestion des espaces, la valorisation des ressources exigent des actions complexes, menées par de nombreux acteurs, à long terme. De même, la compréhension des interactions des populations animales sauvages et domestiques nécessite des protocoles combinant observations, mesures et suivis pluridisciplinaires, répétés sur de longues périodes.

\section{Valoriser les écosystèmes}

Destiné à mettre en œuvre la Convention de lutte contre la désertification (1995), le réseau d'observatoires de surveillance écologique à long terme, Roselt, est entré depuis deux ans dans une phase de consolidation opérationnelle. Il est animé par un consortium associant le Cirad, I'Ird et I'Insah. En Afrique du Nord, de l'Ouest et de I'Est, les Etats ont mis en place des observatoires pour assurer un suivi scientifique de l'environnement et caractériser les mécanismes de la désertification. L'objectif est de produire des indicateurs biophysiques et socio-économiques. Le Cirad est principalement impliqué dans les domaines du pastoralisme, du suivi de la faune et des relations entre l'évolution des écosystèmes et les dynamiques sociales. Il a participé activement au redémarrage d'observatoires en Afrique de I'Est - Kenya, Ethiopie, Djibouti - pour renforcer le dispositif sur le continent africain.

En milieu écologique fragile, I'élevage a souvent été incriminé, un peu rapidement, comme un facteur important de dégradation des ressources. L'Initiative élevage, environnement et développement (Lead) a pour objectif de mieux gérer les ressources naturelles valorisées par l'élevage et de réduire la pauvreté. En 2001, l'initiative a créé un centre virtuel d'information (http://www. virtualcentre.org). Il a pour vocation d'encourager les activités de recherche pluridisciplinaire et d'accroître la prise de conscience des principaux acteurs clés sur les interactions complexes qui existent entre les besoins, les productions animales et la durabilité des ressources naturelles. Le site est animé en anglais par la Fao, en français par le Cirad et en espagnol par le Catie (Costa Rica).

Le Pôle pastoral zones sèches (Ppzs), créé au Sénégal avec I'Isra, le Centre de suivi écologique, I'université Cheikh Anta Diop de Dakar et le Cirad, cherche à comprendre le fonctionnement des écosystèmes et des sociétés pastorales dans les zones arides et semi-arides, afin de proposer des interventions pouvant améliorer ces systèmes.

\section{C'est pourquoi en 2001 le programme} écosystèmes naturels et pastoraux a concentré ses interventions dans des projets pluriannuels, internationaux, construits en partenariat scientifique.

Le programme en est le coordinateur. Des stratégies d'action ont déjà été définies, des systèmes d'information proposés et des méthodes d'aide à la décision ont été testées.

Le programme Ecopas, créé pour la conservation et le développement du parc régional du $W$ et de sa périphérie - Niger, Bénin et Burkina —, a trouvé un financement auprès de I'Union européenne en 2001. Le Cirad assure la coordination et I'animation de la recherche. Les travaux porteront sur la gestion des activités pastorales, l'inventaire et la cartographie des ressources de la biodiversité, la compréhension des dynamiques écologiques des aires protégées, particulièrement de la faune, la valorisation des ressources naturelles et l'influence des populations présentes à la périphérie. Le projet accueillera des étudiants originaires du Nord et du Sud.

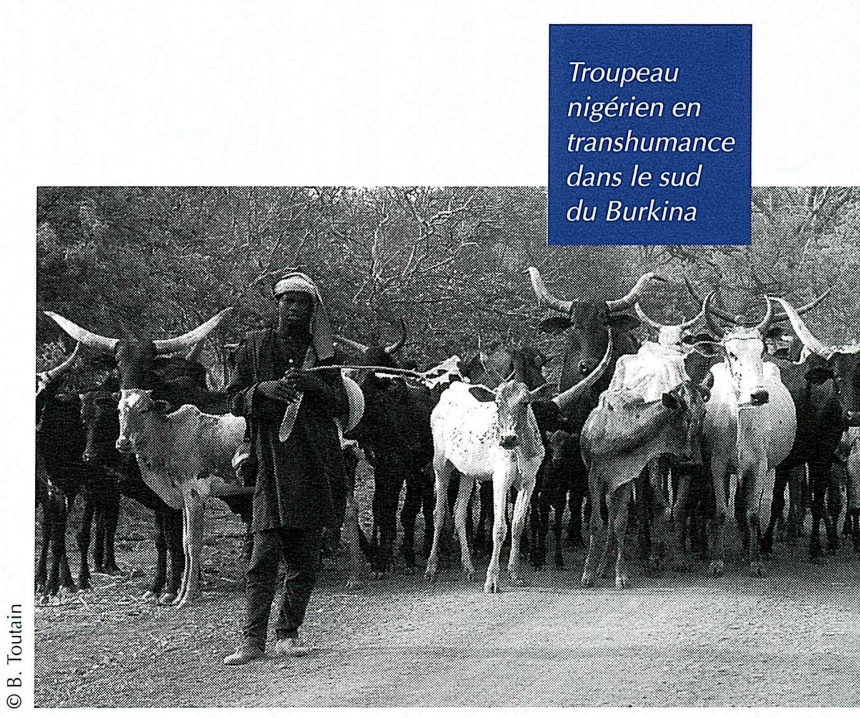




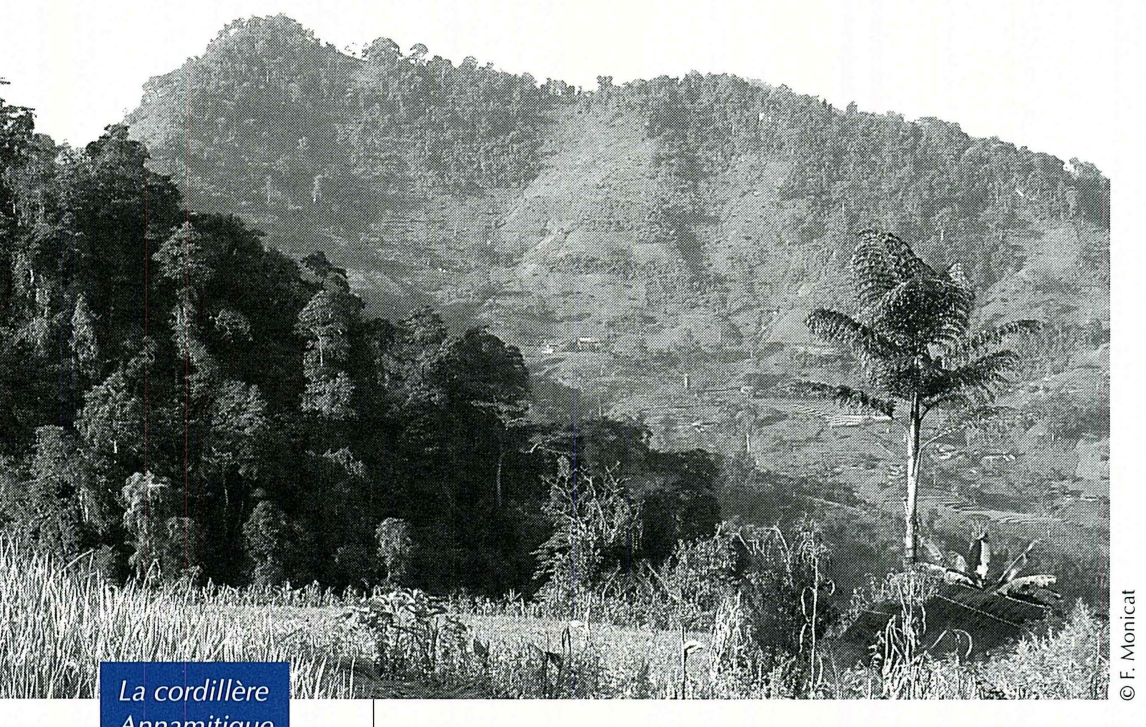

\section{Sauvegarder la biodiversité}

Au Vietnam, les zones de montagne ont conservé une exceptionnelle diversité d'espèces animales sauvages et domestiques. Deux projets financés par le ministère des affaires étrangères et le Fonds français pour l'environnement mondial, lancés par le Cirad avec des partenaires vietnamiens et français, visent à conserver et à valoriser ces ressources génétiques. Dans la région des hauts plateaux et de la cordillère Annamitique, régions parmi les plus pauvres du pays, des actions pilotes sont conduites avec les autorités de quatre provinces pour combiner la gestion des ressources zoogénétiques et l'amélioration des revenus des populations. Le Cirad apporte ses compétences scientifiques. La réserve d'Ea So, sur les hauts plateaux de la province de Dak Lak, est un des derniers îlots de forêts clairières qui abritent des populations reliques de grands bovidés sauvages dont le gaur, Bos gaurus, et le banteng, Bos javanicus. Les caractériser génétiquement, évaluer leur variabilité génétique permettront de définir, pour I'ensemble du Vietnam, une politique de conservation de ces espèces, menacées par la fragmentation des habitats, I'isolement et la dérive génétique. En Nouvelle-Calédonie, le cerf rusa, herbivore introduit, compromet dans certains cas la reconstitution des forêts. Depuis 2000, le Cirad coordonne un projet, financé par le ministère de l'aménagement du territoire et de l'environnement, pour mesurer l'impact de ces populations sauvages sur la biodiversité végétale. Les expérimentations ont été menées sur deux sites, très riches en espèces forestières indigènes. Dans la forêt sclérophylle, les résultats sont contrastés. La majorité des espèces ligneuses ne se régénèrent pas, ou peu, bien que certaines espèces endémiques présentent une résistance remarquable à la consommation par les cerfs. Sur l'autre site, constitué d'une mosaïque de forêt humide et de savane, l'impact des cerfs est plus important sur les zones de savane que sur les forêts. En forêt humide, seul un petit nombre de plantes endémiques, essentiellement des lianes et des fougères, semblent broutées. Des analyses se poursuivent sur les contenus de panses et les fèces, et de nouveaux sites sont prospectés pour valider les bio-indicateurs en cours d'élaboration.

En Amérique latine, des chasses souvent incontrôlées mettent en péril la conservation du pécari, exploité pour sa viande et pour sa peau. Les performances productives de ce suidé sont mal connues, que ce soit en milieu naturel, en élevage extensif ou intensif. Le projet européen coordonné par le Cirad sur le pécari a été lancé en 2001. A partir des expériences et des compétences des différents partenaires, français, espagnols, anglais, péruviens et brésiliens, de nouveaux systèmes d'élevage sont expérimentés. L'objectif est de trouver les systèmes viables les plus productifs qui préservent les habitats naturels et leur biodiversité.

\section{Maladies émergentes}

Partenaire sollicité dans la lutte contre la fièvre de West Nile en Camargue et la fièvre catarrhale du mouton en Corse l'an dernier, le département a entrepris en 2001 de constituer une équipe multidisciplinaire et pluriinstitutionnelle - Ird, Institut Pasteur, Afssa - pour produire des outils fiables et efficaces de surveillance des maladies émergentes, au Nord comme au Sud. L'évaluation du risque impose une connaissance précise de l'épidémiologie de l'agent infectieux et de ses réservoirs naturels dans la zone surveillée. Pour

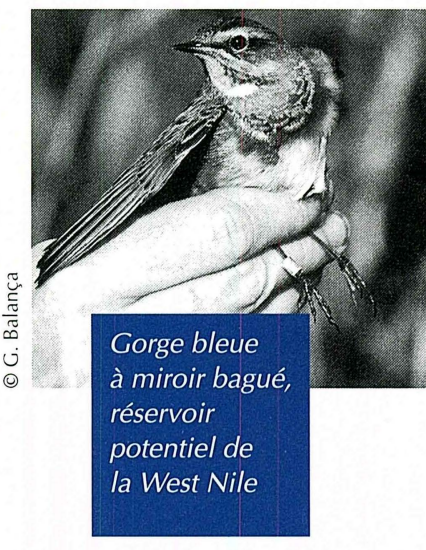
définir l'ensemble des facteurs de I'environnement qui concourent à l'émergence ou à l'amplification d'un processus pathogène, de multiples données doivent être combinées : génétique moléculaire, dynamique des populations, imagerie spatiale, Sig. Des modèles conceptuels de données et des analyses statistiques, spatiales et temporelles seront utilisés pour créer des indicateurs du risque. La gestion opérationnelle d'une crise - alerte, suivi, interventions, surveillance - nécessite un réseau de surveillance efficace et la mise à disposition de ce corpus d'outils pour les intervenants concernés, du secteur privé comme du secteur public. 


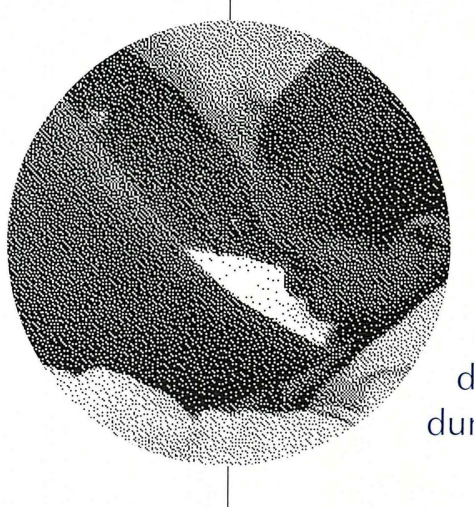

\section{Filières porcines et qualité}

Depuis 1999, à la Martinique, le Cirad participe au développement de la filière porcine. Valoriser la race porcine créole, très rustique et adaptée au climat, est un des principaux objectifs. Des premiers essais d'alimentation à partir d'écarts de triage de la banane ont produit une viande de très bonne qualité, à un coût inférieur à celui obtenu par une alimentation classique. Le projet est de mettre sur le marché une viande de porc labellisée, le " cochon banane».

Pour combattre les nuisances engendrées par les effluents d'élevage porcin, les productions de lisier ont été étudiées. Un procédé anaérobie de dépollution du lisier en biodigesteur a été expérimenté. Cette technique ne peut cependant être généralisée, car son efficacité dépend de nombreuses contraintes : utilisation modérée des eaux de nettoyage des porcheries, élevage sur caillebotis, effectif limité d'animaux, surface et terrain adéquats pour la construction du biodigesteur. Au Vietnam, depuis 2001, un chercheur collabore avec l'institut national d'élevage (Niah). Après un diagnostic de la filière porcine, trois thématiques de recherche ont été retenues : quantité et qualité du porcelet après sevrage, qualité des matières premières et des sous-produits employés dans I'alimentation, élevages périurbains en voie $d^{\prime}$ intensification.

\section{Aquaculture en Asie}

Le succès de la reproduction en captivité des deux principales espèces de poissons-chats a bouleversé I'aquaculture du Mékong : production d'alevins, multiplication des élevages et des unités de transformation du poisson frais. Conquérir de nouveaux marchés extérieurs, notamment celui des EtatsUnis, est un nouvel enjeu, mais cela exige de répondre à des normes contraignantes de qualité et de traçabilité. L'équipe du Cirad se trouve engagée dans ce travail. En 2001, un audit sanitaire a été réalisé. Causes de mortalité dans les élevages, facteurs de risques, pertes dues à la détérioration

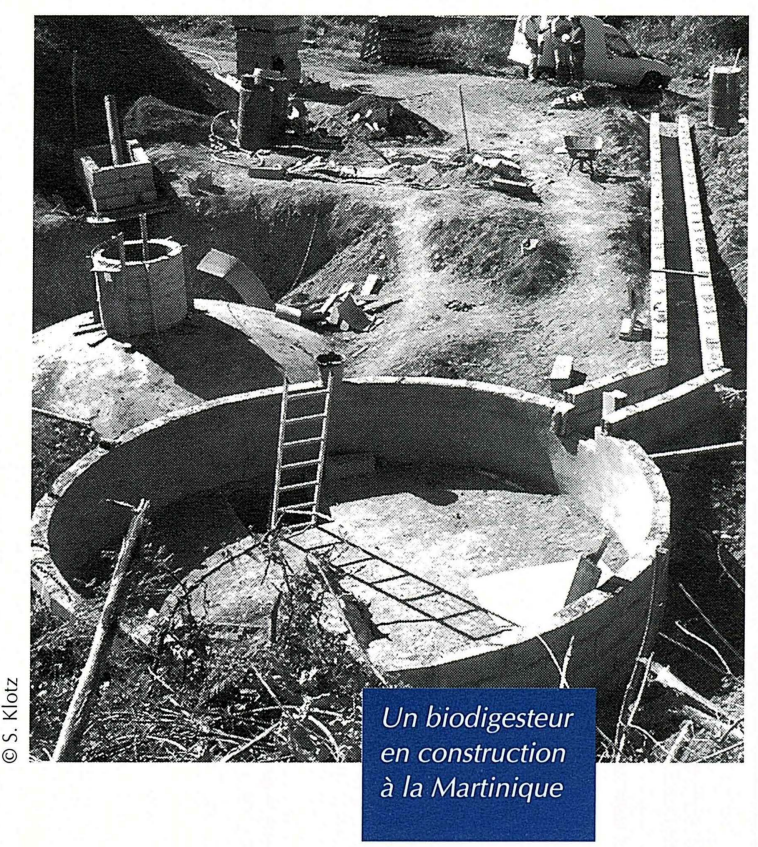

de la qualité de la chair lors des transformations ont été analysés. Ce travail a permis, en outre, d'évaluer l'efficacité des traitements pharmaceutiques appliqués dans les élevages. La collaboration avec l'entreprise Agifish se poursuit pour une amélioration des performances de reproduction et d'élevage larvaire.

Aux Philippines, la sélection d'un tilapia destiné à l'élevage en eau salée se poursuit, en collaboration avec la direction des pêches et des ressources aquatiques. Les premiers tests montrent une plus grande résistance de l'hybride à la salinité, par rapport à l'espèce parentale d'eau douce. La région de Pampanga, où coexistent des élevages piscicoles en eaux douces et saumâtres, a été retenue par le Cirad pour définir les facteurs déterminants de l'innovation. 


\section{Laitrop}

Pour satisfaire la demande en produits laitiers, en plein essor dans les pays du Sud, des chercheurs de plusieurs disciplines et programmes du Cirad ont constitué un groupe de travail, Laitrop. Ses objectifs sont d'évaluer les filières existantes, $d^{\prime}$ 'intensifier la production, d'améliorer la qualité des produits, d'adapter les technologies aux contextes locaux et de modéliser les performances économiques des exploitations et de la filière.

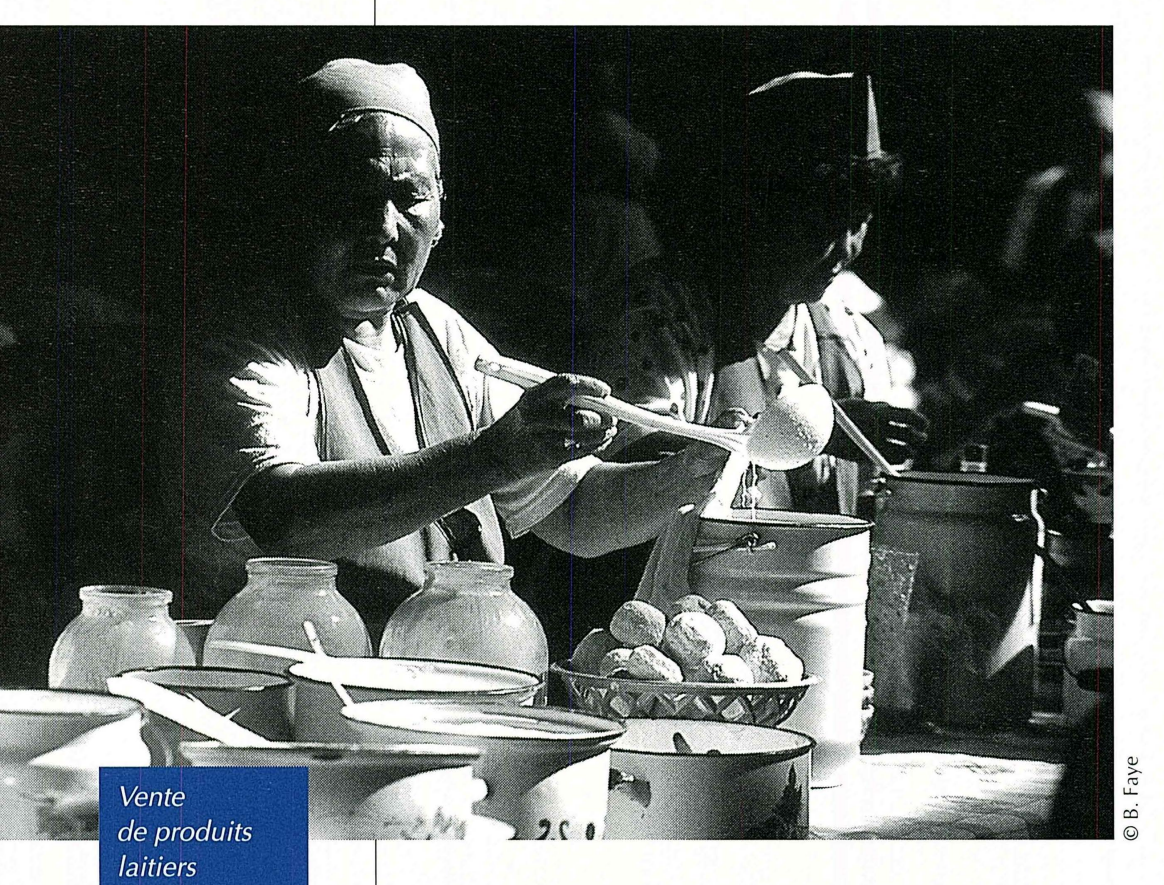

traditionnels

au Kazakhstan

A la Réunion, le Cirad a développé un outil de modélisation intégrant les facteurs suivants : dynamique du troupeau, pâtures, relations entre les différents éléments de l'exploitation et les composants multiples qui interviennent dans les décisions des éleveurs. Cet outil évalue les effets des innovations techniques et du changement des modes d'attribution des aides sur la viabilité des systèmes d'exploitation. Il projette les conséquences qui s'ensuivraient en termes d'emploi, d'autonomie laitière, de préservation des ressources et de revenus à l'échelle régionale.

En Ouganda, le Cirad a participé au développement de la production laitière dans le bassin de Mbarara, en collaboration avec les services vétérinaires. Un diagnostic des systèmes d'exploitation et des suivis zootechniques, sanitaires, alimentaires et socio-économiques ont permis de modéliser les conduites d'élevage et de production laitière. Des outils d'aide à la décision sont proposés pour l'ensemble de la filière.

Depuis 1997, le Cirad intervient au Kazakhstan pour la création d'une démarche qualité des productions laitières traditionnelles, laits fermentés de jument et de chamelle. Des enzymes prépondérantes dans la fermentation ont été identifiées avec des chercheurs de l'université d'Almaty. Récemment, une nouvelle souche de bactérie lactique a pu être isolée.

\section{Qualité des denrées}

Au Sénégal, les services vétérinaires, I'Isra et le Cirad collaborent avec la filière avicole pour améliorer la qualité sanitaire du poulet de chair. L'objectif est d'identifier et de hiérarchiser les facteurs de risque d'une qualité sanitaire insuffisante. Les premiers résultats ont mis en évidence une relation entre les modes d'élevage et d'abattage et la contamination de la viande de poulet par Salmonella et Campylobacter. Ces germes pathogènes sont détruits par une cuisson suffisamment poussée. L'amélioration des résultats d'analyse microbiologique et de résidus antibiotiques montre une prise de conscience des acteurs à tous les maillons de la filière, accouveurs, aviculteurs, abatteurs, et témoigne de leur expérience croissante acquise par les formations.

A la Réunion, la mise en place, à court terme, des normes sanitaires européennes incite les producteurs de lait à suivre la qualité de leur production. Des mesures du taux butyreux et de la concentration en cellules somatiques ont été effectuées par le Cirad dans quatorze élevages bovins laitiers. Une mauvaise hygiène de traite est à l'origine des concentrations de cellules somatiques du lait de tank. Celles-ci augmentent en saison des pluies, car les mamelles sont plus souvent souillées. Les taux butyreux enregistrés en pâturage sur kikuyu ou sur canne à sucre en début de lactation sont meilleurs que sur graminées tempérées. Cependant, sur kikuyu, une complémentation énergétique insuffisante peut altérer le taux butyreux. Des chercheurs du Cirad, de l'Ensar et des pays du Sud ont participé à un atelier, à Rennes, en septembre 2001, pour faire le point sur la qualité des productions animales sous les tropiques. Des exemples français ont été utilisés pour définir des méthodes d'assurance qualité. Par la suite, un atelier dérivé a été organisé en Thaïlande ainsi que des missions d'évaluation et une thèse en cotutelle, au Brésil.

\section{Réserves corporelles du dromadaire}

La bosse du dromadaire, visible et mesurable, montre de grandes variations de volume et de poids et contient la plupart des réserves adipeuses. Des mesures barymétriques et cellulaires - taille moyenne et profil de taille des adipocytes — de la bosse ont été comparées avec la totalité des 
réserves adipeuses de l'animal. L'analyse a révélé que la bosse n'était pas un indicateur fiable pour apprécier l'état d'engraissement d'un troupeau, en raison d'une grande variabilité génétique des individus. Une grille de notation, comportant d'autres critères anatomiques, est fournie aujourd'hui aux éleveurs. Elle leur permet d'évaluer l'état des réserves corporelles de leur bétail et de prendre les décisions nécessaires à la bonne gestion de leur troupeau.
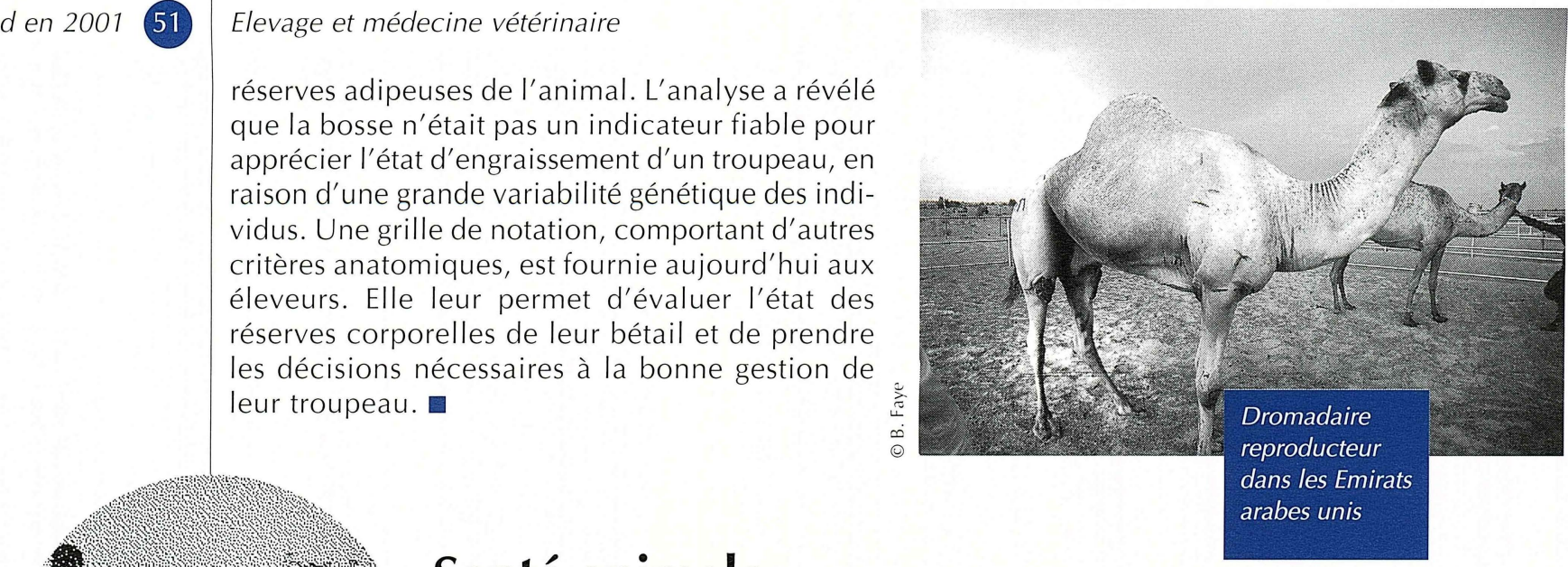

\section{Santé animale}

Pour le programme santé animale, l'année 2001 est marquée par le lancement de cinq projets européens. Quatre projets de développement ont débuté sur la cowdriose, la péripneumonie contagieuse bovine, la trypanosomose et la peste des petits ruminants. Le cinquième projet, sur la peste porcine africaine, inscrit au programme européen «qualité de la vie », a commencé par l'aménagement du laboratoire

\section{Séquençage de Cowdria ruminantium}

Un des résultats scientifiques les plus importants en santé animale a été le séquençage du génome de la souche Gardel de Cowdria ruminantium, responsable de la cowdriose des ruminants. C'est le fruit d'une collaboration exemplaire entre le Cirad, à la Guadeloupe et à Montpellier, et I'Institut du génome humain, à Montpellier. Il ouvre la voie à l'identification de gènes d'intérêt pour la vaccination et pour le diagnostic. Parmi la dizaine d'agents pathogènes étudiés au Cirad-emvt, il s'agit du premier génome entièrement séquencé. D'autres souches de Cowdria et d'autres agents pathogènes seront séquencés prochainement.

\section{Vaccin recombinant capripox}

La souche vaccinale du virus capripox a été utilisée au laboratoire pour le développement d'un vaccin recombinant capable d'immuniser à la fois contre la variole caprine (capripox) et la peste des petits ruminants (Ppr). Des essais de vaccination avec une première souche vaccinale recombinante ont montré une bonne protection des animaux.

Un autre gène a été introduit dans le génome du capripox sous la dépendance de différents promoteurs. L'influence de ces promoteurs sur l'expression du gène in vitro et sur la qualité de l'immunité induite chez la chèvre sera évaluée. Le vecteur capripox a aussi été utilisé pour un vaccin recombinant contre la cowdriose et la variole caprine. Le vaccin recombinant, qui contient un de confinement P3 du Cirad.

Par ailleurs, I'appui du Cirad aux réseaux d'épidémiosurveillance s'est renforcé.

gène codant pour l'antigène MAP-1 de Cowdria, sera prochainement utilisé pour des essais d'immunisation.

\section{Expression de la congopaïne}

La congopaïne, protéase à cystéine de Trypanosoma congolense, est la principale cible pour un vaccin "antimaladie " contre la trypanosomose. Les protéases à cystéines étant difficiles à exprimer, l'obtention d'un antigène recombinant adéquat a demandé plusieurs années de travail. Finalement, I'expression de la congopaïne dans la levure Pichia pastoris, système d'expression eucaryotique le plus récent, a permis d'obtenir un

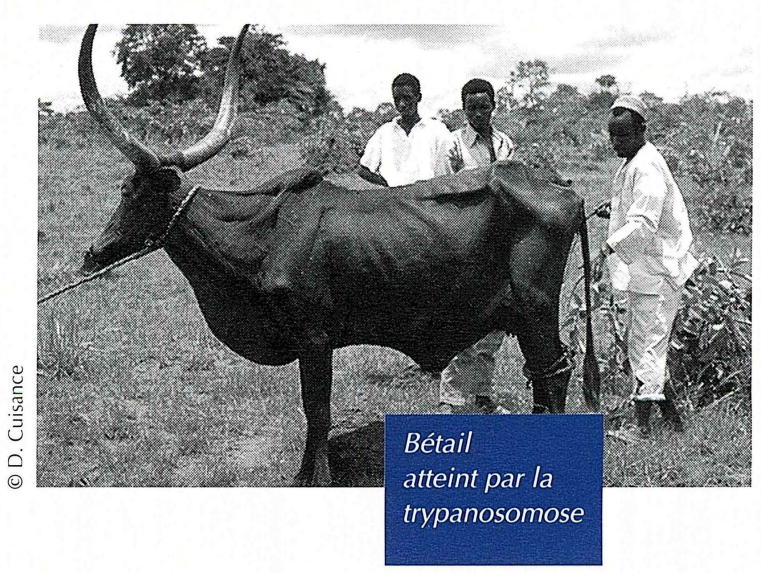


a été mis en évidence chez les bovins et, dans le cadre d'une lutte intégrée, la sélection d'une résistance assistée par marqueur génétique semble possible. Certains allèles d'un gène du complexe majeur d'histocompatibilité de classe II, BoLA$D R B 3$, constituent un bon marqueur de sensibilité. Ce marqueur a été validé de façon très convaincante dans plusieurs populations bovines totalement indépendantes. Une sélection appliquée à la Martinique, par élimination précoce des animaux porteurs du marqueur de sensibilité, a permis de réduire la prévalence de la maladie de $75 \%$ à zéro en cinq ans. Un plan de croisement a été mis en place pour comparer la transmission phénotypique et génotypique des marqueurs. Une étude de biochimie structurale a permis de modéliser en trois dimensions la molécule BoLA-DRB3 et plusieurs hypothèses biologiques ont été émises sur les mécanismes moléculaires de la sensibilité.

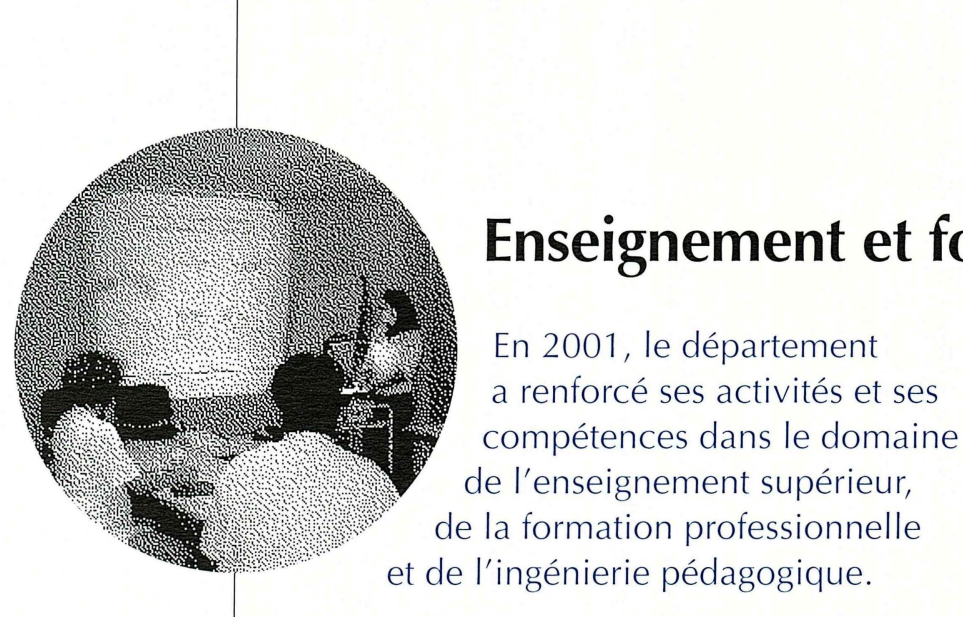

Neuf cents heures d'enseignement en formation diplômante ont été organisées cette année et plus de 150 étudiants ont été accueillis par le département. Une première promotion a obtenu le Dess Productions animales en régions chaudes, réalisé en partenariat avec I'université Montpellier II. Vingt-et-un étudiants ont été recrutés sur dossier pour la session 2001-2002. L'Istom et l'école vétérinaire de Nantes ayant intégré certains modules de ce Dess dans leurs cursus, une trentaine d'étudiants de ces établissements ont suivi l'enseignement du Cirad. La première session du certificat d'études supérieures en épidémiologie animale, délivré par l'école vétérinaire de Maisons-Alfort et le Cirad, s'est ouverte cette année. Onze étudiants y ont participé. Le certificat d'études approfondies vétérinaires Pathologies animales en régions chaudes - Epidémiosurveillance est organisé avec l'école vétérinaire de Toulouse. Quatorze étudiants ont suivi les neuf semaines de cours dispensés par le Cirad. Enfin, soixante-quatorze étudiants ont été accueillis en stage d'application.

Des formations qualifiantes sont aussi proposées, soit à travers des stages individuels adaptés aux besoins spécifiques des professionnels, soit à travers des modules de formation collective organisés par le département. Quatre-vingt-huit

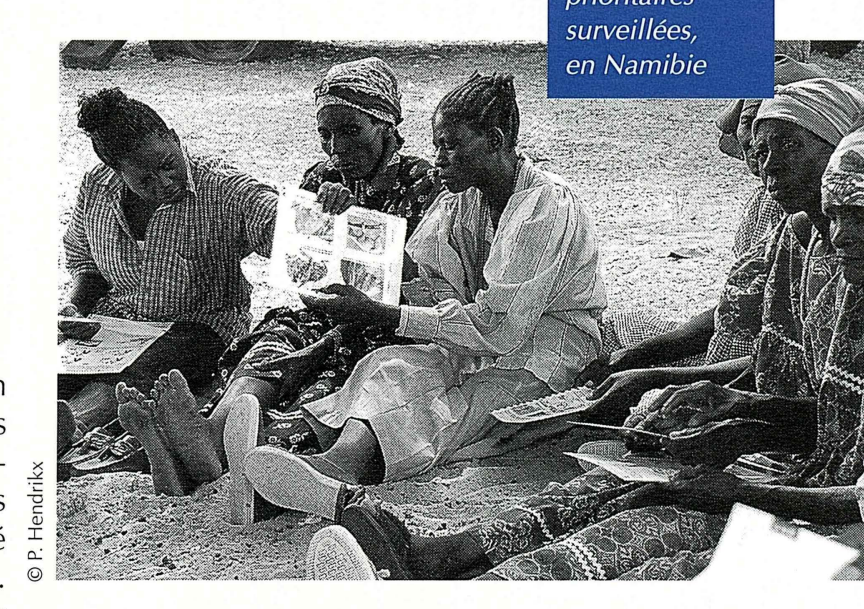

stagiaires, la quasi-totalité originaires des pays du Sud, en ont bénéficié. Un cédérom pédagogique, "Initiation aux systèmes d'information géographique - Applications à l'épidémiologie », a été réalisé pour compléter le module Gestion et traitement des données de l'épidémiosurveillance, en partenariat avec le Cirdes au Burkina.

L'ingénierie pédagogique répond à une demande $d^{\prime}$ institutions partenaires pour élaborer des plans et des programmes de formation. Avec la direction de l'élevage du Sénégal, dans le cadre d'un programme de services agricoles et d'organisations de producteurs (Psaop) financé par la Banque mondiale, une convention a été signée en septembre 2000. Treize personnes ont été formées en 2001. Le Cirad a aussi été sollicité par le Pace pour la formation de ses cadres. Six modules ont été identifiés, dont quatre ont été confiés au Cirad, un à l'Eismv de Dakar au Sénégal et le dernier à l'Itc de Banjul en Gambie. 
es forêts ont enfin acquis droit de cité dans la lutte contre l'effet de serre. La sixième conférence sur le changement climatique, qui s'est tenue à Bonn en juillet 2001, a en effet relancé le protocole de Kyoto et les cent quatre-vingts membres de la convention-cadre des Nations unies sont parvenus à un accord, malgré l'opposition des Etats-Unis.

Ce protocole illustre une évolution sensible de la nature des relations Nord-Sud, qui fait apparaître une interdépendance nouvelle entre pays du Nord et pays du Sud : il faudra désormais partager les contraintes de la gestion d'un bien commun de l'humanité. Le thème retenu par le Cirad pour le Salon international de l'agriculture de 2001 a d'ailleurs été celui des forêts tropicales dans la vie des hommes, et le débat organisé à cette occasion portait sur « les forêts tropicales, des espaces à partager, des enjeux à négocier ».

\section{Forêts}

Mettre en ouvre les conventions internationales dans les domaines de la diversité biologique, de la lutte contre la désertification comme du changement climatique, au profit des sociétés du Sud, fait partie intégrante des actions de recherche du Cirad.

La politique partenariale du département, quant à elle, vise à rapprocher les communautés scientifiques en s'associant au monde universitaire français, en participant à des unités mixtes de recherche, comme l'unité sur l'écologie des forêts de Guyane, et en favorisant la création de pôles de compétence en partenariat avec des institutions de recherche du Sud, notamment à Madagascar et au Mali. 


\section{Le Cirad en 200155 Forêts \\ Forêts naturelles}

Comprendre le fonctionnement de l'un des écosystèmes les plus complexes de la planète, du fait notamment des interventions de l'homme, répond à un double enjeu. Il est essentiel de préserver la biodiversité dans les espaces forestiers, mais aussi de pérenniser les produits et les services que ces formations arborées fournissent aux communautés humaines. Le programme forêts naturelles privilégie une approche intégrée conciliant

\section{Fiscalité forestière}

En collaboration avec le programme espace et ressources du Cirad-tera, une formation à la fiscalité forestière et aux instruments économiques a été organisée à Madagascar. Le premier objectif de ces dix journées d'échange était d'appuyer la mise en œuvre de la nouvelle politique forestière malgache. Ont donc participé des responsables nationaux et régionaux du ministère des eaux et forêts, des responsables de collectivités territoriales de la région, des chercheurs du Fofifa et du Cfsige, centre national de formation. Quels sont les enjeux d'une réforme de la fiscalité forestière et quels sont les choix possibles ? Comment saisir les effets, les risques et les avantages des différentes options de gestion ? Comment mener à bien les procédures administratives ? La démarche, adaptée aux besoins, a été délibérément pratique - questions-réponses, jeux de rôle suivis de commentaires, visites de terrain, études

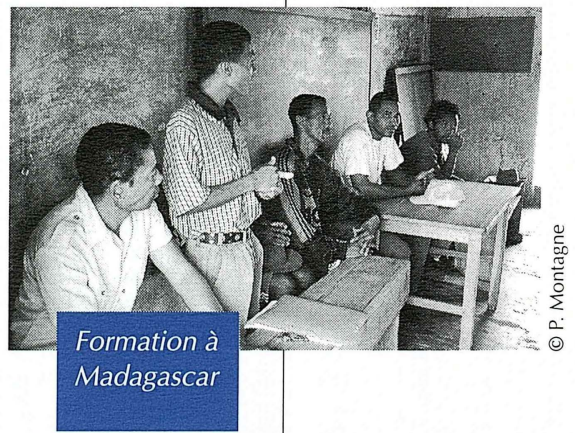

de cas et leçons à en dégager. Par ailleurs, deux enseignants de I'Essa, Ecole supérieure des sciences agronomiques, de I'université d'Antananarivo, sont également intervenus, car transférer à l'Essa I'initiative de ce type de séminaire était I'autre objectif de cette formation.

\section{Inventaire forestier en Indonésie}

A la demande du ministère indonésien des forêts, un système d'information sur les ressources forestières, Ifris, destiné à l'aide en matière de plan d'aménagement des espaces à vocation forestière a été conçu et installé dans le cadre d'un projet financé par l'Union européenne. Elaboré à l'intention des gestionnaires et des aménagistes du paysage, le système Ifris rassemble, classe et gère un ensemble de données précises et constamment actualisées afin que les terres forestières, ressource exploitation raisonnée et conservation de la biodiversité pour participer à la mise en œuvre d'une gestion durable des forêts tropicales.

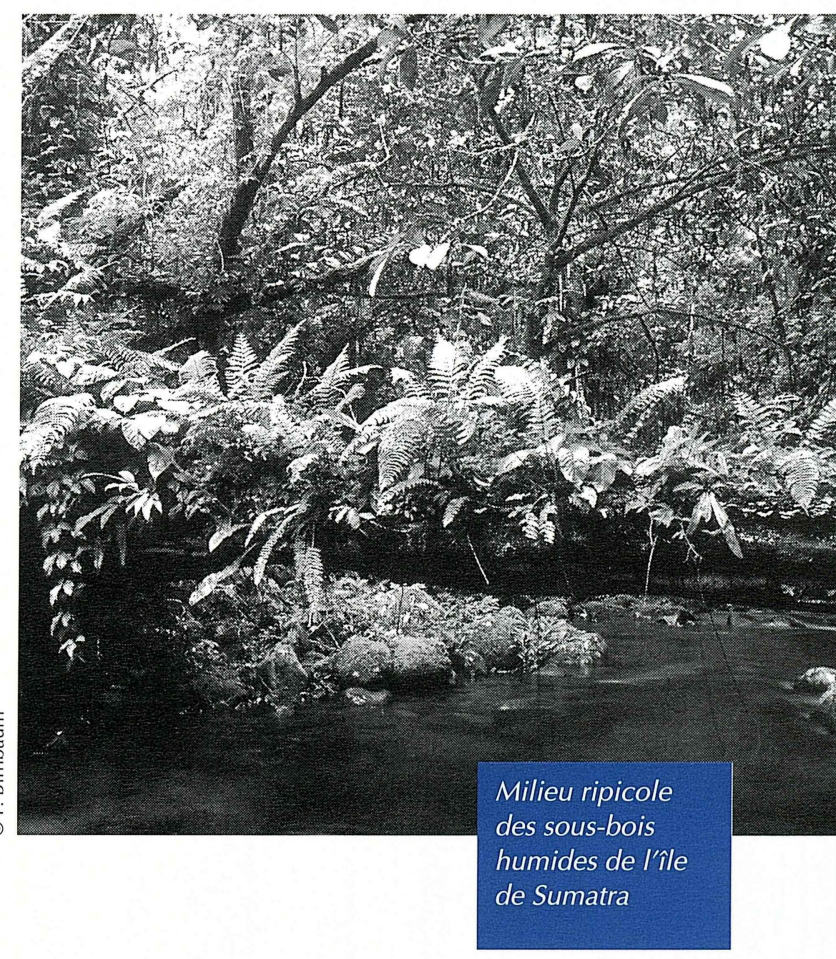

nationale majeure, soient aménagées selon des critères cohérents et fiables. Les nombreux modes d'accès aux informations, adaptés aux besoins des utilisateurs, rendent compte de la multiplicité des facteurs à prendre en compte pour l'aménagement : données satellitaires traitées et utilisées pour créer des cartes thématiques, mais également inventaires forestiers, états du couvert végétal, du sol, de la biodiversité, études socio-économiques, photographies de la faune et de la flore. Les données couvrent à l'heure actuelle une douzaine de cantons dans huit provinces de Sumatra, Sulawesi (Célèbes) et Sumba. 


\section{Aménagement forestier au Gabon}

Avec I'adoption d'un nouveau Code forestier, le Gabon met en place une politique d'exploitation pour que soit prise en compte chacune des fonctions - sociales, écologiques ou économiques de la forêt dense. Dans le centre-est du Gabon, la Sbl, Société des bois de Lastourville, s'est engagée dans la réalisation d'un plan d'aménagement forestier, première étape vers la labellisation de sa production ligneuse. La concession forestière, de 300000 hectares, est située dans la zone d'attraction du chemin de fer transgabonais. La production principale est constituée de grumes d'okoumé, mais une unité de première transformation de bois divers est installée à Lastourville. La Sbl, société familiale à capitaux français, s'est associée avec Thébault, deuxième fabricant de contreplaqué en France, pour créer une unité de déroulage d'okoumé dans la banlieue industrielle de Libreville. Le Cirad apporte un appui technique au service d'aménagement forestier de la société. Afin de concilier les différents intérêts en présence, il intervient de la conception des méthodes d'inventaire des ressources ligneuses et des études préalables, techniques, biologiques et socio-économiques jusqu'à la rédaction du plan. Pour optimiser les techniques d'exploitation et définir un outil industriel adapté, un logiciel $d^{\prime}$ inventaire convivial, en liaison avec un système $d^{\prime}$ information géographique, facilite les requêtes et les simulations nécessaires pour concevoir des stratégies de gestion à moyen et long terme. La stratification forestière est réalisée par analyse directe des images satellitaires et analyse des paysages géomorphologiques. Par ailleurs, un inventaire d'exploitation précis permet la mise en place des techniques à faible impact. Ce partenariat, qui va se poursuivre jusqu'en 2003, concourt à une prise en compte rationnelle de la biodiversité en milieu forestier tropical.

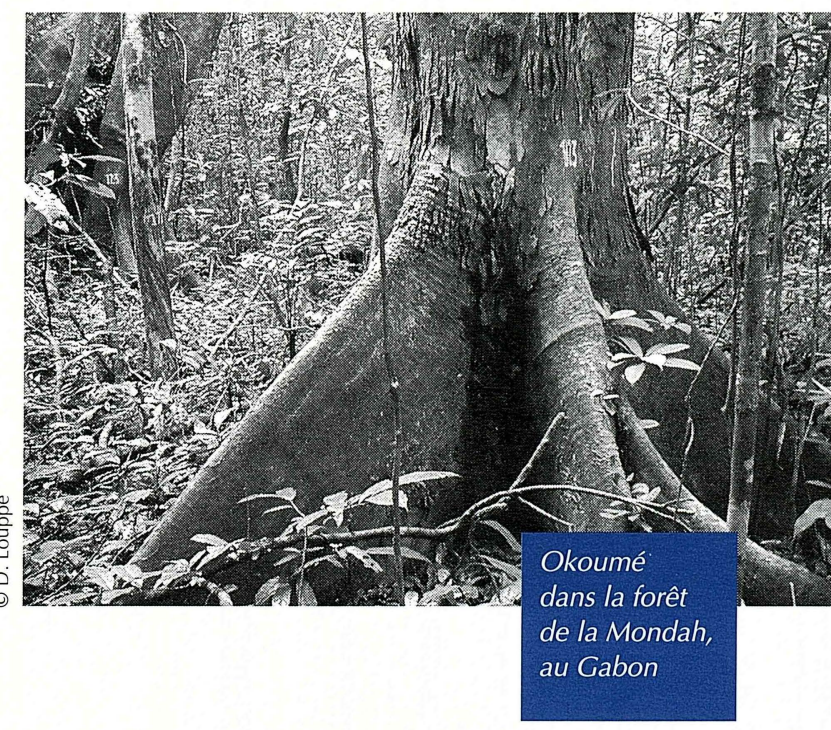

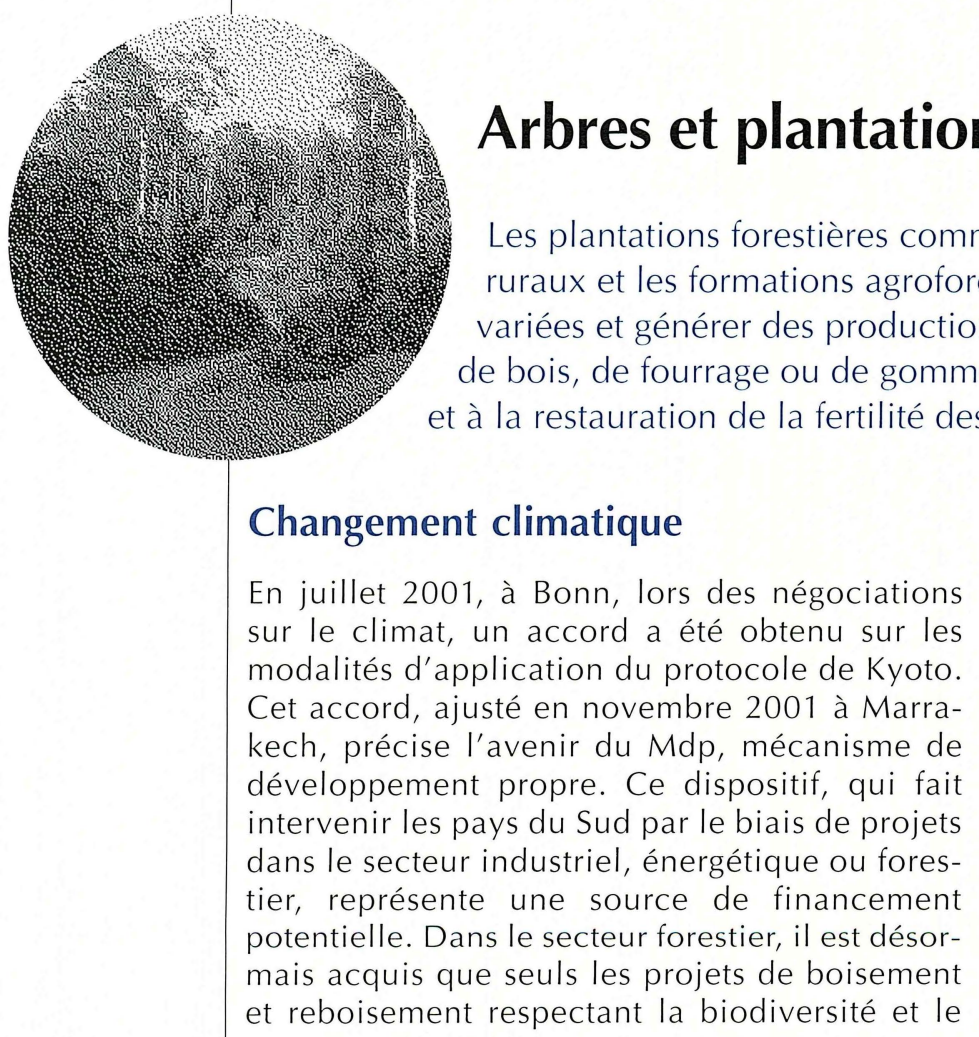


Divers travaux du programme approfondissent ces questions multiples liées aux modalités d'application du Mdp, afin de faire en sorte que ce mécanisme puisse effectivement participer au développement durable des pays du Sud. Elles sont examinées à travers des études locales, comme les plantations d'eucalyptus au Congo, la gestion forestière au Chili ou les pratiques agroforestières au Costa Rica, ou régionales, comme le plan de formation et d'appui institutionnel en Amérique centrale.

\section{L'arbre dans les savanes}

En raison des dynamiques de défrichement agricole et de coupe de bois de feu, parfois d'ampleur régionale, la ressource arborée dans les territoires villageois du nord du Cameroun évolue. D'un côté, les derniers espaces de brousse se contractent, modifiant parcours d'élevage et pratiques de récolte du bois; de I'autre, I'arbre tarde à s'installer durablement dans I'espace agraire. Comment organiser une exploitation raisonnée des savanes d'accès non contrôlé et comment, parallèlement, mieux intégrer l'arbre dans l'espace agraire? Dans le cadre du Prasac, Pôle régional de recherche appliquée au développement des savanes d'Afrique centrale, des études et des opérations d'accompagnement ont été menées avec I'Irad, institut camerounais de la recherche agricole pour le développement. Les diagnostics, associant enquêtes, inventaires et cartographie, ont permis de dégager des enjeux de gestion et de générer un débat local sur l'avenir de la ressource dans le territoire. Les actions définies grâce à ces débats ont été réalisées, en particulier, avec le ministère camerounais de I'environnement et des forêts, pour ce qui concerne les forêts communautaires, et avec le Projet de développement paysannal et
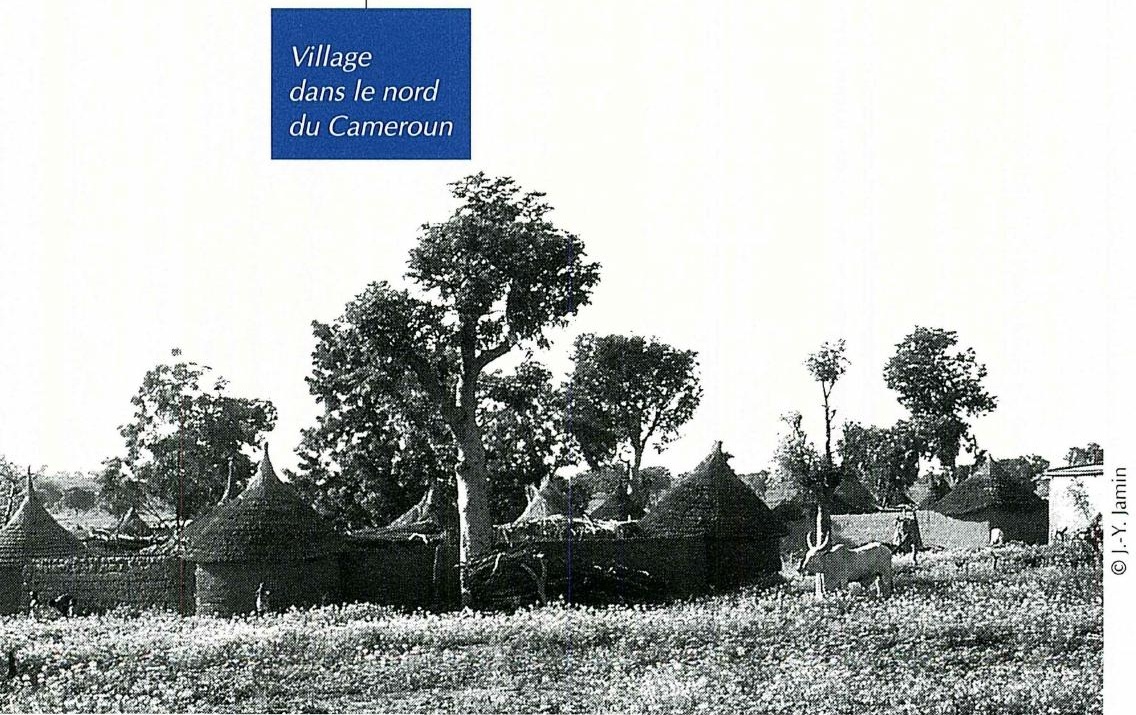

de gestion de terroirs, financé par l'Agence française de développement. Ces opérations, ainsi que la réalisation conjointe de bilans sur les actions de foresterie rurale, conduisent à définir des axes de travail nouveaux, centrés sur la problématique des droits d'usage des arbres.

\section{Calliandra en zone tropicale humide}

De la production de fourrage au bois de feu ou encore à la prévention de l'érosion et à l'ombrage, la mimosacée Calliandra calothyrsus peut remplir de multiples fonctions. Une équipe de scientifiques du Nord et du Sud - Cameroun, Finlande, France, Kenya, Nouvelle-Calédonie, Royaume-Uni -, financée par I'Union européenne, a étudié la productivité de cette légumineuse ligneuse originaire d'Amérique centrale et du Mexique. Par symbiose avec un rhizobium du sol, C. calothyrsus forme des nodules qui fixent I'azote atmosphérique, et la nutrition phosphorique de la légumineuse est améliorée grâce à un champignon mycorhizien. Comment optimiser la production fourragère dans les petites exploitations agricoles de la zone tropicale humide ? Pour déterminer l'inoculum mixte, rhizobium et endomycorhize, le plus efficace, une collection de souches a d'abord été constituée à partir de prélèvements de nodules et d'échantillons de sols. Puis des expériences ont été menées en serre et en pépinière au Kenya, en Nouvelle-Calédonie et au Sénégal. Au terme du projet, une petite unité de production est installée au Cameroun et des cultures pures ont été mises en place au Cameroun, au Kenya et au Costa Rica afin de produire des inoculums des deux symbiotes. Actuellement, des essais d'associations en milieu paysan de légumineuses ligneuses et de cultures vivrières sont réalisés au Kenya et au Zimbabwe dans le cadre d'un nouveau projet. 


\section{Matière organique et plantations}

Les effets d'un reboisement en eucalyptus destinés à la production de bois de pâte à papier ont été étudiés sur un sol de savane du littoral congolais. L'objectif était de mieux assurer la pérennité de l'alimentation minérale et de la production dans ces plantations. Malgré la pauvreté des sols, les eucalyptus hybrides créés au Congo par le programme d'amélioration génétique produisent de fortes quantités de biomasse, grâce à un recyclage intense d'éléments nutritifs. Cependant, les cycles biogéochimiques d'éléments nutritifs au sein de l'écosystème ont été profondément modifiés par le reboisement de la savane. C'est le cycle de l'azote qui a été le plus affecté en raison de l'arrêt des pratiques de brûlis et de la fixation symbiotique. Cet élément est le principal facteur limitant la croissance des plantations. Les bilans entrées-sorties des éléments minéraux montrent que les fortes productions de biomasse des eucalyptus ont lieu aux dépens du capital d'azote hérité de la savane. Les apports par fertilisation nécessaires pour maintenir la production ont été quantifiés. Les résultats de cette étude et d'autres travaux menés par I'Ur2pi, Unité de recherche sur la productivité des plantations industrielles, ont été présentés à des chercheurs de neuf pays tropicaux au cours d'un atelier du réseau Cifor. Ils confirment l'importance primordiale d'une gestion conservatoire de la matière organique pour préserver le statut organominéral des sols et la production durable des plantations forestières tropicales.

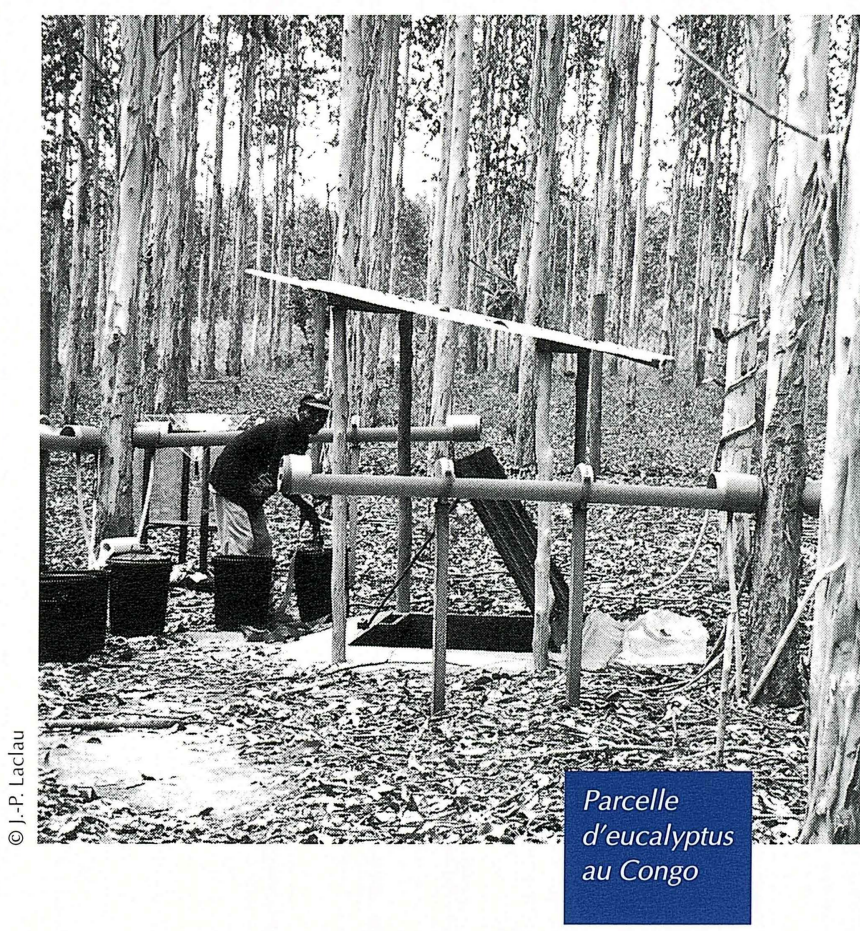

\section{Bois}

En 2001, le programme bois a renforcé ses actions pour promouvoir une utilisation optimale, respectueuse de la diversité, des bois de forêts naturelles et pour améliorer la production de matière première ligneuse des plantations, en conformité avec les exigences du marché.

Par ailleurs, les travaux sur la durée de vie des produits à base de bois et sur des techniques et des procédés

\section{Compétitivité des fillières}

Trois approches complémentaires sont proposées pour renforcer la compétitivité des filières du bois. L'aide à la décision pour l'exploitation et la transformation rationnelle du bois d'œuvre en forêt exploitée est une première démarche. Une thèse a été consacrée à une méthode de valorisation du bois d'œuvre dans une forêt donnée. Les aspects techniques, économiques et stratégiques à prendre en compte pour la première transformation du bois sont intégrés en cinq étapes rétroactives. Puis les axes à privilégier pour la suite du travail sont identifiés. Une étude de cas sur une forêt camerounaise vérifie le bien-fondé, les avantages et les moins nocifs pour l'environnement ainsi que sur la valorisation des déchets et des sous-produits de la filière ont été privilégiés. Les aspects économiques des filières de production, la dynamique des marchés et le positionnement relatif des produits à base de bois ont été un autre volet de recherche. Ces activités participent à une mise en valeur des ressources forestières et ligneuses dans le cadre des conventions internationales. 


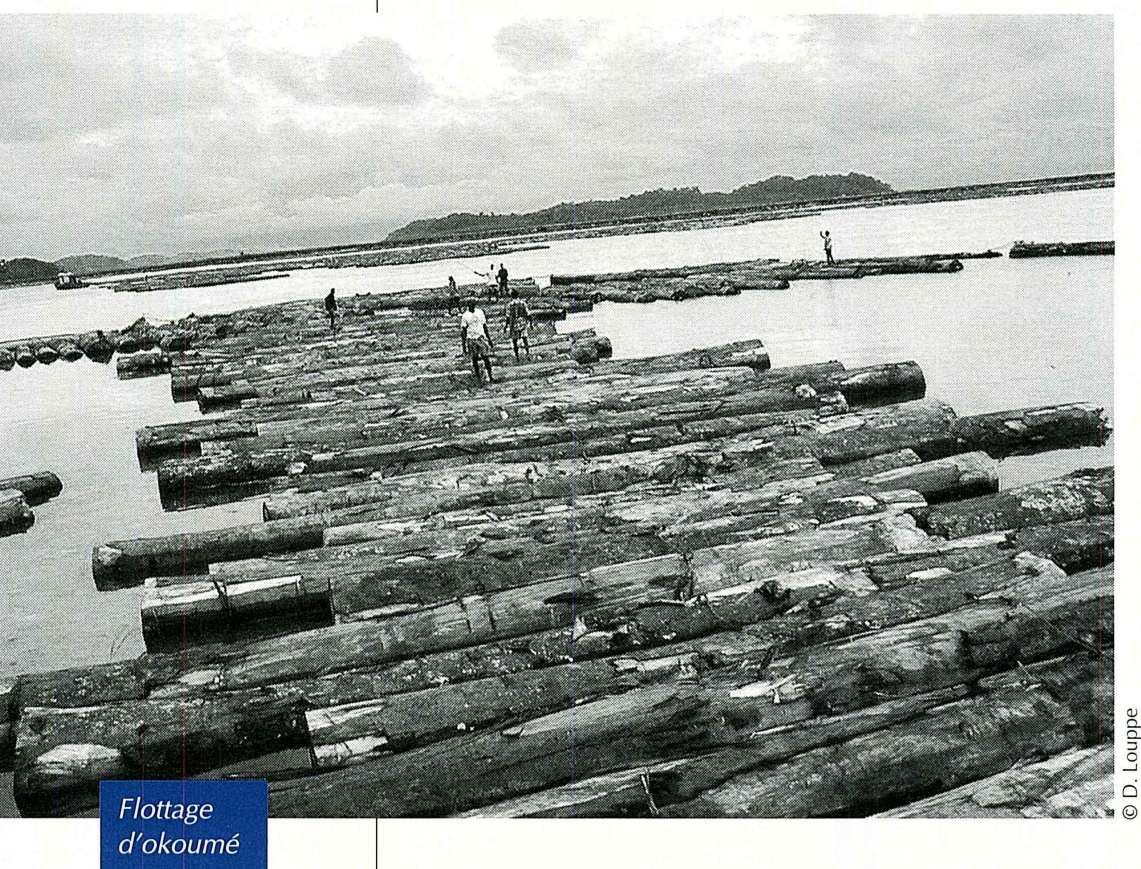

inconvénients de cette méthode. La deuxième approche s'applique à l'échelle d'un pays. L'analyse consiste alors à déterminer ce qui doit être privilégié en fonction du marché mondial des produits, à vérifier les atouts et les faiblesses d'une filière nationale de transformation et de commercialisation sur les plans technique, économique et social. Elle peut aussi être appliquée à l'échelle d'une région forestière suffisamment étendue. A titre d'illustration, on peut signaler que la commercialisation de produits en bois fabriqués au Brésil, au cœur de la forêt amazonienne, a fait l'objet d'une mission d'appui. Quant à l'expertise, elle fournit diagnostics et recommandations aux entreprises. Elle étudie I'adéquation des produits fabriqués aux besoins des marchés - en type de bois, en qualité, en quantité — ou bien I'organisation interne, ou encore les facteurs de production - quel équipement, quelles compétences requises, quels besoins en formation - et les conditions économiques en termes de capacité de production, de qualité des produits et de coût de production. Ainsi, plusieurs missions d'expertise et de formation technique ont été réalisées en appui à une scierie implantée au Mozambique.

\section{Bioénergie}

Convertir des déchets organiques en énergie et produire de l'électricité dans de petites unités décentralisées intéresse les pays développés comme les pays en développement. Le Cirad a coordonné la mise au point d'un système de production par gazéification à partir de paille, d'écorce de pin et de balles de riz. Le procédé construit à l'échelle de pilote de laboratoire, d'une capacité de 50 kilos par heure, a fait l'objet d'un brevet.

Pour obtenir un bon rendement, la gazéification exige un traitement à température élevée, de I'ordre de $1000^{\circ} \mathrm{C}$. Lors de la réaction de conversion, les pailles produisent une grande quantité de cendres, qui fondent et colmatent les appareils. Le processus innovant développé par le Cirad et ses partenaires scinde l'opération en trois étapes. La biomasse est transformée en charbon dans un pyrolyseur, puis le charbon est gazéifié à température modérée dans une chambre de réduction. Les matières résiduelles — fines de charbon, fumées, cendres - sont récupérées et traitées dans une chambre de combustion, à température beaucoup plus élevée, soit $1500^{\circ} \mathrm{C}$. Les cendres sont ainsi vitrifiées et les gaz produits $\left(\mathrm{CO}_{2}, \mathrm{H}_{2} \mathrm{O}\right)$ apportent l'énergie nécessaire à la réaction de gazéification pour générer un gaz à fort pouvoir calorifique $\left(\mathrm{CO}\right.$ et $\left.\mathrm{H}_{2}\right)$. Une fois lavés, ces gaz sont utilisés dans une turbine ou un moteur pour produire de l'électricité.

Ce projet, réalisé en partenariat avec l'université technologique de Compiègne, la société Itc et des industriels danois, a été financé par l'Union européenne, la Danish Energy Agency, Edf et l'Agence de l'environnement et de la maîtrise de l'énergie. Sur la base des résultats obtenus, les travaux se poursuivent dans le cadre d'un autre projet européen.

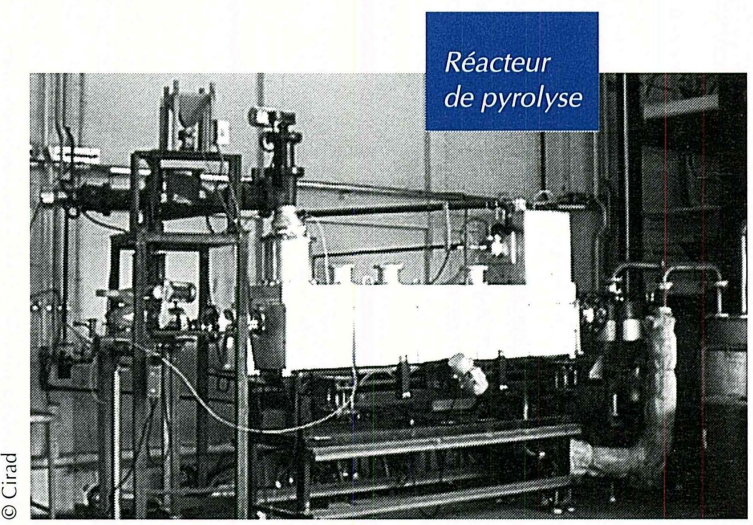

\section{Substances naturelles termicides}

Le recours à des insecticides issus de sousproduits de la transformation du bois peut éviter l'emploi de produits de préservation du bois qui sont nocifs pour les écosystèmes. Ayant acquis une large expérience dans la compréhension des mécanismes de durabilité naturelle du bois, l'équipe du laboratoire de préservation des bois s'est intéressée à deux essences guyanaises de la famille des lauracées naturellement résistantes à 
I'attaque des termites, le bois de rose, Aniba rosaedora, et le grignon franc, Ocotea rubra. Des essais en laboratoire ont prouvé que des produits d'extraction de ces deux essences sont efficaces contre les termites. La potentialité d'utilisation de ces extractibles est telle que les recherches se poursuivent afin d'en évaluer les seuils d'efficacité. A terme, elles aboutiront à la formulation d'un produit de protection du bois contenant ces molécules actives. Ces travaux sont menés dans le cadre d'un partenariat avec le laboratoire de neurobiologie du Cnrs de Tours et avec un industriel et sont financés par le projet bois-matériau de l'Agence de I'environnement et de maîtrise de l'énergie. Ils ont d'ores et déjà fait l'objet d'un dépôt de brevet pour I'utilisation de déchets ou d'extraits de bois en tant qu'insecticides.

\section{Coopération franco-australienne}

Un projet de recherche sur le traitement thermique du bois associant le laboratoire des produits forestiers de l'Engref au Cirad s'est ouvert à une collaboration australienne.

Procédé connu et étudié depuis deux décennies, le traitement thermique du bois confère au matériau une meilleure stabilité dimensionnelle et une meilleure durabilité, parfois au détriment de ses propriétés mécaniques, notamment de sa résistance aux chocs. Par ailleurs, entre la définition des conditions opératoires optimales et le procédé industriel, les sauts technologiques sont souvent mal appréhendés. Ce constat montre que des études fondamentales sont encore nécessaires pour définir précisément les traitements adéquats, en termes de température et de durée du traitement. $C^{\prime}$ est pourquoi les relations avec des organismes de recherche australiens se sont renforcées et des contacts ont été pris avec des laboratoires spécialisés.

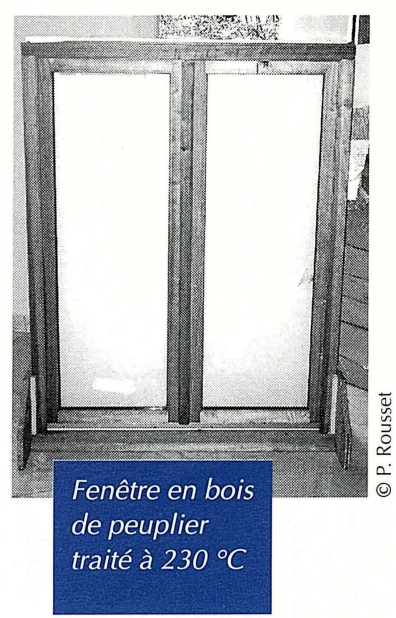

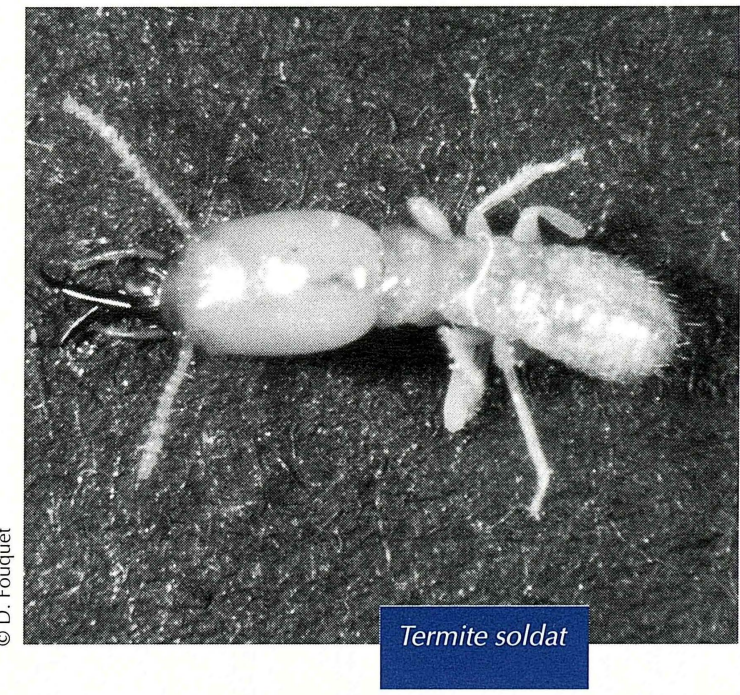

Pour tirer parti des progrès de la simulation numérique, un partenariat technique a été établi avec I'université technologique du Queensland, spécialisée dans la modélisation des transferts de chaleur et de masse en milieu poreux. Ainsi, les améliorations apportées au logiciel de simulation de séchage du bois Transpore devraient permettre de prévoir le comportement du bois dans des conditions extrêmes de température et de surmonter les difficultés à homogénéiser le traitement d'une charge entière.

Cette coopération franco-australienne s'est confirmée avec I'accueil d'un doctorant français en Australie pour une durée d'un an. Grâce au soutien financier de l'ambassade de France et de I'Australian Academy of Science, un premier échange de chercheurs du Queensland Forest Research Institute et du Cirad est prévu en 2002. Ces acquisitions communes de connaissances s'effectueront dans un contexte de nouvelles alliances avec des partenaires industriels australiens. 


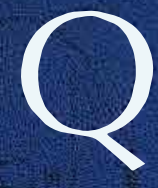

uelles sont les questions de recherche pertinentes dans le contexte actuel marqué par la libéralisation des économies, la décentralisation et la mise en place de conventions internationales? Comment peuvent-elles intégrer les débats liés à la reconnaissance de la multifonctionnalité des agricultures et les enjeux que constituent la durabilité, la lutte contre les inégalités, la gestion des ressources et de l'environnement? Comment contribuer

à la construction négociée de réponses aux défis territoriaux, économiques, sociaux et environnementaux auxquels font face les sociétés rurales? Quelles démarches et méthodes mettre en cuvre pour analyser,

Territoires, environnement et acteurs représenter et modéliser les situations, pour construire des systèmes d'information? Comment utiliser les connaissances produites pour renforcer la capacité des acteurs à se coordonner, à négocier et à décider? Comment s'organiser pour se saisir de ces questions, les traiter et y répondre? Avec quels programmes au Cirad et avec quels partenaires?

Trois ans après sa création, le département Territoires, environnement et acteurs a conduit une réflexion pour formuler une vision commune, arrêter des choix concernant le champ et les questions scientifiques à traiter et élaborer une stratégie de mise en ceuvre. Le nouveau projet du département sera soumis à une évaluation en avril 2002, conduite par une commission de scientifiques extérieurs au Cirad. Il sera ensuite mis en ceuvre au deuxième semestre 2002. 


\section{8.}

Les agricultures familiales sont confrontées aux conséquences de la libéralisation économique et à l'émergence de préoccupations nouvelles concernant la gestion durable des ressources et la qualité des produits alimentaires. Elles doivent s'adapter malgré I'insuffisance fréquente de l'environnement économique et institutionnel, le manque de formation des producteurs

\section{Agricultures familiales au Brésil}

Le séminaire "Agricultures familiales, dynamiques comparées entre le Brésil et la France » a été organisé en novembre à Recife, au Brésil, afin de comparer les trajectoires agricoles des deux pays et $d^{\prime}$ en déduire des enseignements pour la définition de politiques publiques. Organisé par le ministère brésilien du développement agraire, I'Inra et le Cirad, il a rassemblé une soixantaine de personnes $d^{\prime}$ institutions brésiliennes et françaises.

Malgré d'évidentes différences dans les processus de construction des agricultures familiales des deux pays, les participants ont souligné les convergences, notamment en matière de problématique de développement et d'action publique. La légitimité des recherches portant sur les modalités de I'intervention publique a été affirmée, ainsi que I'intérêt de conduire des travaux sur les techniques adaptées à l'agriculture familiale, afin d'en valoriser les produits et d'améliorer leur qualité. D'autres thèmes ont été identifiés : I'articulation des marchés, la prise en compte des multiples fonctions de I'agriculture, le développement territorial. Un investissement renouvelé dans la formation des hommes a également été recommandé.

Le Cirad a par ailleurs publié un ouvrage de synthèse, Paysans du sertão, qui montre, contrairement à une idée répandue, la grande diversité des agricultures familiales du Nordeste du Brésil et l'importance de leurs mutations techniques, économiques et sociales.

\section{Diagnostic de l'agriculture mahoraise}

A Mayotte, l'équipe de recherche sur les systèmes d'activités, les organisations et le développement local a commencé ses travaux par un bilan et un diagnostic du développement local, en partenariat avec la Direction de l'agriculture et de la forêt et sous la maîtrise d'ouvrage de la préfecture. Des enquêtes ont été menées auprès de cinq cents ménages agricoles et $d^{\prime}$ une soixantaine $d^{\prime}$ organisations, les marchés des produits agricoles ont été étudiés et un zonage des dynamiques agricoles a été réalisé. et les difficultés de la structuration professionnelle. A partir de l'analyse de la diversité des situations locales, le programme agricultures familiales investit dans la promotion des dispositifs d'appui et dans le renforcement des capacités des acteurs et de leurs organisations.

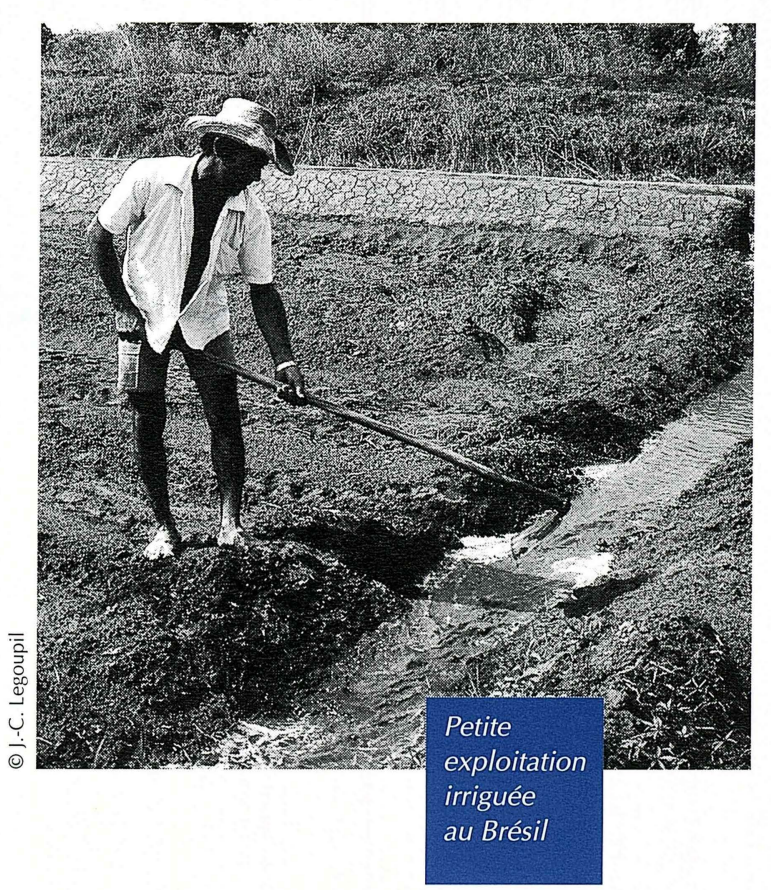

L'agriculture mahoraise connaît aujourd'hui de grandes difficultés et est inorganisée. Elle est appuyée par des services techniques qui peinent à répondre aux besoins des ruraux. Elle concerne pourtant la majorité des ménages de l'île, qui développent des systèmes d'activités complexes gérant des objectifs multiples - alimentation, revenus, préservation d'un milieu naturel fragile et entretien de réseaux de solidarité. Une forte dynamique collective existe, articulée autour des quartiers, des villages ou du territoire. 
Ce foisonnement contraste avec les dysfonctionnements des organisations agricoles, impulsées par l'administration, qui ne concernent qu'une minorité de ménages.

Le bilan permet de recentrer le débat agricole et propose de passer d'une vision sectorielle à une perspective de développement local, en reconnaissant les multiples fonctions de l'agriculture.

\section{Organisations paysannes et rurales}

La Banque mondiale, qui révise sa stratégie de développement rural afin de combattre plus efficacement la pauvreté, a sollicité le Cirad et I'Odi pour produire le texte de référence sur le rôle des organisations paysannes et rurales dans le contexte de la mondialisation. Des propositions ont été présentées et discutées à Washington, dans le cadre de la réunion annuelle des équipes de la Banque mondiale travaillant dans le développement rural (Rural Week). Une publication de cette synthèse est en cours par la Banque mondiale.

L'étude souligne le rôle central des organisations de producteurs dans la construction de toute stratégie de développement rural et l'importance de la concertation et de la négociation. Pour impliquer ces organisations dans les programmes $\mathrm{d}^{\prime}$ action de la Banque mondiale, le Cirad propose de les associer aux concertations et aux différents stades des projets, de l'identification à l'évaluation. Cela suppose que les organisations de producteurs aient accès à de nouveaux fonds de formation pour renforcer leurs compétences et mieux comprendre les changements de l'environnement des agricultures familiales, afin d'améliorer leur positionnement stratégique. A cet effet, le Cirad propose de créer un centre de ressources au sein de la Banque mondiale, qui apporterait un appui aux chargés des projets et aux responsables de la Banque dans les pays où elle intervient.

de café

en Guinée forestière

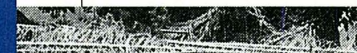

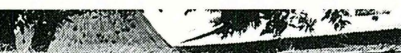
The

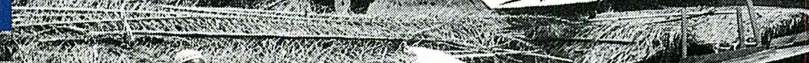

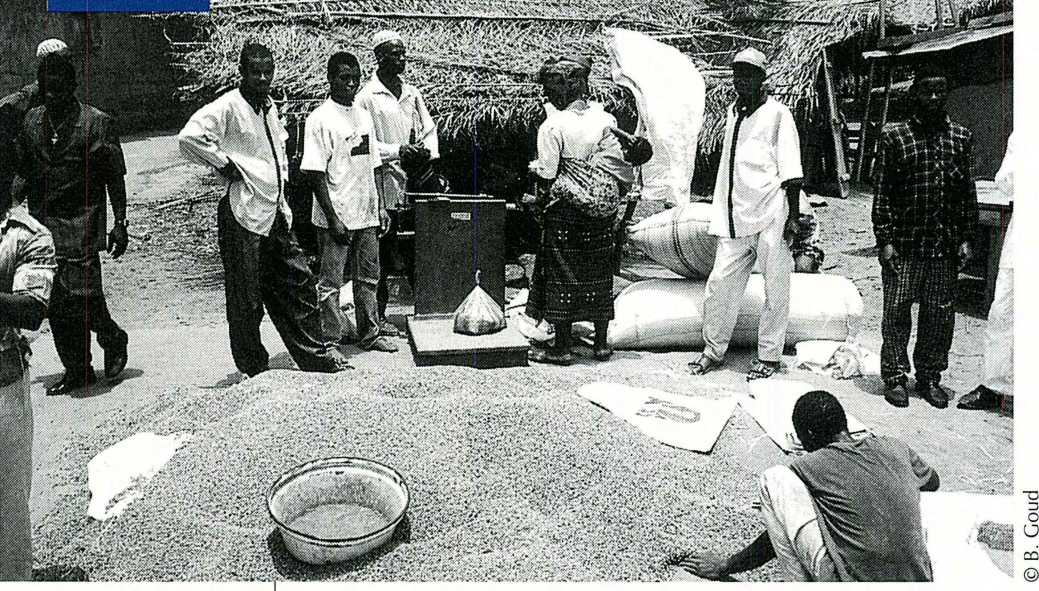

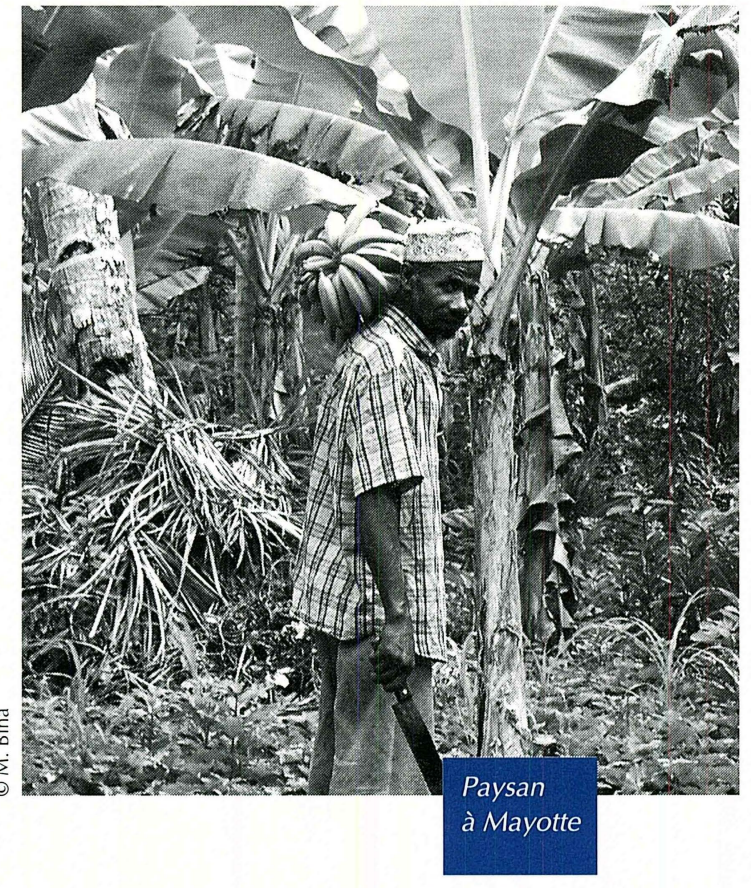

\section{Université paysanne africaine}

L'Université paysanne africaine est un cycle international de formation destiné aux responsables $\mathrm{d}^{\prime}$ organisations paysannes et professionnelles, en alternance avec leur activité professionnelle, afin de renforcer leurs compétences et leur poids dans les négociations. Elle a été mise en œuvre par le réseau Agricultures paysannes et modernisation, dont le siège est au Cameroun. Appuyée par la Fondation Charles Léopold Meyer, elle reçoit le soutien financier du ministère français des affaires étrangères. Le Cirad et le Ciepac ont collaboré à l'élaboration du projet et à la définition du contenu des formations.

Le cycle de formation comprend six modules et se déroule sur deux ans. Les participants sont invités à resituer leur expérience et celle de leur organisation dans leur contexte et dans une perspective historique. Le premier module s'est déroulé en février au Sénégal et a porté sur l'évolution des sociétés locales, du contexte national et international. Vingt-cing responsables d'organisations paysannes et professionnelles, venant de douze pays, y ont participé. Le deuxième module, portant sur le nouvel environnement économique de I'agriculture, s'est déroulé en mai au Cameroun, et le troisième, sur les réorganisations institutionnelles, s'est tenu en septembre au Bénin. Les trois derniers modules, qui auront lieu en 2002, porteront sur la place des organisations dans un monde en mutation, sur les objectifs et les démarches de la planification stratégique et sur la programmation et la négociation. 


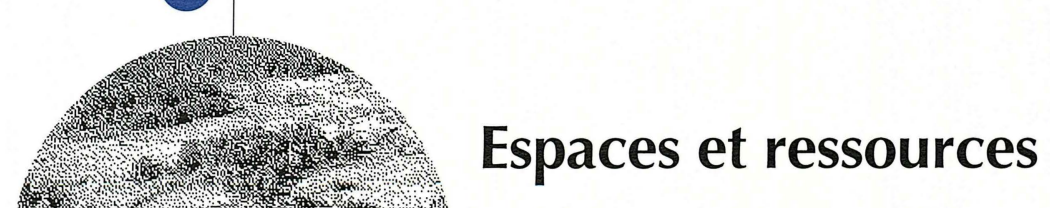

Le programme espaces et ressources analyse la gestion des espaces ruraux et les stratégies des acteurs qui produisent, mobilisent des ressources et organisent ces espaces. II représente et modélise les connaissances et l'information obtenue et il élabore des démarches d'aide à la décision pour les gestionnaires du développement rural.

\section{Systèmes multiagents}

A la suite des formations organisées en 1999 et 2001 en Thaïlande, et en 2000 aux Philippines, plusieurs universités de Thaïlande organisent avec le Cirad un nouveau cycle de formation sur les systèmes multiagents pour la gestion intégrée des ressources naturelles et les sciences sociales. Le projet, financé par I'Union européenne, a commencé en août et doit se poursuivre jusqu'à la fin de 2003.

Des chercheurs et des enseignants du Cirad, du Cemagref, de l'Irri, d'universités françaises et européennes (Paris VI et Aix-Marseille en France, Manchester et Surrey au Royaume-Uni, Amsterdam et Wageningen aux Pays-Bas, Neuchâtel en Suisse) dispensent des cours en informatique, en sciences sociales et en gestion des ressources naturelles. Ces cours ont lieu, en alternance, dans trois universités thaïlandaises : Chulalongkorn (Bangkok), Chiang Mai et Khon Kaen. L'objectif est de créer un noyau de chercheurs et de doctorants qui assistent à l'ensemble des formations et constituent un réseau développant différentes applications en gestion des ressources naturelles et renouvelables.

\section{Périmètres irrigués en Afrique du Sud}

Les périmètres irrigués des anciens bantustans d'Afrique du Sud connaissent aujourd'hui de sérieux problèmes : infrastructures détériorées, rendements bas, cadre institutionnel faible, manque d'appui et d'accès aux services. Le gouvernement souhaite réhabiliter ces périmètres et en transférer la responsabilité aux usagers. Pour aider les décideurs à organiser ces opérations, une équipe du Cirad et de l'université de Pretoria propose une démarche de recherche-action visant à modéliser les composantes de la viabilité économique des périmètres transférés, puis à tester des scénarios en interaction avec les acteurs techniques et politiques locaux. La démarche a d'abord été expérimentée dans deux périmètres irrigués de la province du Nord. Un modèle, Smile, a été développé, qui prend en compte les coûts, la répartition des terres, les systèmes de culture, les stratégies des paysans et les options possibles pour un système de tarification de l'eau. Des scénarios ont été testés, qui montrent que la situation actuelle $n^{\prime}$ est pas viable, que les coûts peuvent difficilement être réduits, que le problème majeur est le nombre d'occupants non actifs, peu enclins à payer une redevance sur l'eau, enfin, que la faible productivité limite la capacité de financement des paysans. Ils montrent aussi qu'il est possible d'améliorer la situation en clarifiant les droits fonciers pour diminuer le nombre d'occupants inactifs ou en formant les paysans pour faire évoluer les systèmes de culture. La démarche va être intégrée aux préconisations du Département national de l'agriculture auprès des départements provinciaux et un logiciel est en cours de développement.

\section{Formations pour le développement rural}

Dix-neuf chercheurs et ingénieurs, venant du Mali, de Madagascar, du Sénégal, du Cameroun, du Bénin et du Vietnam, ont participé à une formation sur les systèmes $d^{\prime}$ information, notamment géographique, pour le développement rural.

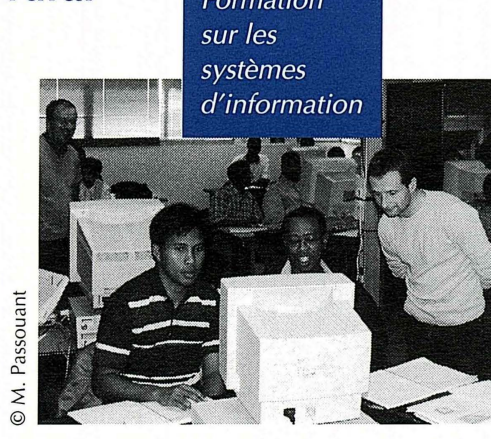

Organisée avec le département des forêts, cette session a eu lieu à Montpellier en novembre. Les stagiaires ont acquis les bases méthodologiques et opérationnelles pour construire et mettre en œuvre un système d'information reliant des bases de données existantes. L'objectif est d'apporter les connaissances et les pratiques pour décrire, représenter et analyser à la fois les dimensions thématiques et géographiques des processus de développement. Cette formation, pour le département, s'inscrit dans le cadre de projets conduits en coopération — biodiversité du sorgho, 
amélioration des systèmes d'exploitation de la zone cotonnière, système d'information à l'Office du Niger au Mali. Elle a permis de renforcer les liens entre le Cirad et les institutions participantes.

Par ailleurs, dix-huit stagiaires du Brésil, de France, de Madagascar, du Portugal et du Vietnam ont participé en décembre à Montpellier à un stage sur l'économie de l'environnement et des ressources naturelles. Les participants ont acquis les concepts et les bases théoriques de l'économie de l'environnement et ont été confrontés aux outils d'aide à la négociation et à la décision de politiques environnementales et de gestion des ressources : modélisation, méthodes d'évaluation. Un jeu de rôle, des études de cas et des travaux pratiques leur ont donné des clés pour apprécier I'application des théories et des méthodes aux situations concrètes.

\section{Systèmes d'information}

La gestion de l'information est un élément central pour administrer les périmètres irrigués et pour aider les gestionnaires à conduire une réflexion stratégique et à définir de nouveaux modes d'organisation ainsi que d'autres rapports avec les usagers.

Depuis 1998, le Cirad travaille avec l'Office du Niger, au Mali, afin de mettre en place un système d'information pour le suivi de la maintenance des réseaux hydrauliques. Un logiciel de programmation et de suivi informatisés de la maintenance, Simon, a été conçu avec la participation

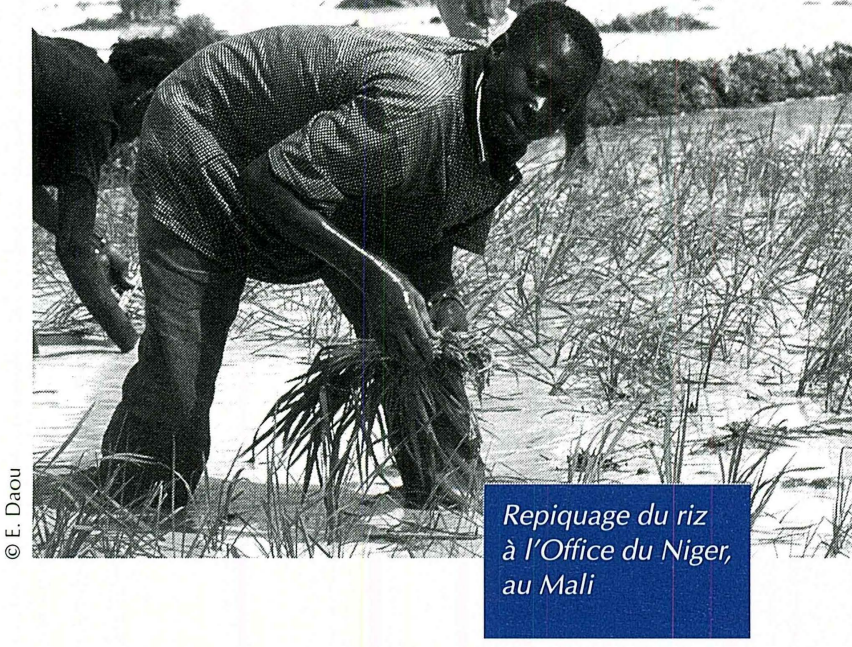

des utilisateurs. Après une phase de développement et de test, I'application informatique a été mise en place. Un effort particulier a porté sur la formation des gestionnaires et des utilisateurs du logiciel.

Les services décentralisés de I'Office exploitent le logiciel depuis octobre 2000. L'Office dispose maintenant de données informatisées sur la quasiintégralité de son réseau de canaux primaires et secondaires. Sur la zone de N'Débougou, I'ensemble des fonctionnalités du logiciel ont été utilisées, avec l'élaboration d'un programme prévisionnel d'entretien et son rapprochement avec les travaux effectivement réalisés. Un système $d^{\prime}$ information géographique a été couplé à cette base de données, après constitution d'un fonds cartographique de référence, pour représenter non seulement le réseau d'irrigation, mais aussi les entretiens planifiés et réalisés.

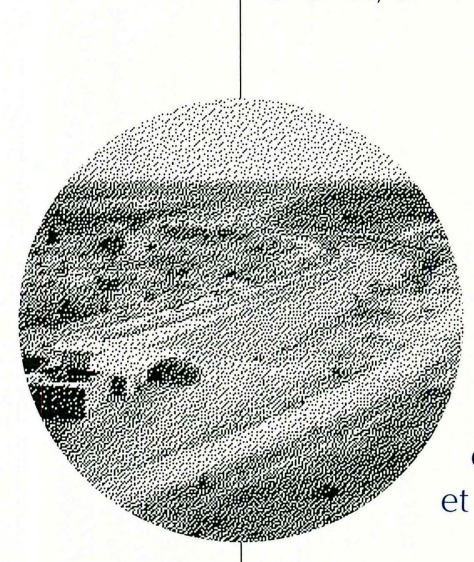

\section{Périmètres irrigués collectifs}

Depuis 1999, le Programme commun pour les systèmes irrigués conduit des recherches dans le domaine de l'eau agricole avec le Cemagref, le Cirad et I'Ird. II a organisé en janvier à Montpellier le séminaire "La gestion des périmètres irrigués à l'aube du $X X \mathrm{I}^{\mathrm{e}}$ siècle : enjeux, problèmes, démarches ", qui a rassemblé cent trente participants. Des travaux menés au Brésil, en
Le programme savanes et systèmes irrigués met en œuvre des démarches pluridisciplinaires à l'échelle des régions, des terroirs, des périmètres irrigués et des exploitations agricoles, pour mieux comprendre le fonctionnement de ces espaces complexes. II élabore des outils d'aide à la décision et à la négociation pour les instances de gestion et de décision, favorise

l'émergence de cadres de concertation entre acteurs et l'élaboration de plans de développement à différentes échelles.

Equateur, en France, au Mali, au Maroc, au Sénégal, au Sri Lanka et en Tunisie ont été présentés. Les débats ont souligné la complexité et la diversité des systèmes irrigués et l'intérêt de démarches associant participation des paysans et modélisation des processus. 
Par ailleurs, les résultats des recherches conduites dans le cadre de ce même programme ont été présentés en décembre lors d'un séminaire au Brésil, organisé par la Compagnie de développement de la vallée du São Francisco (Codevasf), I'Embrapa et le Cirad. Cent cinquante personnes y ont participé. Alors que la gestion des périmètres irrigués a été transférée aux organisations de producteurs il y a plus de dix ans, les questions demeurent sur la participation réelle de ces organisations et sur le rôle de l'Etat en matière d'infrastructure et de politique agricole. L'importance de produire de l'information et de la partager a été soulignée : à l'échelle des exploitations pour améliorer leurs résultats; à l'échelle des districts pour piloter la distribution de l'eau, la maintenance, la politique tarifaire et appuyer l'assistance technique; à l'échelle des unités administratives de la Codevasf pour suivre et évaluer les performances des périmètres irrigués publics.

\section{Suivi des filières cotonnières}

Un dispositif de suivi des filières cotonnières en Afrique, Résocot, a été créé pour appréhender les performances des différents modes d'organisation, pour aider les opérateurs à redéfinir leur rôle dans la filière et les décideurs à trouver l'équilibre entre concurrence et régulation. Ce réseau couvre six pays : Bénin, Burkina, Cameroun, Côte d'Ivoire, Ghana, Mali. II implique des chercheurs de ces pays, de I'Imperial College of Wye au RoyaumeUni et du Center for Development Research au Danemark. Financé par la Coopération française et la Coopération néerlandaise, il est coordonné par le programme savanes et systèmes irrigués et par le programme coton du Cirad.

La phase pilote, d'une durée de dix-huit mois, a commencé en février. Un cadre méthodologique commun a été défini pour décrire l'organisation de la filière cotonnière et pour apprécier les

Marché de coton au Cameroun

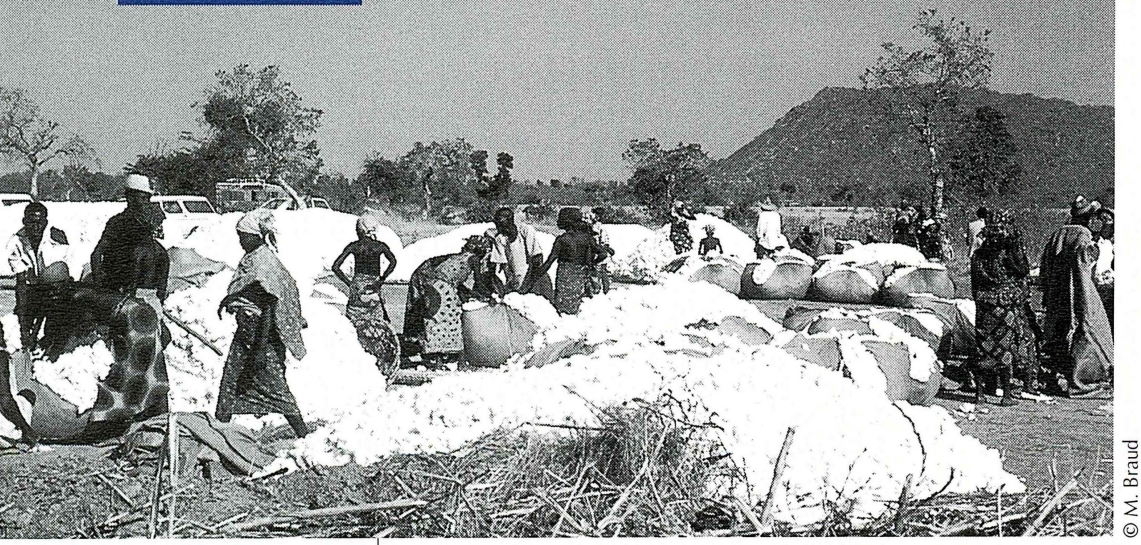

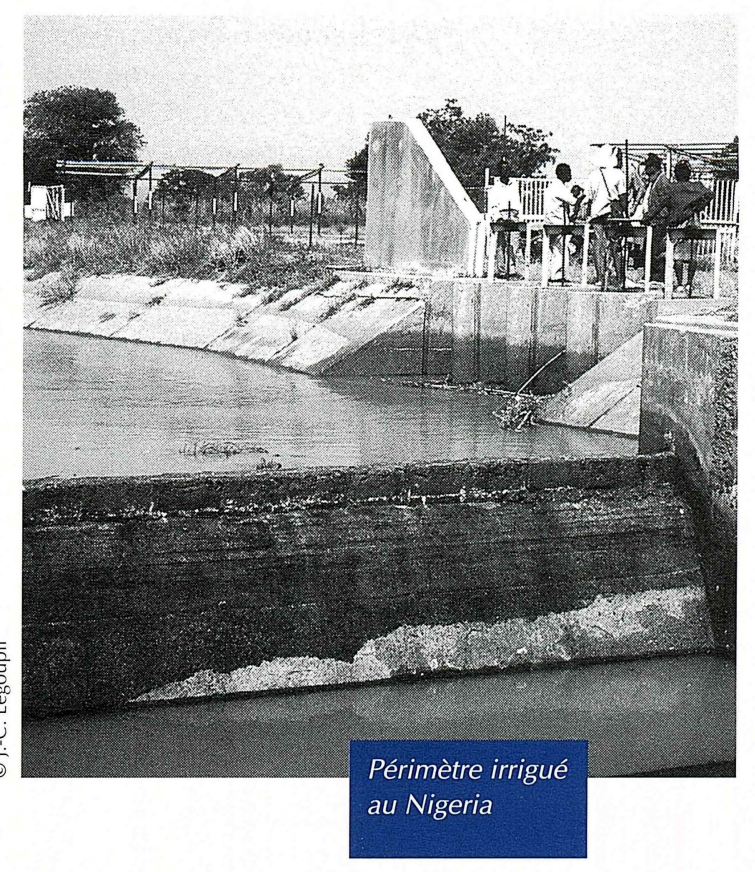

performances en termes de réduction de la pauvreté, de durabilité environnementale et de compétitivité internationale, à l'aide d'indicateurs issus de la théorie économique néo-institutionnelle. Des ateliers de lancement ont été organisés dans les six pays pour sensibiliser les acteurs de la filière à la démarche et à la nécessité de leur participation.

Les informations sont recueillies dans une base de données conçue pour faciliter leur exploitation et la rédaction de synthèses. Des ateliers auront lieu dans chaque pays pour restituer les résultats. Un dispositif similaire regroupe quatre pays anglophones, grâce à un financement de la Coopération britannique.

\section{Conseil aux exploitations}

En novembre au Bénin, quarante-cinq praticiens - responsables paysans, animateurs de développement, conseillers de gestion, chercheurs et experts - ont participé à un atelier sur le conseil aux exploitations familiales. L'atelier était coanimé par le Cirad, I'Iram, I'Inter-Réseaux, lieu d'échange issu de la fusion de plusieurs réseaux thématiques sur le développement rural, et le cabinet Ambre. Douze équipes de terrain ont présenté les expériences menées au Bénin, au Burkina, au Cameroun, en Côte d'Ivoire, au Mali et au Tchad. Les conclusions qui se sont dégagées constituent des pistes d'intervention pour améliorer les dispositifs actuels et pour lancer des expériences novatrices. Tout d'abord, les outils et les méthodes de conseil doivent s'adapter aux situations socio-économiques et répondre aux attentes des producteurs, notamment des exploitants non 
alphabétisés gérant de petites unités de production. Afin de pérenniser les dispositifs, il est nécessaire que les organisations de producteurs et les structures interprofessionnelles participent à leur gestion. Les collaborations avec les autres services d'appui à l'agriculture doivent également être intensifiées. Enfin, le développement des services d'appui, en particulier le conseil aux exploitations, exige d'aborder la question des politiques agricoles, le rôle de l'Etat dans la formation des agriculteurs et dans le financement des dispositifs d'appui, ainsi que l'effet de ces dispositifs sur les disparités sociales.

\section{Savanes d'Afrique centrale}

Le Pôle régional de recherche appliquée au développement des savanes d'Afrique centrale (Prasac) rassemble les structures de recherche agronomique du Cameroun, de la République centrafricaine et du Tchad (Irad, Icra, Itrad et Lrvz), alliées à des partenaires scientifiques du Nord (Cirad, Ird et université de Leyde). En 2001, le pôle a mis I'accent sur la valorisation de ses acquis. Un ouvrage, Le sud du Tchad en mutation - Des champs de coton aux sirènes de l'or noir, propose un tableau dynamique de la zone soudanienne du Tchad et examine les facteurs du changement dans cette région, depuis les perspectives de privatisation de la filière cotonnière jusqu'aux nouvelles constructions routières, en passant par les promesses du pétrole. Cet ouvrage a reçu le prix Albert Bernard de I'Académie des sciences d'outre-mer. Par ailleurs, un atlas agricole des savanes d'Afrique centrale a été publié et sa version électronique interactive est en cours de réalisation en collaboration avec le programme agronomie du Cirad. Des fiches ont été rédigées pour vulgariser les résultats obtenus en matière de technologie alimentaire. Elles concernent les méthodes de mise en marché - connaître son marché, faire un test de commercialisation, organiser les producteurs, échanger les savoir-faire -, la fabrication de divers produits - jus de fruit, oignon en poudre, amidon de manioc, beignets d'igname - et les filières - production laitière, tomate séchée. Enfin, un modèle simulant les dégâts d'insectes sur le coton, Simbad, est en cours de finalisation avec le programme coton.

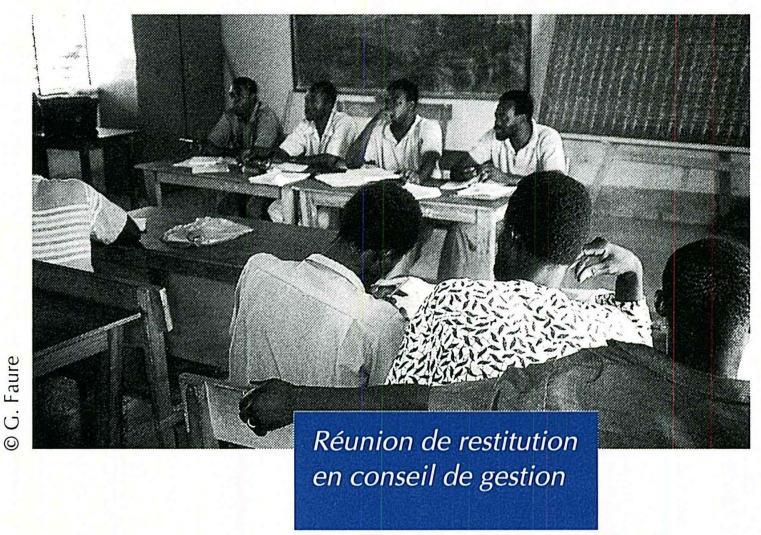

\section{Tropiques humides et insulaires}

Le programme tropiques humides et insulaires participe à la construction et à la promotion de projets de recherche interdisciplinaires et pluri-institutionnels pour le développement régional. Il favorise le regroupement des compétences scientifiques du Cirad et de ses partenaires pour l'exploitation des écosystèmes où les cultures pérennes sont fortement présentes et de ceux, comme I'Amazonie,

\section{Espace amazonien}

L'occupation actuelle de l'espace amazonien est la synthèse de contextes historiques complexes, de stratégies gouvernementales hétérogènes et de cycles économiques erratiques, liés successivement au caoutchouc, aux minerais, aux grands projets de développement destinés à attirer le capital privé et aux stratégies récentes visant à l'insertion de la région dans l'économie mondiale. Une équipe de chercheurs associant le Cirad et le ministère brésilien de l'environnement a où l'élevage a pris une place privilégiée.

Ses travaux sont utilisés par les responsables de la planification régionale.

analysé les divers facteurs et acteurs sociaux liés à chaque forme d'occupation de l'espace amazonien. Le diagnostic a été publié dans un ouvrage, Diagnóstico dos formatos de ocupação do espaço amazônico. Quatre chapitres abordent de façon détaillée la dynamique régionale et les modes d'occupation, la problématique socio- 
économique et environnementale, les impacts de l'action de l'Etat et les conflits provoqués par I'appropriation du territoire et l'utilisation des ressources naturelles. Ce diagnostic montre que la plupart des problèmes de la région proviennent de la mise en œuvre de politiques sectorielles disparates ne tenant compte ni du fonctionnement du milieu amazonien ni de la complexité de la région. L'organisation de la production qui se met progressivement en place est faible et mal structurée. Elle a du mal à promouvoir un développement régional durable et à offrir des conditions de vie dignes aux populations. Elle nuit en outre à la préservation des ressources naturelles.

\section{Zonage agricole en Guinée}

Avec I'appui scientifique du Cirad et le soutien financier du ministère français des affaires étrangères, I'Institut de recherche agronomique de Guinée a effectué un zonage des quatre grandes régions naturelles du pays - Guinée maritime, moyenne Guinée, haute Guinée et Guinée forestière. Les résultats ont été vulgarisés à l'aide d'un ensemble de fiches techniques. Pour chaque région naturelle, une fiche présente la carte des zones agroécologiques homogènes, leur milieu physique, leurs systèmes de production et leurs problématiques agropastorales. Elle est accompagnée de cartes thématiques et $d^{\prime}$ une notice explicative sur la méthode utilisée et les résultats obtenus. En se fondant sur ce zonage, des "villages d'étude » ont été implantés dans chaque région. Ils forment la base d'un réseau de paysans expérimentateurs chez qui les chercheurs mettent en place une démarche participative pour identifier les besoins, tester les innovations, évaluer l'adoption des techniques et mesurer leur impact sur les exploitations. La programmation des activités et la restitution des résultats se

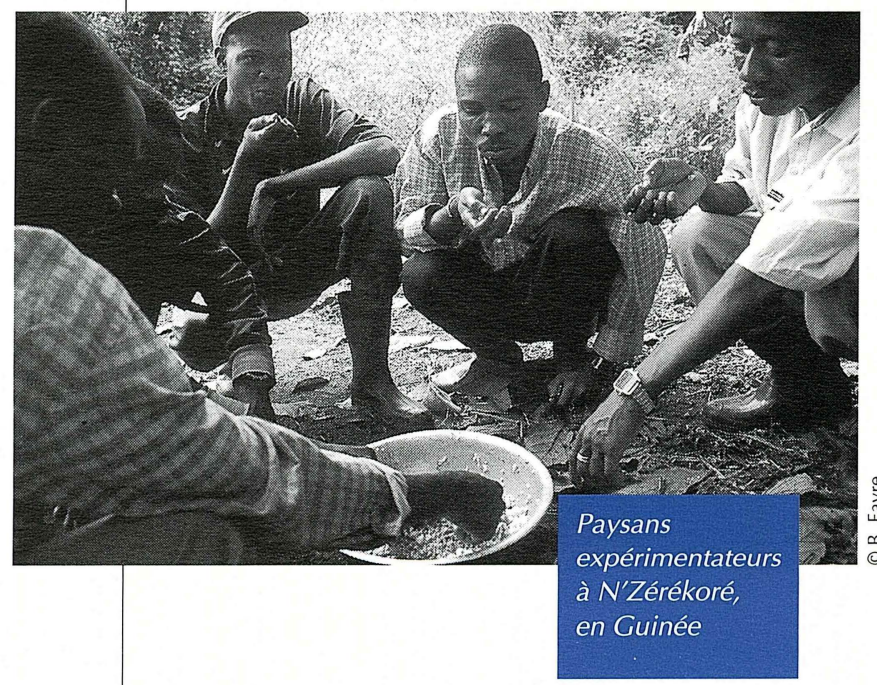

font avec les producteurs et les organismes de développement intervenant dans le village. Ces résultats seront utilisés pour organiser les séances des nouveaux comités régionaux de recherchedéveloppement et pour mieux programmer les recherches thématiques.

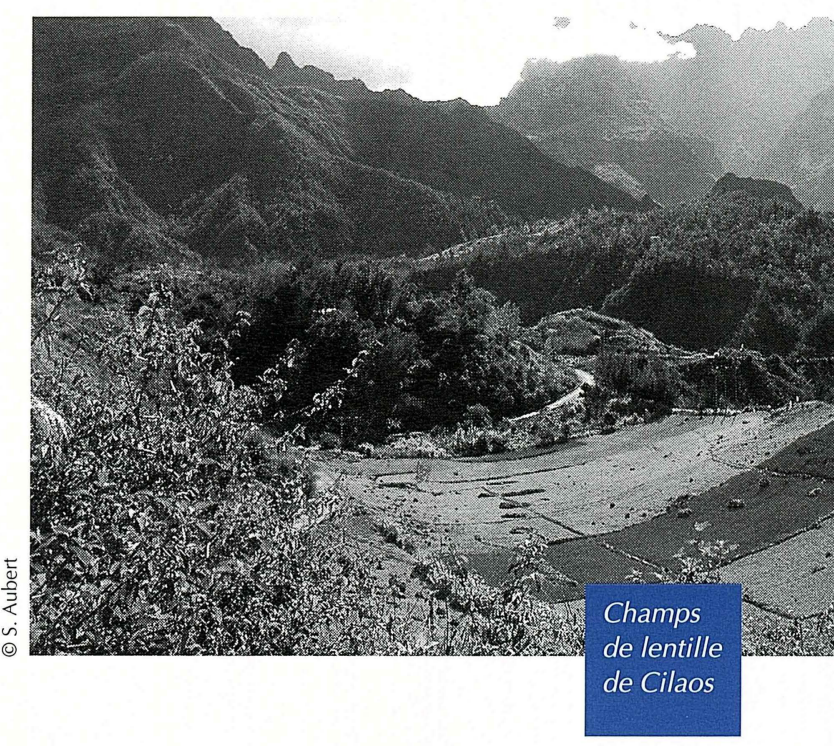

\section{Contrats territoriaux d'exploitation}

A la Réunion, la coopérative viticole de Cilaos et I'Association pour la promotion rurale, sous l'égide du Commissariat à l'aménagement des Hauts, ont mis en place un projet de contrat territorial d'exploitation dans la zone du cirque de Cilaos. Le Cirad a été sollicité pour apporter un appui en terme de méthodes et d'outils afin de construire un diagnostic territorial associant tous les acteurs impliqués. Ce diagnostic porte sur les conditions de maintien d'une agriculture de qualité, son impact sur le tourisme et sa dimension environnementale. Des scénarios d'évolution prospectifs du territoire communal, liés notamment au développement de l'urbanisme, ont été élaborés sur la base d'une analyse des stratégies des producteurs, d'un zonage à dires d'acteurs et d'une étude foncière. Les animateurs du projet et le Cirad ont participé à la rédaction du programme d'action du contrat territorial d'exploitation et à l'animation de deux séminaires associant une quarantaine de partenaires - acteurs locaux, organismes techniques et associations, acteurs institutionnels et élus. Ce travail a permis d'expérimenter une méthode d'animation et de diagnostic innovante, préalable à la mise en place d'un contrat territorial d'exploitation. Un suivi et une évaluation de la démarche seront conduits prochainement et permettront de tirer des enseignements utiles pour d'autres projets à la Réunion. 


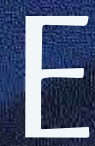

n 2001, le département d'amélioration des méthodes pour l'innovation scientifique a poursuivi ses efforts de production scientifique, mais aussi de conception et de diffusion des outils, logiciels, modèles et méthodes qui sont au cour de son mandat.

L'importance qu'il accorde aux thèmes définis avec les acteurs des pays du Sud $s^{\prime}$ est traduite par une programmation scientifique ambitieuse, par le développement des résultats obtenus avec ses partenaires du Sud et par des actions de formation. Il a su également renouveler ses alliances en contribuant à l'émergence des pôles de compétence en partenariat, au Sénégal, au Brésil et au Vietnam. Et il a obtenu $\mathrm{d}^{\prime}$ excellents résultats auprès du cinquième programme-cadre de recherche et de développement technologique de l'Union européenne.

Le département s'est aussi employé à construire des dispositifs mixtes de recherche, à dispenser des enseignements dans plusieurs écoles doctorales, notamment à Montpellier, à la Réunion et à Nogent-sur-Marne, et à lancer des actions en matière d'enseignement à distance, entre autres, le campus numérique du Jardin tropical de Paris. Son rapprochement avec I'Inria s'est accéléré, avec I'affectation de chercheurs du Cirad au sein de cet institut,

et sa participation au pôle de défense des cultures de Baillarguet s'est concrétisée, avec l'installation de l'équipe d'entomologie auprès de ses partenaires de I'Inra, de l'Ird, de l'Agro Montpellier et du Csiro.

\section{Amélioration des méthodes}

A la Réunion, I'année a été marquée par la réalisation de l'infrastructure du pôle protection des plantes et par l'émergence du pôle agroalimentaire. En Nouvelle-Calédonie, de nouvelles perspectives de collaboration se sont ouvertes pour accompagner la création d'un pôle pilote agroalimentaire, lancée par les autorités locales.

\section{pour l'innovation} scientifique

En outre, la quasi-totalité des postes ouverts pour répondre aux orientations de la relance stratégique du Cirad a été pourvue. Ces recrutements permettent en particulier d'assurer l'essor des activités sur les terrains du Sud et de conforter de nouvelles dynamiques scientifiques.

Enfin, le département a poursuivi et étendu la démarche qualité, notamment pour optimiser le processus de construction et de gestion de ses projets, depuis la programmation des travaux jusqu'à la valorisation des résultats, en passant par la formation et l'accueil des partenaires et par le suivi et la fiabilisation des résultats de recherche. 


\section{(1) Agroalimentaire}

La demande alimentaire mondiale progresse, les consommateurs sont de plus en plus exigeants quant à la qualité des produits. Pour rendre les produits tropicaux plus compétitifs sur les marchés tant locaux qu'internationaux, il faut réduire leur coût, améliorer leur qualité et leur sécurité et assurer I'approvisionnement des marchés ruraux et urbains. Le programme agroalimentaire développe des outils et des méthodes qui

\section{Gestion de la sûreté alimentaire}

Le secteur agroalimentaire des pays du Sud est confronté à de nouveaux défis liés aux exigences des consommateurs. D'un côté, les règlements européens sont de plus en plus stricts, tant sur la qualité sanitaire des produits que sur leur origine, ce qui entrave l'accès des pays du Sud aux marchés du Nord et risque de marginaliser encore plus leurs producteurs, avec les répercussions socioéconomiques qui pourraient en résulter. D'un autre côté, les consommateurs, urbains et ruraux, des pays du Sud se préoccupent davantage de la qualité et de la sûreté de leurs produits alimentaires. Les travaux conduits par des chercheurs de diverses disciplines dans plusieurs filières - élevage de volaille, fromages traditionnels, lait de chamelle, céréales, cossettes d'igname mettent en évidence le rôle essentiel du secteur agroalimentaire dans le pilotage d'une démarche globale de qualité, mais aussi la nécessité d'une construction sociale de cette qualité s'appuyant sur les divers acteurs concernés. Cette approche pluridisciplinaire, qui associe dynamiques d'organisation socio-économique, perception du risque, modes de gestion de ce risque par le consommateur et outils d'assurance qualité adaptés au contexte local, amène le Cirad à élaborer progressivement de nouveaux modes de gestion de la qualité et de la sûreté alimentaire.

\section{Enzymęs végétales}

Afin de mieux valoriser les matières premières agricoles, des essais ont été menés sur l'activité biocatalytique de certains sous-produits, en collaboration avec les technologues du département Cirad-flhor. C'est le cas notamment de la papaïne, une lipase du latex de la papaye, et de la bromélaïne, une enzyme du rachis de l'ananas aux activités lipasiques et acyltransférasiques.

Les travaux sur la papaïne ont montré sans conteste que le latex de papaye séché et broyé manifeste une forte activité acyltransférasique. Cette propriété vient s'ajouter à l'activité protéolytique contribuent à mieux valoriser les productions, à perfectionner les procédés et équipements de transformation et à améliorer la qualité des produits. II apporte un appui aux entreprises dans le domaine de l'innovation technique et des systèmes d'assurance qualité. II s'intéresse aussi à la socio-économie de l'alimentation, en particulier à l'analyse de l'évolution des modes de consommation.

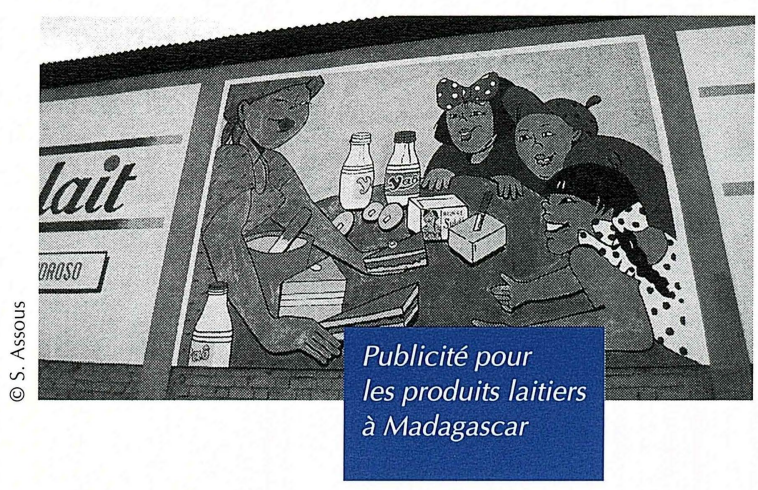

bien connue de ce matériel. Un catalyseur aussi rustique et, de plus, stable et bon marché par rapport aux enzymes microbiennes industrielles, s'avère précieux. Ses potentialités industrielles sont considérables, comme l'ont montré les études sur la synthèse des triacylglycérols à chaînes moyennes destinés à l'alimentation infantile. Les latex étant des cocktails d'enzymes, il y a tout lieu de penser que d'autres activités enzymatiques - bétaglucosidases, polyphénols oxydases, etc. - pourraient y être identifiées.

En revanche, les préparations de bromélaïne étudiées ont manifesté une très faible activité lipolytique et une activité de synthèse nulle. Toutes les biomasses végétales exprimant une activité protéasique n'ont donc pas nécessairement une activité lipasique.

Les enzymes, avec leurs activités caractérisées, pourraient être utilisées dans la biotransformation des produits alimentaires. 


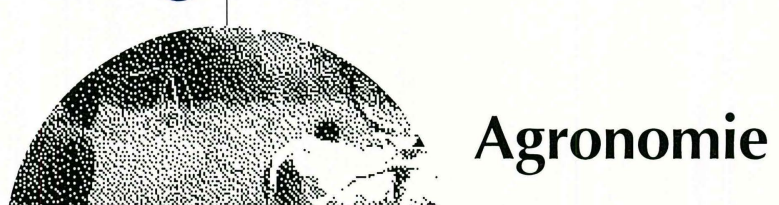

Pour mettre en œuvre des programmes d'intervention culturale ou de gestion des ressources naturelles qui répondent aux enjeux d'une agriculture durable, les agronomes travaillant en milieu tropical ont besoin de s'appuyer sur des bases scientifiques, des méthodes et des outils spécifiques. Le programme agronomie a pour mission de développer cet appui pour

\section{Atlas numérique interactif}

La diffusion des systèmes d'information géographique se heurte parfois aux coûts des logiciels et des matériels, et aux temps d'apprentissage souvent longs. Pour répondre aux attentes de ses partenaires, le programme développe un logiciel à la fois simple d'utilisation et bon marché. Il est conçu pour recueillir les données compilées par les acteurs des projets - textes, images, cartes, tableaux de données, couches d'informations spatialisées, etc. - et pour réaliser des analyses spatiales car il intègre les fonctionnalités d'un système d'information géographique.

Ce logiciel est rapidement pris en main par les non-spécialistes et permet de valoriser un projet bien mieux qu'un rapport ou un atlas imprimé. Son " moteur » est conçu pour recevoir, avec des changements minimes, différentes bases de données. Son interface n'est pas à usage unique, c'est une boîte à outil réutilisable pour d'autres projets, avec la possibilité d'ajouter ou de modifier certaines fonctionnalités.

\section{Mesurer le stress hydrique}

L'alimentation en eau des couverts végétaux est déterminante pour leur bon fonctionnement. Depuis plus de vingt ans, la température de surface, mesurée au sol ou par télédétection satellitaire, sert à estimer leur état hydrique. Mais les indicateurs de stress hydrique calculés à partir de

hydrique des plants de cotonnier par infrarouge thermique cette mesure sont peu fiables du fait de la présence de portions de sol nu dans le champ de visée du capteur. Pour s'affranchir de cette contrainte, le programme a réalisé la mesure directionnelle de la température de surface dans une culture en rang de cotonnier selon deux approches : par une expérimentation in situ à Montpellier et à I'aide du modèle les équipes du Cirad et ses partenaires de la recherche et du développement. Ses objectifs : conduire des recherches de base dans les domaines de l'agronomie où le contexte tropical implique la mise au point ou l'adaptation d'outils et de méthodes ; concevoir des procédures d'investigation et de diagnostic, des outils d'aide à la décision; accompagner les institutions partenaires dans I'utilisation de ces méthodes et de ces outils ; contribuer à la formation des chercheurs.

tridimensionnel de bilan d'énergie du couvert Thermo (Amap), qui utilise la modélisation de l'architecture du cotonnier, de la couverture du sol et des phénomènes physiques. Il semble possible, sur la base des simulations du modèle Thermo, d'élaborer des méthodes génériques plus fiables de détermination des indices de stress hydrique. Thermo est, par ailleurs, un outil d'analyse détaillée adapté à de multiples problématiques liées à l'utilisation de l'eau par la plante, qui pourrait être utilisé pour piloter l'irrigation.

\section{Photopériodisme du sorgho}

Jusqu'à récemment, les sélectionneurs s'attachaient à améliorer le sorgho tropical en éliminant son photopériodisme. Aujourd'hui, ils s'efforcent plutôt de créer une plante assez photopériodique, dont I'architecture assure un indice de récolte et un rendement supérieur; I'ensemble de ces propriétés permettant au producteur d'adapter la date de semis aux aléas climatiques. Mais comment sera structurée une telle plante? Le Cirad, en collaboration avec I'Icrisat et I'Ier, a mené une étude comparative sur la phénologie du sorgho au champ, au Mali, et dans un phototron, à Montpellier. Ces expérimentations et les modélisations réalisées prouvent que le sorgho ne réagit pas simplement à la longueur du jour, mais aussi aux variations de durée d'un jour à l'autre, à la minute 
près. L'étude de ce fonctionnement inattendu, qui explique certains phénomènes observés en champ, débute à peine, mais déjà la question se pose de savoir si on a affaire à une spécificité du sorgho ou à un phénomène latent chez toutes les plantes cultivées.

\section{Raisonner la fertilisation}

Raisonner la fertilisation, c'est combiner des objectifs productifs, économiques et environnementaux parfois contradictoires, c'est trouver le juste compromis en se fondant notamment sur la connaissance du fonctionnement du sol et des spécificités des variétés cultivées. Ainsi, dans le sud du Mali, l'étude sur une toposéquence d'un système de cultures annuelles - mil, sorgho et maïs - sous parc à karité montre que les caractéristiques du parc et des arbres diffèrent selon leur position. La fertilité du sol est plus forte à mi-pente et en bas de pente, où la quantité d'azote potentiellement fournie par le sol est de 60 kilos par hectare sous houppier et de 30 hors houppier. Au Cameroun et en Colombie, dans le cadre d'un projet européen, des variétés de maïs tolérantes ou sensibles à l'acidité du sol ont été soumises à différentes combinaisons $d^{\prime}$ engrais : engrais phosphaté, phosphate organique (fientes), chaux,

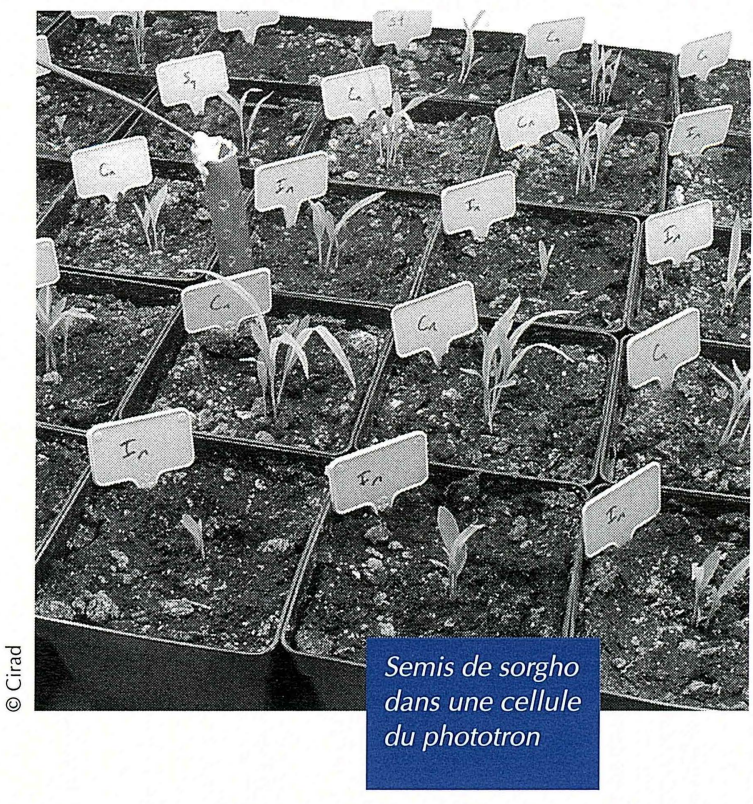

résidus végétaux. Les variétés sensibles répondent seulement à la combinaison chaux, résidus et phosphates, alors que les variétés tolérantes répondent quel que soit le traitement. Dans ces deux exemples, les données recueillies permettront d'optimiser la fertilisation.

\section{. 34.46 Biotechnologies et ressources génétiques végétales}

Le programme biotechnologies et ressources génétiques végétales contribue à l'amélioration variétale en développant de nouvelles méthodes qui assurent une gestion optimale des ressources génétiques, facilitent la création et l'identification de génotypes performants, notamment pour la qualité technologique de leurs produits et leur tolérance aux contraintes biotiques et abiotiques, et accélèrent la diffusion

\section{Génomique à grande échelle}

Deux plates-formes de la Génopole de Montpellier sont accueillies par le Cirad. La plateforme de systèmes automatisés a été créée au cours de l'année 2000 pour répondre aux besoins des projets de génomique. Elle se compose de cinq systèmes robotisés, qui permettent de produire des banques génomiques (repiquage de clones, réarrangement de clones, duplication de banques), de fabriquer des filtres à haute densité, d'extraire I'Adn génomique et plasmidique et de préparer des Pcr. La plate-forme de des variétés sélectionnées. II conduit des projets spécifiques, producteurs de ressources biologiques nouvelles, et dispense de plus en plus de formations aux biotechnologies.

génotypage, lancée à la fin de l'année 2001, regroupe une chaîne robotisée de préparation de $\operatorname{Pcr}$ (384 puits), des thermocycleurs (96 et 384 puits) et deux séquenceurs automatiques dédiés exclusivement au génotypage (microsatellites, Aflp...). 
Tous les laboratoires de la Génopole ont accès à ces plates-formes, dont l'équipement a été en partie financé par la Génopole, et par des fonds régionaux, institutionnels ou contractuels. Leur fonctionnement, sous la responsabilité d'un agent du Cirad, est facturé aux laboratoires utilisateurs. Ces outils de haute technologie devraient favoriser les études biologiques à grande échelle de la recherche publique et privée et impliquer la Génopole dans les domaines de l'industrie et des biotechnologies.

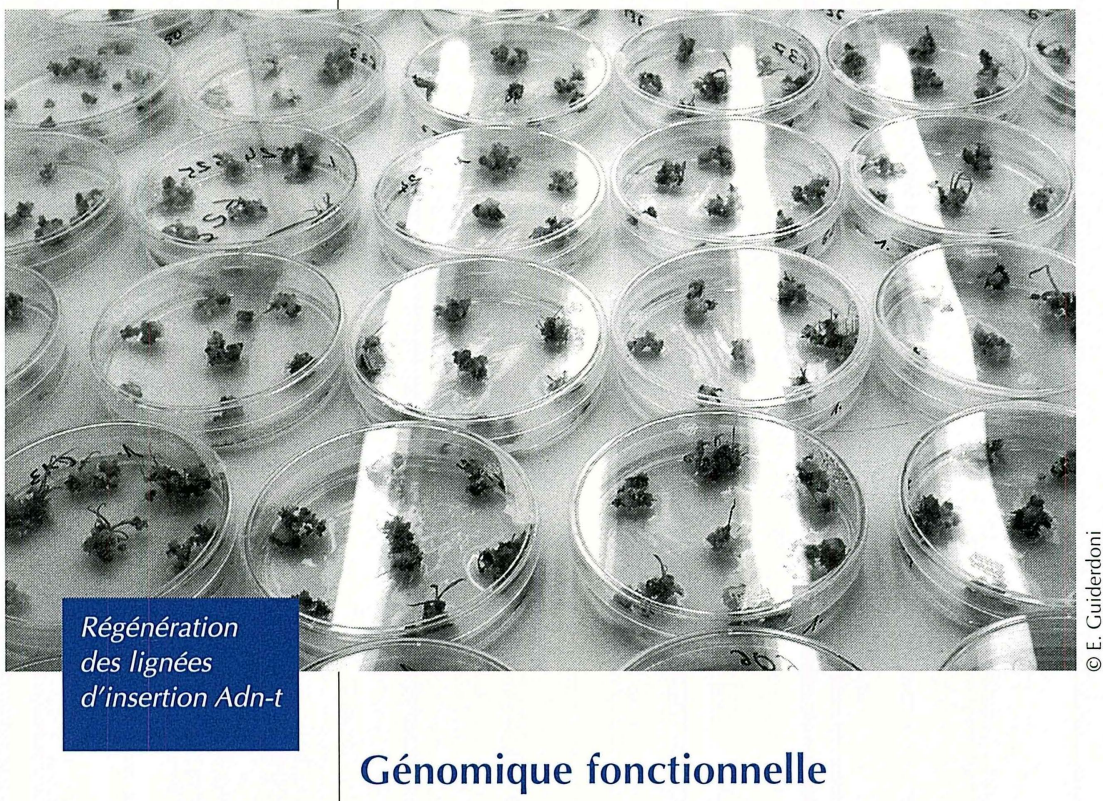

La génomique fonctionnelle vise à découvrir la fonction des gènes, leur mode de régulation et leurs interactions à l'échelle d'un système biologique et d'un génome. Elle repose sur l'analyse à haut débit des produits de transcription et de traduction de milliers de gènes. Elle procède selon une succession d'étapes : constitution de catalogues de séquences exprimées, analyse comparée des profils d'expression de ces séquences dans des situations contrastées (variété, organe, stress, stade de développement...), qui permet d'identifier des gènes candidats différentiellement régulés et des interactions entre gènes, validation de leur fonction par recoupement avec leur position sur le génome (colocalisation avec des Qtl), par leur inactivation (lignées d'insertion) ou par leur surexpression dans la plante. A ces étapes s'ajoute l'étude systématique des interactions entre protéines ou protéines-séquences régulatrices grâce aux systèmes de double et simple hybride chez la levure, pour découvrir les facteurs de régulation des gènes et établir leurs réseaux relationnels. Le Cirad s'est engagé dans la création de collections de lignées d'insertion et dans le développement de lignées recombinantes de riz, qui, avec les outils du projet Génoplante, seront utilisées pour repérer les gènes impliqués dans des caractères complexes comme son architecture et sa tolérance aux contraintes abiotiques.

\section{Formation aux biotechnologies}

Poursuivant la formation aux biotechnologies de ses partenaires du Sud, le Cirad a animé des séminaires à Abidjan, en Côte d'Ivoire, et à Njombé, au Cameroun. Ces séminaires étaient axés sur I'utilisation des marqueurs moléculaires en amélioration des plantes et traitaient d'applications précises : la sélection du riz, pour la Côte d'Ivoire, et celle des bananiers et plantains, pour le Cameroun.

Une vingtaine de chercheurs et universitaires africains - sélectionneurs, phytopathologistes — ont participé à chaque séminaire, qui était dirigé par une équipe de chercheurs du Cirad et d'universitaires du pays d'accueil.

Ces formations ont rencontré un vif succès, non seulement de par leur contenu, qui correspondait à une véritable demande des sélectionneurs de terrain, mais aussi du fait de l'interactivité instaurée entre enseignants et stagiaires. Le programme de formation était affiné au début du stage, avec les participants eux-mêmes, afin de l'adapter aux attentes de chacun. Une place importante était réservée aux travaux pratiques, qui se sont déroulés dans les laboratoires des centres de recherche agronomique partenaires. Chacun a pu ainsi extraire I'Adn du matériel végétal prélevé localement et apprécier la diversité génétique révélée. Une occasion aussi de démontrer que ces laboratoires, pour la plupart $d^{\prime}$ installation récente, étaient parfaitement opérationnels pour ces nouveaux outils.

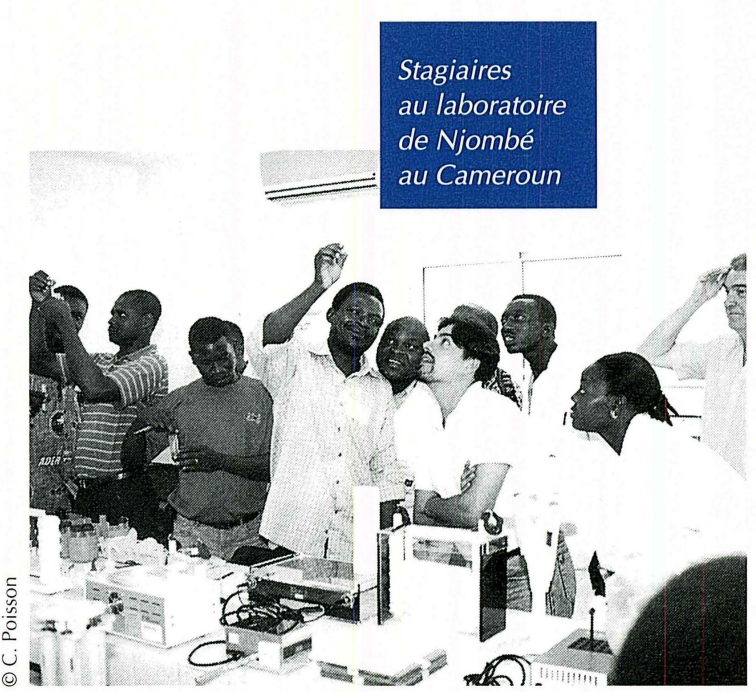




\section{$\left.(2+3)^{2}\right)$ Economie, politiques et marchés}

L'écart de compétitivité et de ressources entre les pays se creuse.

La libéralisation des échanges crée des difficultés dans l'ajustement des économies et complique la mise en œuvre des politiques. Dans certains cas, une intervention publique ou collective s'impose pour améliorer l'équité et l'efficacité de la production et des échanges. Le programme économie, politiques et marchés s'attache à identifier

\section{Union européenne et pays Acp}

Les agricultures de I'Union européenne et des pays de la zone Afrique, Caraïbe, Pacifique (Acp) sont à la fois complémentaires et concurrentielles. Pour éclairer les enjeux de la coopération entre ces deux ensembles et fournir aux décideurs des éléments d'appréciation sur l'intérêt d'alliances dans le cadre des négociations commerciales internationales, une étude a été entreprise, qui visait à déterminer les dossiers sur lesquels ces agricultures ont des intérêts convergents, mais aussi ceux pour lesquels elles entrent en compétition.

Le document issu de cette étude se compose de notes de problématique sur Lomé, l'Omc et la Pac, d'une note de cadrage macroéconomique sur les échanges entre I'Union européenne et les pays Acp et de quinze fiches par produit avec les cartes correspondantes. Il s'achève par une synthèse générale, qui expose les problématiques sousrégionales, précise le degré de concurrence entre les agricultures de l'Union européenne et des pays Acp et propose des stratégies d'alliance au sein des instances internationales.

Ce document a été présenté au ministère français de I'agriculture et de la pêche puis à la Commission européenne. Il devrait contribuer à orienter les argumentaires pour les négociations. Il permettra aussi de mieux formuler des scénarios vraisemblables, qui seront testés grâce à des simulations réalisées à partir de modèles.

\section{Gaz à effet de serre}

Le programme a participé au projet sur les stratégies de contrôle des émissions de gaz à effet de serre, qui réunit une dizaine de centres de recherche de I'Union européenne, pour élaborer des scénarios d'analyse de politiques climatiques. Sa contribution, liée à celle de l'institut de la santé publique et de l'environnement des Pays-Bas (Rivm), porte sur les techniques agricoles capables de réduire les émissions de l'agriculture et sur la quantification des coûts marginaux d'abattement. Une base de données a été construite, qui permet d'intégrer les ces situations afin d'élaborer

un argumentaire économique fondé

sur les besoins et les attentes des acteurs.

Il s'efforce de fournir des indications sur

les instruments de politique ou de marché

adaptés aux économies du Sud et de déceler

les défaillances du marché. Il conçoit

des outils et des méthodes qui permettent

de mieux comprendre les situations,

d'en proposer une représentation fiable

et d'en prévoir les conséquences.

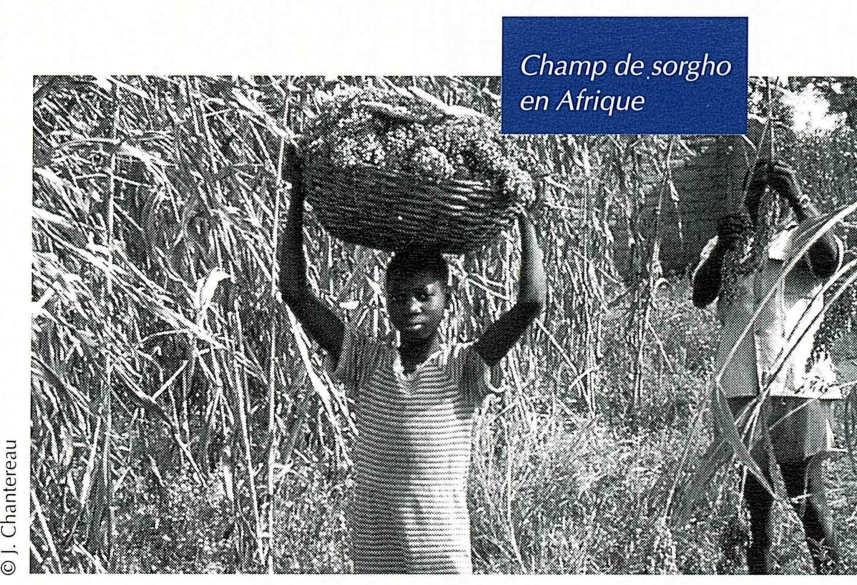

informations recueillies dans la littérature et auprès des experts. Un modèle économique simple a été élaboré, pour des simulations de politique climatique à l'échelle d'un pays ou d'une région. Le modèle permet d'analyser l'impact de la tarification du carbone sur les niveaux d'émission et les choix techniques dans le secteur agricole.

\section{Pôle de formateurs africains}

Dans le contexte actuel de libéralisation commerciale et de désengagement de l'Etat, les priorités de l'intervention publique dans le secteur agricole doivent reposer sur un argumentaire solide, centré sur les concepts de défaillance de marché et de défaillance d'Etat : I'intervention publique 
est collectivement souhaitable dans les domaines où le marché et l'Etat n'assurent pas une bonne coordination entre acteurs.

Une réflexion a été engagée, avec un groupe de dix-neuf experts provenant de onze pays d'Afrique de I'Ouest et du Centre, sur la démarche d'élaboration des politiques agricoles. L'objectif général était d'amener les membres du groupe, appelé pôle de formateurs africains, à renforcer leurs compétences dans le domaine et à inter-

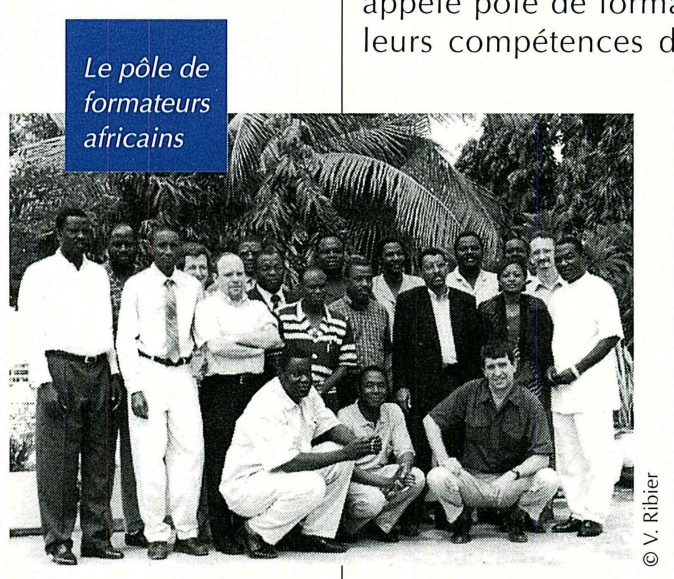

venir comme formateurs auprès des acteurs de la politique agricole — cadres des administrations, mais aussi responsables d'organisations non gouvernementales, de collectivités locales et d'associations de producteurs.

La réflexion, qui a porté sur les étapes de la construction d'une politique agricole argumentée, a été menée sous la forme de trois ateliers d'une semaine, espacés de deux mois, entre lesquels chaque participant a approfondi la démarche et l'a appliquée aux réalités de son pays. Un manuel pédagogique, élaboré à la suite des ateliers, constitue la référence méthodologique commune à l'ensemble des membres du groupe. Certains d'entre eux ont d'ores et déjà été sollicités pour mettre en œuvre la méthode dans le cadre d'expertises ou de formations.

\section{Multifonctionnalité de l'agriculture}

La multifonctionnalité de l'agriculture peut se définir comme la production de biens ou de services joints à la production agricole et non rémunérée par le marché : biens environnementaux, emploi familial non rétribué, entretien des paysages... Cette définition conduit à justifier, sous certaines hypothèses, une intervention publique pour la production de ces biens ou services. Les justifications et les formes de l'intervention publique qu'impose la multifonctionnalité sont au cœur de débats houleux à l'Omc. Un pays peut-il préserver ses emplois et son environnement sans nuire à ses partenaires commerciaux ? Les règles actuelles de coopération à l'Omc permettent-elles à un pays de valoriser les fonctions multiples de son agriculture? Sinon, quelles modifications des critères de coopération commerciale convient-il d'envisager?

Le programme a tenté de répondre à ces questions dans le cadre d'une étude réalisée pour le ministère de I'agriculture. Les recherches aboutissent à ce résultat paradoxal qu'en présence de multifonctionnalité effective le protectionnisme, destructeur de bien-être dans le cadre économique standard, peut engendrer un niveau de bien-être supérieur à celui du libre-échange. Elles conduisent à I'obligation de compenser les perdants du protectionnisme en leur versant un dédommagement, ou " compensation internationale", prélevé sur les recettes douanières et sur le montant des soutiens du pays qui se protège.

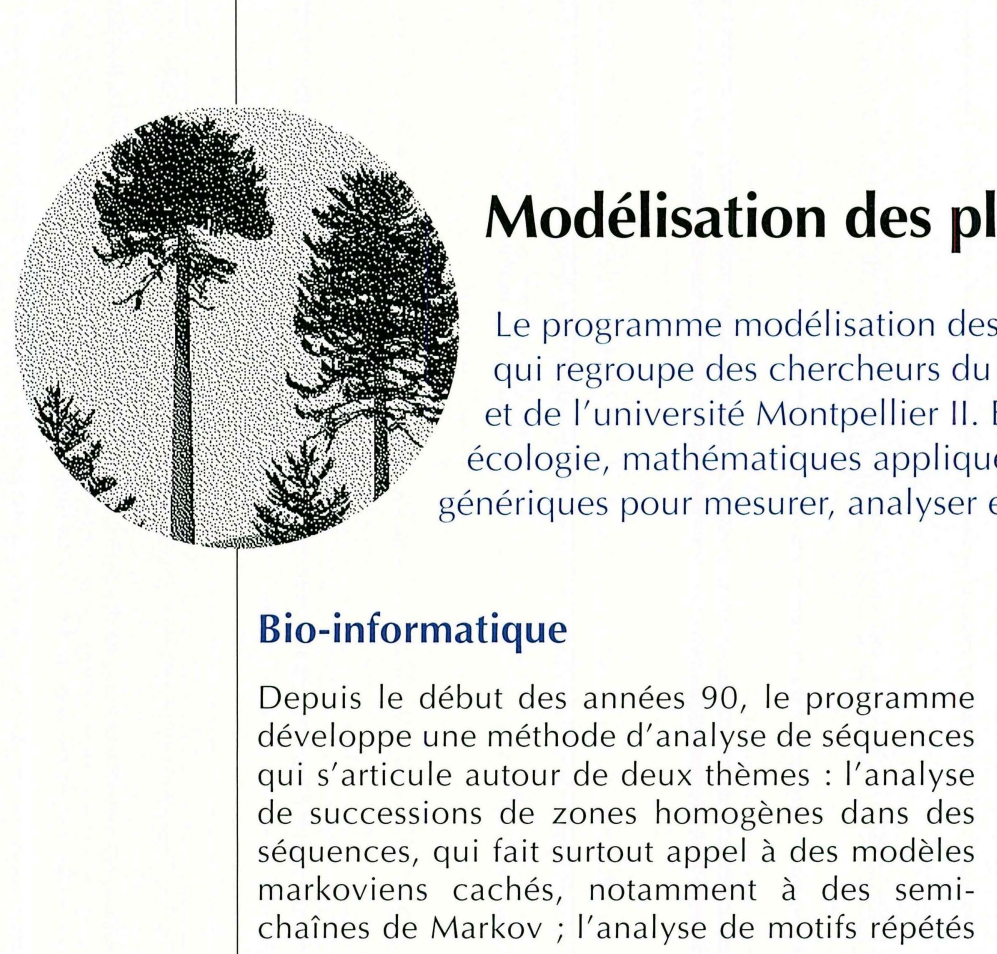




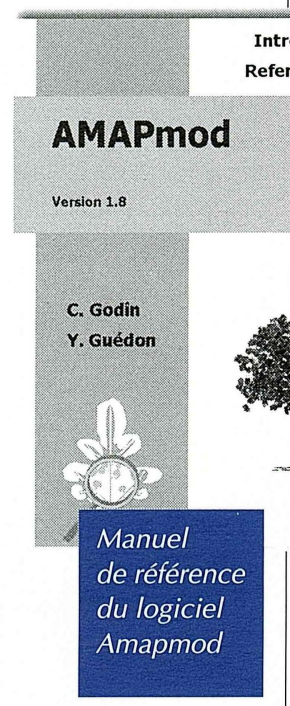

Introduction and Reference Manual

méthodes d'analyse exploratoire, de modélisation statistique et de comparaison. La première étape a consisté à développer des méthodes de comparaison d'arborescences. Il s'agit maintenant de concevoir des modèles statistiques pour étendre les chaînes de Markov cachées aux données de type arborescence, afin d'y identifier des zones homogènes. Cette deuxième phase fait l'objet d'une collaboration avec I'Inria.

\section{Greenlab en Chine}

Le projet Greenlab, qui a débuté en 1998 au Liama, laboratoire commun à l'Inria et à l'Institut d'automatique de Beijing, visait à instaurer une coopération franco-chinoise autour des modèles mathématiques de plantes et de leurs applications agronomiques et forestières. Il associe des mathématiciens et informaticiens de l'Académie des sciences de Chine, des agronomes de l'université $d^{\prime}$ 'agriculture de Chine, où sont réalisées les expérimentations, et des chercheurs du Cirad, de l'Inra et de I'Inria. Après trois ans d'existence et le renouvellement de l'équipe du Cirad présente en Chine, le projet a franchi une étape décisive. Le modèle mis au point a été validé sur des plantes cultivées chinoises, comme le blé, le maïs, le soja, le tournesol et le cotonnier, et son premier prototype logiciel a été réalisé. Le modèle, de type structure-fonction, formule la croissance en couchinois et français du projet Greenlab he vrory $x^{2} x^{2}$ plant un automate, qui rend compte du programme morphogénétique de la plante, et des rétroactions, qui lient l'organogenèse, la photosynthèse et les paramètres environnementaux grâce au concept d'architecture végétale.
Ce partenariat ouvre de vastes perspectives scientifiques, du fait du potentiel de recherche que représente le Liama et des applications du modèle dans le domaine de la modélisation des plantes cultivées et de l'optimisation des itinéraires culturaux. Il s'inscrit aussi dans une politique d'alliance, qui confère au projet une bonne notoriété.

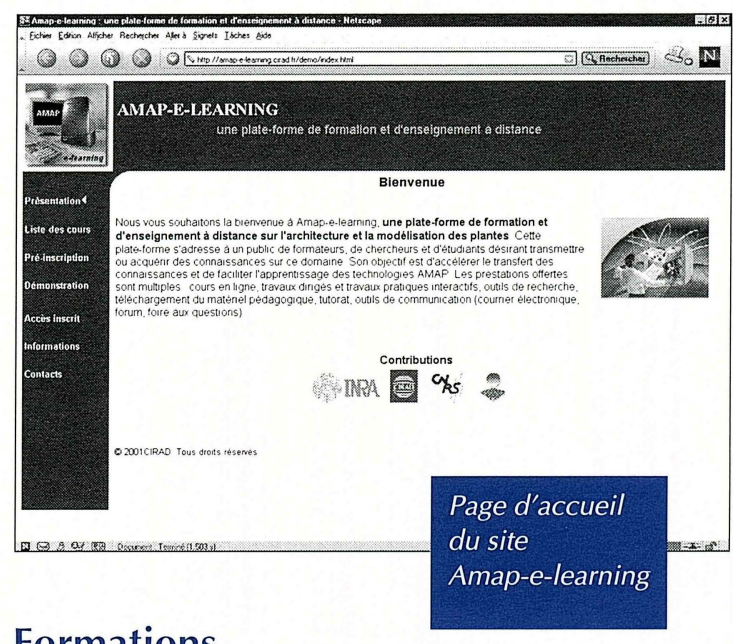

Formations

En 2001, le programme a intensifié ses actions de formation. Trois modules de cours ont été créés dans les écoles doctorales montpelliéraines : modélisation intégrée du fonctionnement et de I'architecture de plantes et de couverts végétaux, en collaboration avec le Lepse ; structures multiéchelles, aspects formels et algorithmes, en collaboration avec le Lirmm ; modélisation stochastique de phénomènes biologiques. Des écoles-chercheurs et ateliers ont été organisés, avec, en tout, plus de 80 chercheurs ou ingénieurs du Cirad, de l'Inra et d'autres établissements formés : introduction à la numérisation des plantes et au logiciel Amapmod; simulation du développement des plantes et utilisation du logiciel Amapsim ; imagerie volumique; utilisation de la plate-forme logicielle Capsis pour la modélisation de la dynamique des peuplements forestiers ; apprentissage des logiciels de la gamme Cepha. Parallèlement, les séminaires hebdomadaires sur la modélisation des plantes se sont poursuivis en Chine et des cours de troisième cycle en télédétection, traitement d'images et simulation des paysages ont été dispensés à I'Ait, en Thaïlande. Le programme a également installé une plate-forme $\mathrm{d}^{\prime}$ enseignement et de formation à distance sur I'architecture et la modélisation des plantes, Amap-e-learning. Elle a été testée avec succès sur le terrain, en 2001, dans le cadre de la formation organisée sur la mesure et I'analyse de I'architecture des plantes. 


\section{Commercialisation des logiciels}

Le Cirad s'est engagé dès 1991, à partir de concepts originaux sur la modélisation de l'architecture des plantes, dans le développement de logiciels de conception et de visualisation de paysages en images de synthèse, connus sous le nom d'Amap. Leur précommercialisation réalisée par le Cirad s'étant avérée prometteuse, avec plus de mille licences professionnelles distribuées dans le monde, il a été décidé de transférer cette technologie à la société d'édition de logiciels spécialisés Bionatics. Cette société a pris en charge le développement commercial de la gamme Amap dans le cadre d'un accord qui préserve les intérêts du Cirad, tant sur le plan des droits d'auteurs que sur celui des recettes financières.

\section{$4+2 x^{2}$ Protection des cultures}

Le programme protection des cultures mène des recherches dans le domaine de la lutte intégrée contre les parasites et ravageurs des productions tropicales, subtropicales et méditerranéennes. Les stratégies qu'il met au point reposent sur l'utilisation d'une gestion raisonnée de la résistance génétique et des systèmes de culture adaptés et sur l'emploi de pesticides et d'antagonistes

\section{Lutte antiacridienne}

Madagascar a été récemment durement éprouvée par une invasion de criquets migrateurs (Locusta migratoria capito) et des pullulations de criquets nomades (Nomadacris septemfasciata). L'invasion n'a été maîtrisée qu'après quatre années d'une lutte coûteuse et plus de quatre millions d'hectares traités aux insecticides chimiques. Pourtant, dès les années 70 , des données scientifiques, que des chercheurs du Cirad ont contribué à établir, permettaient de prévoir le début des invasions. Lors des périodes de rémission, la seule région à biologiques, avec le souci constant de préserver l'environnement. Actuellement, ses recherches concernent l'analyse des populations de bioagresseurs, les interactions plante-parasite et les composantes épidémiologiques.

surveiller attentivement est le sud-ouest de l'île, où se trouve l'aire grégarigène $d^{\prime}$ 'où partent les invasions. En y observant la pluviométrie et la densité des populations de criquets, il est possible de déterminer les régions à risque et d'intervenir précocement.

Afin de restaurer ce dispositif de prévention, le Cirad a été chargé, par l'ambassade de France, d'épauler la section d'avertissement du Centre national antiacridien (Cna), nouvellement créé. II s'agit, entre autres, de mettre au point un outil d'aide à la décision pour le suivi de la situation acridienne. Il permettra d'intégrer dans un système $\mathrm{d}^{\prime}$ information géographique (Sig), et sur un pas de temps décadaire, les données météorologiques et acridiennes, de localiser les zones à risque et d'orienter les opérations de traitement préventif. La première phase du projet s'achève. Les travaux sur le Sig et l'actualisation de la cartographie des biotopes de l'aire grégarigène du criquet migrateur ont débuté ; le dispositif de recherche sur le criquet nomade a été mis en place; le personnel technique malgache a été formé à la conduite des observations. Au terme des trois années du projet, le Cna devrait disposer d'un nouveau système d'alerte précoce contre les invasions acridiennes. 


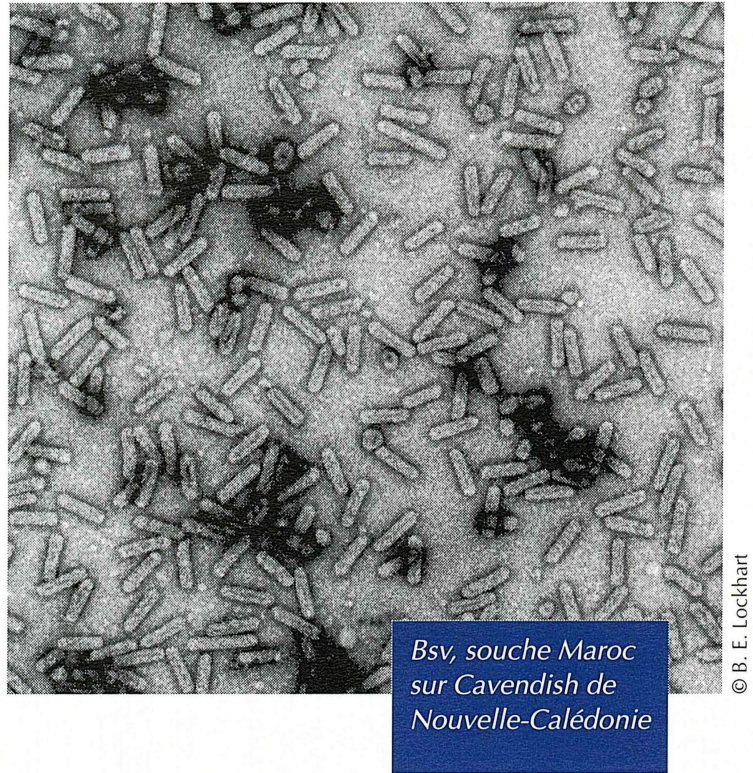

\section{Virologie}

Les virus des végétaux se propagent généralement par l'intermédiaire de vecteurs. Le Banana streak virus, un badnavirus responsable de la maladie de la mosaïque en tirets du bananier, emprunte habituellement ce mode de contamination. Il est cependant capable, comme l'a montré une étude récente, de se propager par voie génétique. C'est la première fois qu'un tel phénomène est observé dans le règne végétal : un motif dormant du virus, intégré aux chromosomes des bananiers de l'espèce Musa balbisiana, peut, malgré un agencement complexe, reconstituer une particule virale pathogène sous l'effet d'un stress biotique ou abiotique - croisement génétique, micropropagation de masse ou écart de température. C'est ce qui a été constaté pour des populations d'hybrides interspécifiques issus de parents sains, dont la moitié développait la maladie sans aucune contamination extérieure possible. Une analyse génomique fine (Aflp) a prouvé l'origine génétique de la maladie, liée à la présence de séquences virales intégrées au génome du parent balbisiana. Le mécanisme responsable de l'apparition du virus lors des croisements est en cours d'étude. Par ailleurs, lors de la culture in vitro de bananiers silencieux, qui renferment des séquences virales dormantes, l'étape de prolifération est déterminante sur l'expression du virus. D'autres plantes hôtes de badnavirus, dont le mode de culture est proche de celui du bananier, comme la canne à sucre, l'igname et l'ananas, pourraient présenter ce mode de contamination. La nature de ces interactions, qui peuvent relever d'une coévolution des génomes de l'hôte et du virus, fait l'objet de nouveaux enjeux pour l'agriculture.

\section{Systématique}

Dans les régions tropicales, l'évolution des pratiques agricoles et l'introduction accidentelle de déprédateurs modifient constamment la situation phytosanitaire des agrobiocénoses. Pour comprendre ces évolutions et déterminer l'origine des déséquilibres qui conduisent aux pullulations de ravageurs, mais aussi pour détecter les auxiliaires potentiels de leur éradication, il est indispensable d'identifier rigoureusement les organismes présents. C'est la mission de l'unité de faunistique.

Les systématiciens disposent pour ce faire de nouveaux moyens, qui viennent s'ajouter aux caractères morphologiques, utilisés traditionnellement pour déterminer les espèces : les marqueurs biochimiques et surtout moléculaires, qui permettent d'identifier plus précisément les organismes - jusqu'à la sous-espèce et même la population à laquelle ils appartiennent - et sont utilisables à un stade précoce de leur développement. Les outils informatiques, comme les logiciels spécifiques pour inférer des phylogénies, les systèmes d'aide à l'identification et, depuis peu, les systèmes de reconnaissance automatique des formes et des espèces, viennent aussi renforcer leurs compétences.

Le regroupement de spécialistes de la systématique qui est envisagé sur le site de Baillarguet, près de Montpellier, devrait permettre d'exploiter pleinement ces nouvelles techniques. II associera, outre l'unité de faunistique du Cirad, des équipes de I'Inra et de I'Ird et travaillera en relation avec le Centre de biologie et de gestion des populations, déjà installé sur le site. Il est prévu, entre autres, d'y établir une base de données moléculaires pour réaliser en routine les déterminations, ce qui allégera le travail des systématiciens, qui pourront se consacrer davantage à la recherche.

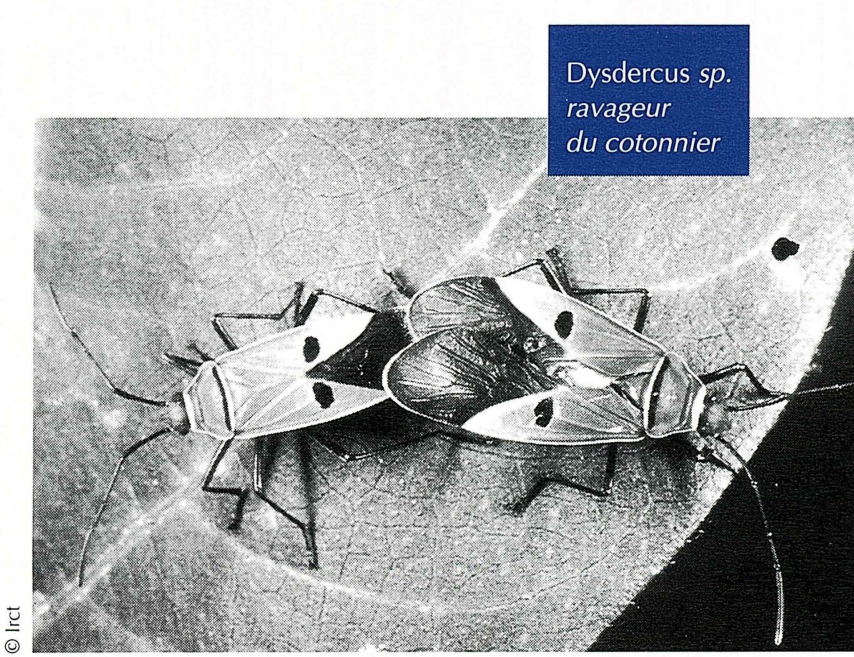


Le conseil d'administration

L'organisation générale

La direction générale

Les départements

Le conseil scientifique

Le comité d'éthique

Le Cirad en bref

Les délégations scientifiques

Les représentants

Le Cirad dans le monde

Le budget et le personnel

Les chercheurs formés par le Cirad

Les adresses du Cirad

Liste des sigles 


\section{Le conseil d'administration}

Président

Daniel Nahon

Elisabeth Beton-Delègue, représentant le ministre des affaires étrangères

Alain Coléno, représentant le ministre de la recherche et des nouvelles technologies

Philippe Court, représentant le ministre du budget et de la réforme budgétaire

Patrick d'Aquino, représentant élu des salariés

Jean-Pierre Decor, ancien directeur général adjoint d'Aventis

Tristan Durand-Gasselin, représentant élu des salariés

Jacqueline Godet, professeur à I'université Lyon I

Bertrand Hervieu, président de l'Inra

Eric Jallas, représentant élu des salariés

Henri-Félix Maître, représentant élu des salariés

Daniel Metayer, représentant le ministre de I'outre-mer

Jeanne-Marie Parly, professeur des universités, conseiller d'Etat

Marc Roesch, représentant élu des salariés

Jean-Michel Severino, directeur général de l'Agence française de développement

Laurence Tubiana, inspecteur général de l'agriculture

Philippe Vaast, représentant élu des salariés

Philippe Vissac, représentant le ministre de I'agriculture, de I'alimentation, de la pêche et des affaires rurales 


\section{L'organisation générale du Cirad en 2002}
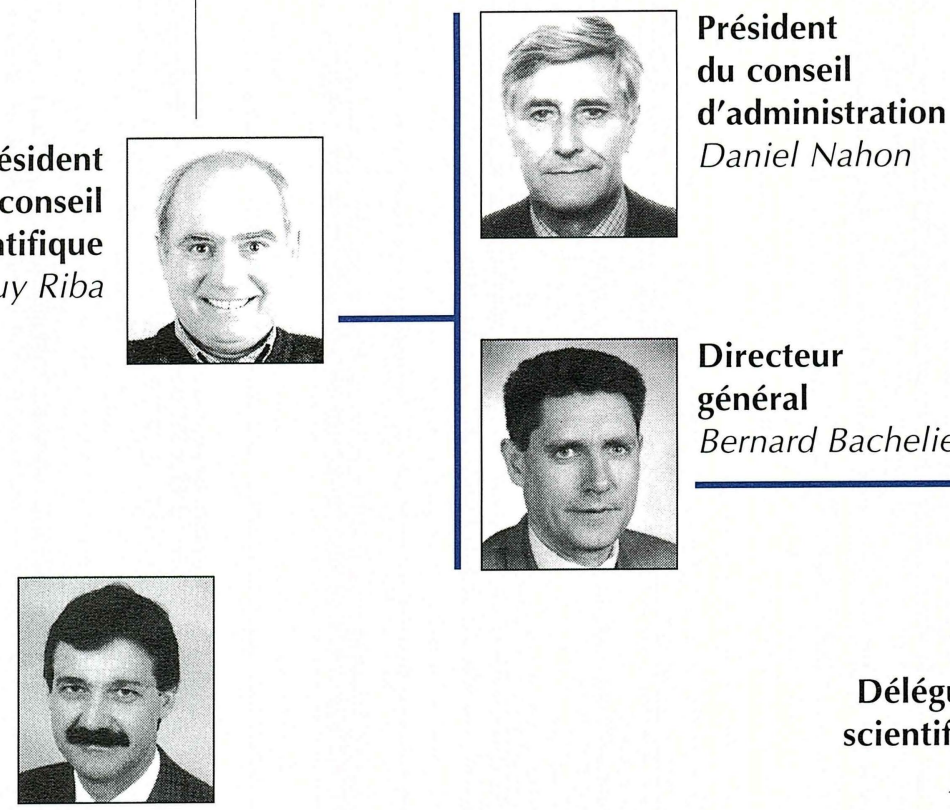

Président du conseil scientifique

Guy Riba
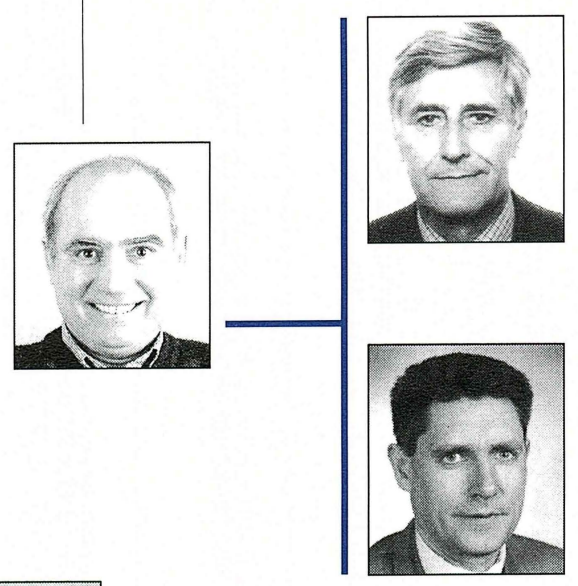

Daniel Nahon

Secrétaire général

Vincent Dollé

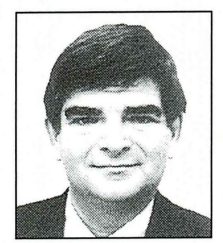

Directeur scientifique Michel Griffon

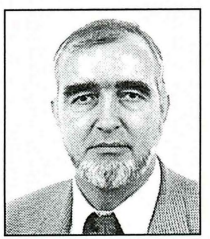

Directeur des relations extérieures

Alain Derevier

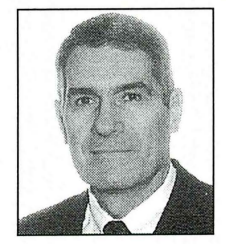

Président du centre de Montpellier Maurice Izard

Directeurs de département

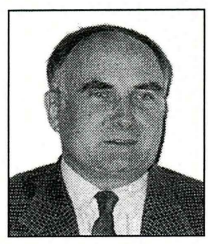

Cirad-ca

Alain Capillon

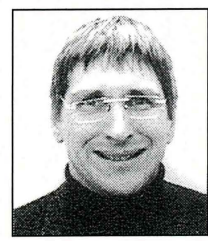

Cirad-cp

Denis Despréaux

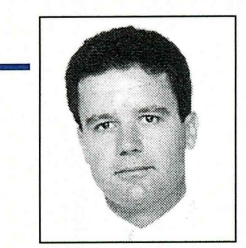

Délégué à l'informatique et aux télécommunications Joël Sor

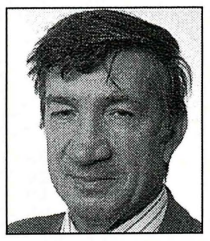

Cirad-flhor Jean-Pierre Gaillard

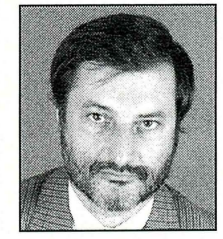

Cirad-emvt Joseph Domenech

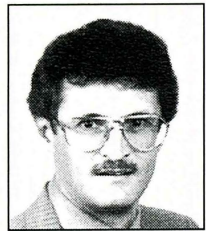

Cirad-forêt Jacques Valeix

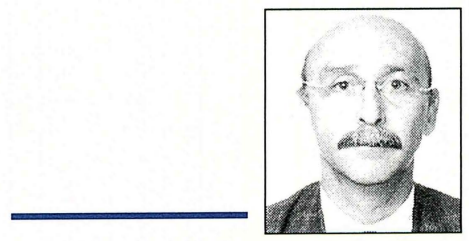

Cirad-tera Rolland Guis

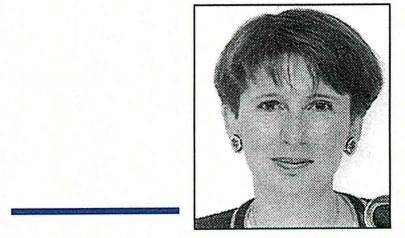

Cirad-amis Anne-Yvonne Le Dain 


\section{La direction générale}

\author{
Comptabilité \\ et affaires financières \\ Marc Gélis, directeur

\section{Ressources humaines} \\ François Fort, directeur
}

\section{Aménagements} et maintenance

Didier Servat, directeur

Appui à la gestion

Christian Altairac, chef de service

\section{Outre-mer français}

François Pointereau, délégué

Délégations

dans l'outre-mer français (voir page 87)

\section{Information scientifique et technique}

Information et documentation

Lucile Grasset

Edition et multimédia

Martine Séguier-Guis

\section{Direction scientifique}

Directeur adjoint Jacques Meunier

\section{Délégations}

Agronomie, gestion de l'environnement et des ressources naturelles Eric Malézieux

Connaissance et amélioration des plantes Philippe Feldmann

Défense des cultures Jean-Philippe Deguine

Productions animales Philippe Lhoste

Technologie Guy Linden

Economie et sociologie Benoit Daviron

Mathématiques et informatique appliquées en cours de nomination

\section{Echanges scientifiques internationaux \\ Michel Benoit-Cattin}

\section{Observatoire} du changement

Marie de Lattre-Gasquet

\section{Direction des relations extérieures}

Afrique et océan Indien Jérôme Gauthier
Amérique latine et Caraïbe André de Courville

\section{Asie et Pacifique sud Patrick Durand}

Partenariats internationaux et méditerranéens Christian Hoste

\section{Représentations à l'étranger} (voir page 87 )

Partenariat de développement

Alain Guyot

\section{Communication externe}

Anne Hébert 


\section{Les départements du Cirad}

\section{Cultures annuelles (Cirad-ca)}

Alain Capillon, directeur

Jean-Luc Khalfaoui, directeur adjoint chargé

de l'animation scientifique

Jean-Marc Deboin, chef du service d'appui à la gestion Philippe Ourcival, chargé de la valorisation

Robert Domaingue, chef du programme canne

à sucre

Jacques Pagès, chef du programme coton

Pierre Fabre, chef du programme cultures

alimentaires

Francis Forest, chef du programme

écosystèmes cultivés

\section{Cultures pérennes (Cirad-cp)}

Denis Despréaux, directeur

Dominique Nicolas, directeur adjoint

chargé des affaires scientifiques

Thierry Corbineau, adjoint au directeur,

chef du service d'appui à la gestion

Christian Picasso, chargé de la valorisation

Philippe Petithuguenin, chef du programme cacao Dominique Berry, chef du programme café André Rouzière, chef du programme cocotier Jérôme Sainte-Beuve, chef du programme hévéa Alain Rival, chef du programme

palmier à huile

Productions fruitières et horticoles

(Cirad-fl hor)

Jean-Pierre Gaillard, directeur

Jacky Ganry, directeur adjoint

chargé des affaires scientifiques

Pierre-Jean Ballard, chef du service d'appui

à la gestion

Jean-Paul Meyer, chargé de la valorisation

Thierry Goguey Muethon, chef du programme arboriculture fruitière

Jacky Ganry, chef du programme bananiers, plantains et ananas

Rémi Kahane, chef du programme productions horticoles

Elevage et médecine vétérinaire (Cirad-emvt)

Joseph Domenech, directeur

Hubert Guerin, directeur adjoint chargé des affaires scientifiques

Guilhem Lacombe, chef du service d'appui à la gestion

Jérôme Thonnat, chef du service enseignement et formation

Jean-François Renard et Jean-Michel Sionneau, chargés de la valorisation
François Monicat, chef du programme écosystèmes naturels et pastoraux

Bernard Faye, chef du programme productions animales

Emmanuel Camus, chef du programme santé animale

Forêts (Cirad-forêt)

Jacques Valeix, directeur

Eric Loffeier, directeur adjoint chargé des affaires scientifiques

Yves Danglehant, adjoint au directeur, chef

du service d'appui à la gestion

Gilles Mille, chargé de la valorisation

Jean-Guy Bertault, chef du programme

forêts naturelles

Bernard Mallet, chef du programme

arbres et plantations

Christian Sales, chef du programme bois

Territoires, environnement et acteurs

(Cirad-tera)

Rolland Guis, directeur

Patrick Caron, directeur adjoint chargé des affaires scientifiques

Brigitte Nesius, chef du service d'appui à la gestion Anne-Marie Gotanègre, chargée de la valorisation

Bruno Losch, chef du programme agricultures familiales

Emmanuel Torquebiau, chef du programme espaces et ressources

Guy Faure, chef du programme savanes et systèmes irrigués

Alain Ducreux, chef du programme tropiques humides et insulaires

Amélioration des méthodes pour l'innovation scientifique (Cirad-amis)

Anne-Yvonne Le Dain, directrice

Gérard Chuzel, directeur adjoint chargé des affaires scientifiques

Francis Ercole, chef du service d'appui à la gestion

Alain Chauchard, chargé de la valorisation

Dany Griffon, chargé du suivi de la qualité

Gérard Chuzel, chef du programme agroalimentaire par intérim

Florent Maraux, chef du programme agronomie Jean Christophe Glaszmann, chef du programme biotechnologies et ressources génétiques végétales Daniel Deybe, chef du programme économie, politiques et marchés

Daniel Barthélémy, chef du programme modélisation des plantes

Xavier Mourichon, chef du programme protection des cultures 


\section{Le conseil scientifique}

Président

Guy Riba, Inra, France

Ricardo Abramovay, Cidade Universitaria, São Paulo, Brésil

Martine Antona, représentante élue des salariés Bernard Chevassus-au-Louis, Afssa, Inra, Mnhn Emile Cros, représentant élu des salariés Alain de Janvry, University of California, Etats-Unis Marcel de Raïssac, représentant élu des salariés

\section{Le comité d'éthique}

\section{Président}

Hubert Curien, président de l'Académie des sciences

Guy Aubert, directeur général du Cned, ancien directeur du Cnrs

Fifi Benaboud, conseillère principale auprès du directeur exécutif et coordinatrice du Programme transméditerranéen, Centre Nord-Sud du conseil de l'Europe

\section{Les délégations scientifiques}

Agronomie, gestion de l'environnement et des ressources naturelles

Délégué scientifique

Eric Malézieux

Comité scientifique

Président

Bernard Seguin, Inra

Membres externes

Christian Feller, Ird

Robert Habib, Inra

Bertrand Ney, Ina-pg

François Papy, Inra

Jean-Pierre Raison, université Paris $X$

Bernard Saugier, université Paris XI

Gilles Thevenet, Itcf

Jacques Wéry, Agro Montpellier

Connaissance et amélioration des plantes

Délégué scientifique

Philippe Feldmann

Chargée de mission

Hélène Joly
Bernard Dupuy, représentant élu des salariés Jacques Lançon, représentant élu des salariés Patrice Levang, Ird, Indonésie

Oumar Niangado, Délégation Fondation Novartis, Mali

Bernard Reynaud, Cirad, responsable du pôle de protection des plantes à la Réunion Janet Riley, lacr-Rothamsted, Royaume-Uni Herman Van Keulen, Plant Research International, Pays-Bas

Anne-Lucie Wack, Cirad

Jean Cases, directeur honoraire du Cnrs

Bernard Genetet, professeur émérite de la faculté de médecine de Rennes

Maurice Godelier, directeur d'études à l'Ehess Jean-François Mattéi, philosophe, Institut universitaire de France

Alain Ruellan, ancien directeur de l'Ird

Secrétariat général

Anne-Lucie Wack, Cirad

Comité scientifique

Président

André Charrier, Agro Montpellier

Membres externes

Michel Caboche, Inra

Michel Delseny, Cnrs, université de Perpignan

Serge Hamon, Ird

Antoine Kremer, Inra

Pierre-Louis Lefort, Geves

Défense des cultures

Délégué scientifique

Jean-Philippe Deguine

Comité scientifique

Président

Charles-Antoine Dedryver

Membres externes

Stéphane Blanc, Inra

Thierry Candresse, Inra

Alan Kirk, laboratoire européen Ebcl/Usda

Marc-Henri Lebrun, Cnrs, Aventis

Catherine Masson-Boivin, Lstm, Ird

Jean-Loup Notteghem, Agro Montpellier 
Technologie
Délégué scientifique

Guy Linden

Comité scientifique

Président

Didier Majou, Actia

Membres externes

Jean-Charles Costier, entreprise Costier, Perpignan

Robert Duchamp, Ensam, Paris

Gérard George, Skw, Grasse

Daniel Guitard, Lept-Ensam, Bordeaux

Philippe Schill, Michelin

Gilles Trystram, Ensia

Georges Vermeersch, Sofiproteol, Paris

Economie et sociologie

Délégué scientifique

Benoit Daviron

Comité scientifique

Président

Denis Requier-Desjardins, université

de Versailles-Saint-Quentin-en-Yvelines

Membres externes

Francis Akindes, université de Bouaké, Côte d'Ivoire Jean-Marie Boisson, université Montpellier I

Marie-Christine Cormier-Salem, Ird

Christopher Delgado, Ifpri

Afranio Garcia, Ehess

Sylvie Lambert, Inra

Bertil Sylvander, Inra

Steve Wiggins, université de Reading, Royaume-Uni
Productions animales

Délégué scientifique

Philippe Lhoste

Comité scientifique

Président

Bernard Hubert, Inra

Membres externes

François Bocquier, Agro Montpellier

Alain Bourbouze, lam

Jean Chantal, Env Toulouse

Antoine Cornet, Ird

Jean-Baptiste Coulon, Inra

Edmond Tchakérian, Institut de l'élevage

Mathématiques

et informatique appliquées

Délégué scientifique

en cours de nomination

Comité scientifique

Présidente

Elisabeth de Turckheim, Inra

Membres externes

Catherine Christophe, Inra

Gérard d'Aubigny, LabSad, Grenoble

Jean-Jacques Daudin, Ina-pg

Stéphane Grumbach, Inria

Michel Habib, Lirmm, Montpellier

Claude Lobry, Cimpa, Nice

Jean-Pierre Treuil, Ird

Burkina, Georges Subreville

Cameroun, Jean-Louis Reboul

Caraïbe (pays insulaires), Hubert Manichon

Chine, Zheng Li

Congo, Philippe Deleporte

Côte d'Ivoire, Patrice de Vernou

Etats-Unis, Jill Barr

Guinée, Edmond Viricelle

Indonésie, Gabriel de Taffin

Madagascar, Michel Partiot

Mali, Georges Subreville (en résidence

au Burkina), Yves Nouvellet, adjoint

Océan Indien, Michel Trebel

Pacifique sud, Thierry Mennesson

Sénégal, Jacques Dubernard

Thaïlande, Eric Gohet

Vanuatu, Jean-Pierre Labouisse

Vietnam, Gilles Mandret 


\section{Le Cirad dans le monde}

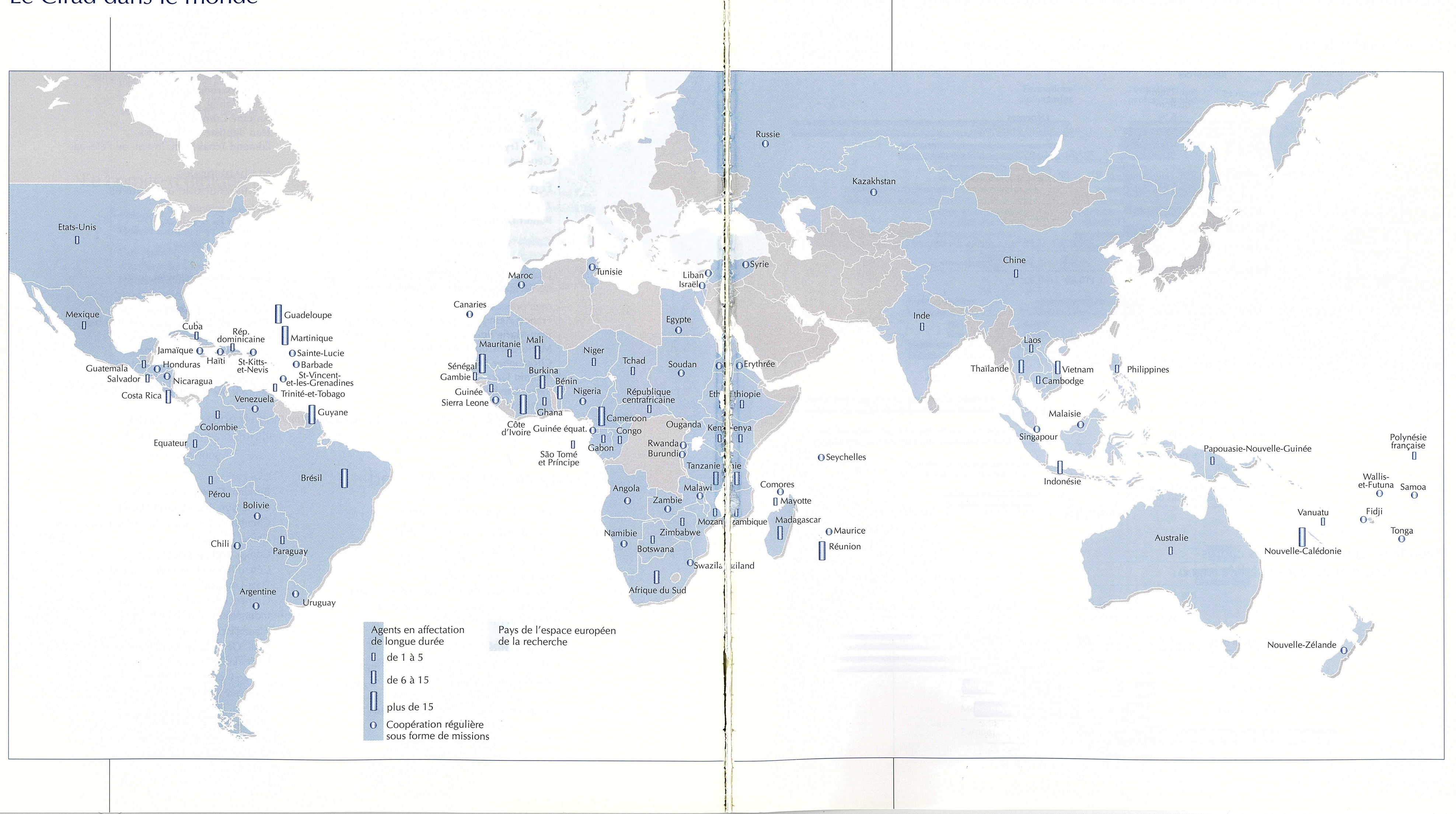




\section{Le budget et le personnel du Cirad en 2001}

\section{Ressources et dépenses}

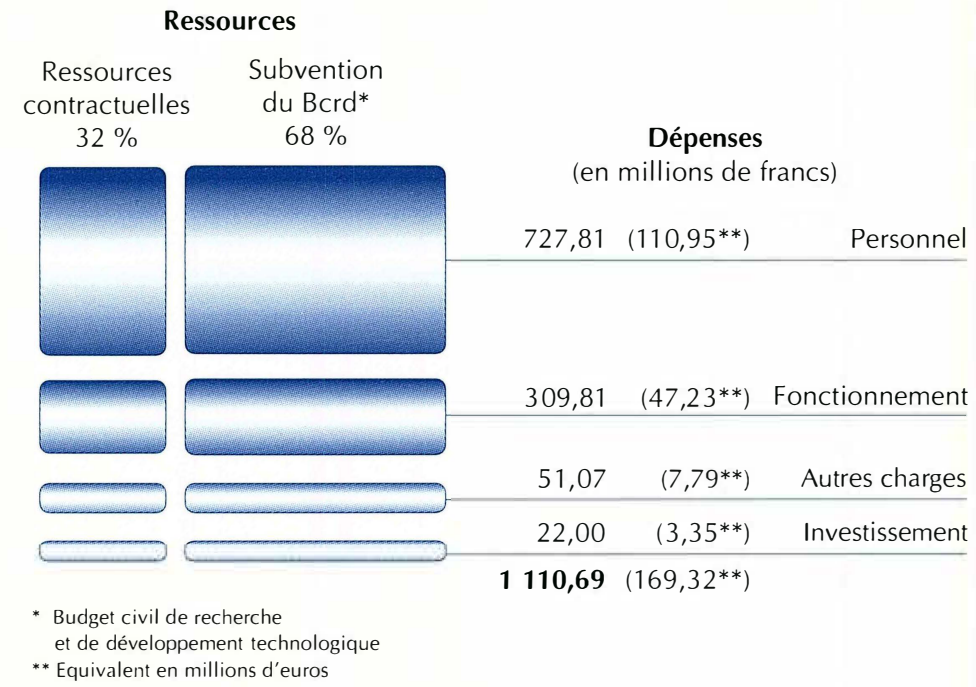

Répartition du personnel par catégorie et localisation

\begin{tabular}{l} 
Cadres en métropole \\
$\begin{array}{l}\text { Collaborateurs et agents } \\
\text { de maîtrise en métropole }\end{array}$ \\
$\begin{array}{l}\text { Cadres dans I'outre-mer français } \\
\text { et à l'étranger }\end{array}$ \\
$\begin{array}{l}\text { Collaborateurs et agents de maîtrise } \\
\text { dans l'outre-mer français et à l'étranger }\end{array}$ \\
\hline
\end{tabular}

Répartition géographique des cadres dans I'outre-mer français et à l'étranger

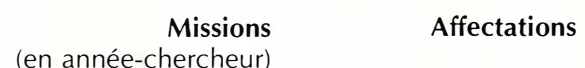

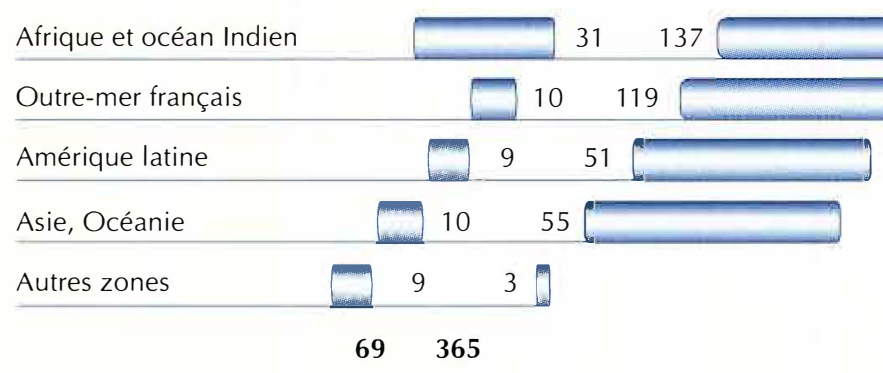




\section{Les chercheurs formés par le Cirad en 2001}

Répartition par discipline et par type de formation

$$
\begin{array}{cl}
\begin{array}{c}
\text { Formations } \\
\text { diplômantes }
\end{array} & \begin{array}{l}
\text { Formations } \\
\text { professionnelles }
\end{array}
\end{array}
$$

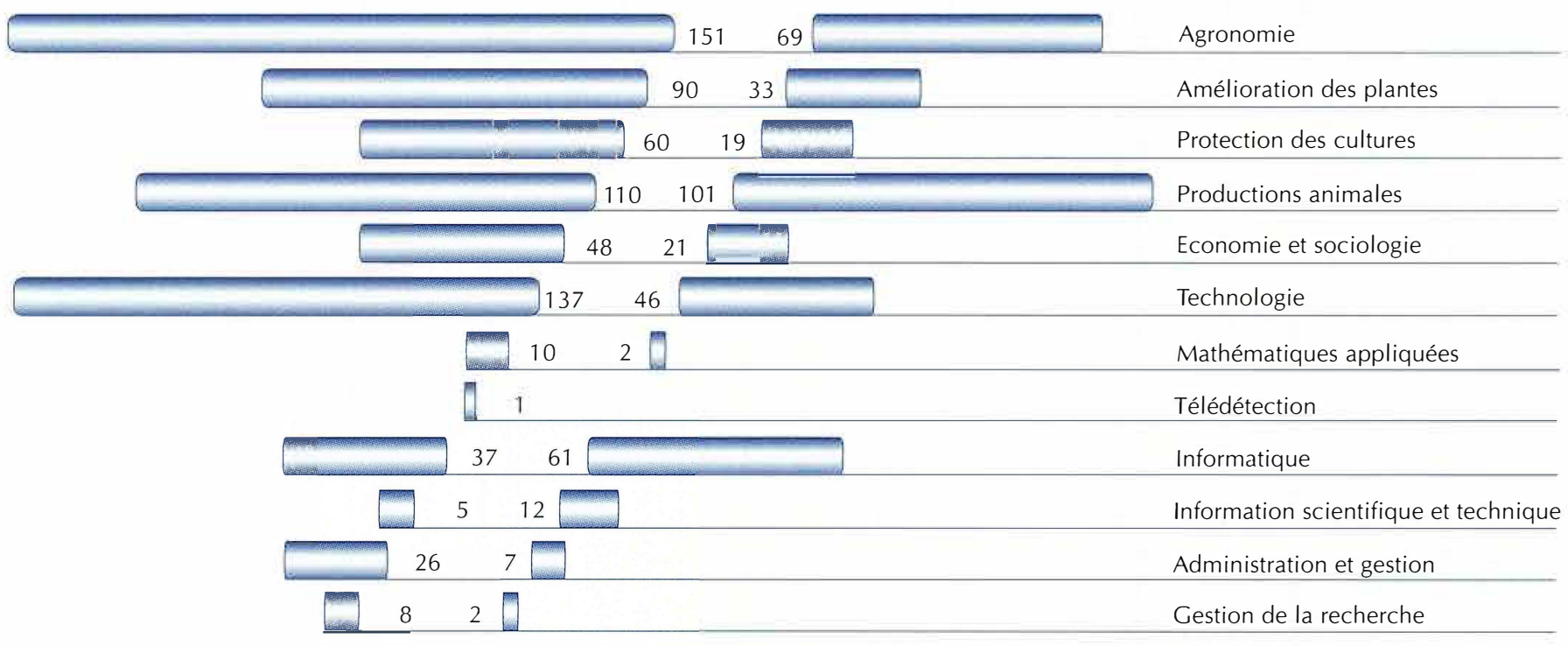

$683 \quad 373$

Origine géographique des chercheurs en formation

\begin{tabular}{l} 
Afrique du Nord \\
\hline Afrique de l'Ouest \\
\hline Afrique centrale \\
\hline Afrique de l'Est \\
\hline Afrique australe et océan Indien \\
\hline Amérique du Nord latine, Caraïbe \\
\hline Moyen-Orient, Asie, Océanie \\
\hline Europe
\end{tabular}




\section{Les adresses du Cirad}

Siège social

42, rue Scheffer

75116 Paris

France

Téléphone : 0153702000

Télécopie : 0147551530

Centre de recherche

de Montpellier

Avenue Agropolis

34398 Montpellier Cedex 5

France

Téléphone : 0467615800

Télécopie : 0467615986

Campus du Jardin tropical de Paris

45 bis, avenue de la Belle-Gabrielle

94736 Nogent-sur-Marne Cedex

France

Téléphone : 0143947200

Télécopie : 0143947349

Station de recherches agronomiques

Inra-Cirad de Corse

Sra Inra-Cirad

20230 San Giuliano

France

Téléphone : 0495595921

Télécopie : 0495595937

Le Cirad

dans l'outre-mer français

\section{Guadeloupe}

M. le délégué

Station de Neufchâteau

Sainte-Marie, 97130 Capesterre-Belle-Eau

Téléphone : 0590861790

Télécopie : 0590861791

\section{Guyane}

M. le délégué

BP 701, 97387 Kourou Cedex

Téléphone : 0594327350

Télécopie : 0594327351

\section{Martinique}

$M$. le délégué

BP 153, 97202 Fort-de-France Cedex

Téléphone : 0596719201

Télécopie : 0596630724

\section{Mayotte}

M. le délégué

BP 1304, 97600 Mamoudzou

Téléphone : 0269612121

Télécopie : 0269612119

\section{Nouvelle-Calédonie}

M. Thierry Mennesson, directeur général de I'Iac BP 73, 98890 Païta

Téléphone : (687) 437415

Télécopie : (687) 437416

\section{Polynésie française}

M. le délégué

BP 467, 98713 Papeete

Téléphone : (689) 424703

Télécopie : (689) 424693

\section{Réunion}

M. le délégué

BP 20, 97408 Saint-Denis Messageries Cedex 9

Téléphone : 0262528000

Télécopie : 0262528001

\section{Le Cirad à l'étranger}

Afrique de l'Est (Ethiopie, Kenya, Ouganda)

M. le correspondant

OAU/IBAR

Maendeleo House - Loïta Street

Po Box 30786, Nairobi

Téléphone : (254) 2250751 ou 733614408

Télécopie : (254) 2227270

\section{Afrique du Sud}

M. le représentant

Agribis C.C.

Po Box 70793, Bryanston 2021

Téléphone : (27) 117067783

Télécopie : (27) 117067654

\section{Amérique centrale}

M. le correspondant

c/o lica/Promecafe

Apartado postal 6742-1000, San José, Costa Rica

Téléphone : (506) 5560938

Télécopie : (506) 5560938

\section{Bénin}

$\mathrm{M}^{\text {me }}$ la correspondante

08 BP 1077, Cotonou

Téléphone : (229) 380034 ou 388086

Télécopie : (229) 300968

\section{Botswana}

M. le correspondant

c/o Saccar

Private Bag 00108, Gaborone

Téléphone : (267) 328775

Télécopie : (267) 328806 


\section{Brésil}

M. le représentant

SHIS-QI 15

Conjunto 3 , casa 1

71 635-230 Brasilia DF

Téléphone : (55) 612482079 ou 5665

Télécopie : (55) 612482619

\section{Burkina}

$M$. le représentant

01 BP 596, Ouagadougou 01

Téléphone : (226) 307070

Télécopie : (226) 307617

\section{Cameroun}

$M$. le représentant

BP 2572, Yaoundé

Téléphone : (237) 2212541

Télécopie : (237) 2202969

Caraïbe (pays insulaires)

M. le représentant

Station de Neufchâteau

Sainte-Marie, 97130 Capesterre-Belle-Eau

Guadeloupe - France

Téléphone : 0590861790

Télécopie : 0590861791

\section{Chine}

$M$. le représentant Inra-Cirad

501, Tower B of Fuhua Mansion

8, Chaoyangmen North Avenue

Dongcheng District

100027 Beijing

Téléphone : (86) 1065541871

Télécopie : (86) 1065541872

\section{Congo}

M. le correspondant

BP 1264, Pointe-Noire

Téléphone : (242) 943184

Télécopie : (242) 944795

\section{Côte d'Ivoire}

$M$. le représentant

01 BP 6483, Abidjan 01

Téléphone : (225) 20221869 ou 20211625

Télécopie : (225) 20214368

\section{Etats-Unis}

$M^{\text {me }}$ la correspondante

Development Research Associates

8313 Woodhaven Blvd.

Bethesda, Maryland 20817

Téléphone : (1) 3013656855

Télécopie : (1) 3013656855

Guinée

M. le correspondant

clo Scac

Ambassade de France

BP 570, Conakry

Téléphone : (224) 454246

Télécopie : (224) 454246

\section{Indonésie}

M. le représentant

Plaza Bisness Kemang, 3rd floor

Jalan Kemang Raya 2

Jakarta Selatan 12730

Téléphone : (62) 217199067 ou 217194601

Télécopie : (62) 2171793304

\section{Madagascar}

M. le représentant

Ampandrianomby

BP 853, Antananarivo

Téléphone : (261) 202240623

Télécopie : (261) 202240821

\section{Mali}

M. I'adjoint au représentant

BP 1813, Bamako

Téléphone : (223) 229054 ou 750150

Télécopie : (223) 218717

\section{Océan Indien}

$M$. le représentant

BP 20

97408 Saint-Denis Messageries Cedex 9

Réunion - France

Téléphone : 0262528000

Télécopie : 0262528001

\section{Pacifique sud}

$M$. le représentant

BP 73, 98890 Païta

Nouvelle-Calédonie

Téléphone : (687) 437415

Télécopie : (687) 437416

\section{Sénégal}

M. le représentant

37, avenue Jean XXIII

BP 6189, Dakar-Etoile

Téléphone : (221) 8224484

Télécopie : (221) 8211879

\section{Thaïlande}

M. le correspondant

Cirad Office

Administrative Building (9th floor)

Kasetsart University, Bangkhen Campus

10900 Bangkok

Téléphone : (66) 29428683

Télécopie : (66) 29428684

\section{Vanuatu}

$M$. le correspondant

BP 231, Santo

Téléphone : (678) 36320

Télécopie : (678) 36355

\section{Vietnam}

M. le représentant

Cirad Regional Representative

Fortuna Tower

12th floor unit 1206

6B Lang Ha Street, Hanoi

Téléphone : (84) 48314675 ou 903215792 (mobile)

Télécopie : (84) 48314676 


\section{Liste des sigles}

Aac, Australian Academy of Science, Australie Aciar, Australian Centre for International Agricultural Research, Australie

Acp, Afrique, Caraïbes, Pacifique

Ademe, Agence l'environnement et de la maîtrise de l'énergie, France

Afd, Agence française de développement, France Aflp, Amplified fragment length polymorphism

Afssa, Agence française de sécurité sanitaire des aliments, France

Agro Montpellier, Ecole nationale supérieure agronomique de Montpellier, France

Ait, Asian Institute of Technology, Thaïlande

Anacafe, Asociación Nacional del Cafe, Guatemala

Avrdc, Asian Vegetable Research and Development Center, Taïwan

Bnetd, Bureau national d'études techniques

et de développement, Côte d'Ivoire

Brg, Bureau des ressources génétiques, France

Caobisco, Association des industries de la chocolaterie, de la biscuiterie et de la confiserie, Belgique

Carbap, Centre africain de recherches sur bananiers et plantains, Cameroun

Catie, Centro Agronómico Tropical de Investigación y Enseñanza, Costa Rica

Cbgp, Centre de biologie et de gestion des populations, France

Cedimes, Centre d'études du dévéloppement international et des mouvements économiques et sociaux, France

Cemagref, Centre national du machinisme agricole du génie rural, des eaux et des forêts, France

Cenargen, Centro Nacional de Pesquisa de Recursos genéticos e biotechnologia, Brésil

Ceraas, Centre d'étude régional pour l'amélioration de I'adaptation à la sécheresse, Sénégal

Cerna, Centre régional de nutrition et d'alimentation appliquées, Bénin

Ces, Centre de suivi écologique, Sénégal

$\mathrm{Cfc}$, Commun Fund for Commodities

Cfsige, Centre de formation aux sciences de l'information géographique et de l'environnement, Madagascar

Cicy, Centro de Investigación Científica de Yucatán, Mexique

Ciepac, Centre international pour l'éducation permanente et I'aménagement concerté, France

Cifor, Center for International Forestry Research, Indonésie Cip, Centro Internacional de la Papa, Pérou
Cirdes, Centre international de recherche-développement sur l'élevage, Burkina

Cired, Centre international de recherche sur l'environnement et le développement, France

Cna, Centre national antiacridien, Madagascar

Cnearc, Centre national d'études agronomiques des régions chaudes, France

Cnra, Centre national de recherche agronomique, Côte d'Ivoire

Cnre, Centre national de recherche sur l'environnement, Madagascar

Cnrs, Centre national de la recherche scientifique, France

Cns, Centre national de séquençage, France

Codevasf, Companhia de Desenvolvimento de Vale do São Francisco, Brésil

Conicyt, Comisión Nacional de Investigación Científica y Tecnológica, Venezuela

Coraf, Conseil ouest et centrafricain pour la recherche et le développement, Sénégal

Cpaaf, Centro de Pesquisa Agroforestal da Amazónia, Brésil Ehess, Ecole des hautes études en sciences sociales, France

Eismv, Ecole inter-Etat de sciences et médecine vétérinaire, Dakar, Sénégal

Embrapa, Empresa Brasileira de Pesquisa Agropecuaria, Brésil

Engref, Ecole nationale du génie rural, des eaux et des forêts, France

Ensa, Ecole nationale supérieure agronomique, Sénégal Ensam, Ecole nationale supérieure des arts et métiers, France Ensar, Ecole nationale supérieure agronomique de Rennes, France

Ensia, Ecole nationale supérieure des industries agricoles et alimentaires, France

Ephe, Ecole pratique des hautes études, France

Essa, Ecole supérieure des sciences agronomiques, Madagascar

Env, Ecole nationale vétérinaire, France

Fao, Food and Agriculture Organization of the United Nations, Italie

Fcr, Fonds de coopération régionale, Guyane

Ffem, Fonds français pour l'environnement mondial, France

Fofifa, Centre national de recherche appliquée au développement rural, Madagascar

Frutotec, Centro de Technologia de Hortifrutícolas, Brésil

Fundecitrus, Fundo de Defesa de Citricultura, Brésil

Funai, Fundacão Nacional do Indio, Brésil 
Gcrai, Groupe consultatif pour la recherche agricole internationale, Etats-Unis

Geves, Groupement d'étude et de contrôle des variétés et des semences, France

Gtz, Deutsche Gesellschaft für technische

Zusammenarbeit, Allemagne

lac, Institut agronomique néo-calédonien,

Nouvelle-Calédnonie

lam, Institut agronomique méditerranéen Montpellier, France

Icafé, Instituto del café, Costa Rica

Icgi, International Cotton Genome Initiative

Icra, Institut centrafricain de recherche agronomique,

République centrafricaine

Icrisat, International Crops Research Institute for the

Semi-Arid Tropics, Inde

ledes, Institut d'étude du développement économique

et social, France

lem, Institut européen des membranes

ler, Institut d'économie rurale, Mali

Ifen, Institut français de I'environnement, France

Ifpri, International Food Policy Research Institute, Etats-Unis

lica, International Institute for Cooperation in Agriculture,

Costa Rica

Ilri, International Livestock Research Institute

Ina-pg, Institut national agronomique Paris-Grignon, France

Inia, Instituto Nacional de Investigação Agronomíca,

Mozambique

Inibap, International Network for the Improvement of

Banana and Plantain, France

Inpa, Instituto Nacional de Pesquisa do Amazonia

Inra, Institut national de la recherche agronomique, France

Inrab, Institut national de recherches agricoles du Bénin,

Bénin

Inria, Institut national de recherche en informatique

et en automatique, France

Insah, Institut du Sahel, Mali

los, Institut de sociologie, Vietnam

Ipgri, International Plant Genetic Ressources Institute, Italie

Irad, Institut de recherche agricole pour le développement,

Cameroun

Irag, Institut de recherche agronomique de Guinée, Guinée

Iram, Institut de recherches et d'applications des méthodes

de développement, France

Ird, Institut de recherche pour le développement, France

Irrdb, International Rubber Research and Development

Board, Malaisie

Irri, International Rice Research Institute, Philippines

Isra, Institut sénégalais de recherches agricoles, Sénégal

Issct, International Society of Sugar Cane Technologists,

Etats-Unis

Istom, Institut supérieur d'agroéconomie international, France

Itc, International Trypanotolerance Center, Gambie

Itcf, Institut technique des céréales et des fourrages, France
Itrad, Institut tchadien de recherche agronomique pour le développement, Tchad

Lead, Livestock, Environment and Development (en français, Initiative élevage, environnement, développement)

Lepse, Laboratoire d'écophysiologie des plantes sous stress environnementaux, France

Liama, Laboratoire franco-chinois d'informatique et de mathématiques appliquées, Chine

Lirmm, Laboratoire d'informatique, de robotique et de micro-électronique de Montpellier, Cnrs, France

Lrvz, Laboratoire de recherche vétérinaire et zootechnique, Tchad

Minef, Ministère de l'environnement et des forêts, Cameroun

Mpob, Malaysian Palm Oil Board, Malaisie

Niah, National Institute for Animal Husbandry, Vietnam

Nipp, National Institute of Plant Protection, Vietnam

Odi, Overseas Development Institute, Royaume-Uni

Oie, Office international des épizooties

Omc, Organisation mondiale du commerce, Suisse

Oua, Organisation de l'unité africaine

Pac, Politique agricole commune

Pace, Programme africain de contrôle des épizooties

Pcr, Polymerase chain reaction

Ppzs, Pôle pastoral zones sèches, Sénégal

Prasac, Pôle régional de recherche appliquée au développement des savanes d'Afrique centrale, Tchad

Psaop, Programme de services agricoles et d'organisations de producteurs, Sénégal

PT Smart, PT Sinar Mas Agro Ressources and Technology Corporation, Indonésie

Qfri, Queensland Forest Research Institute, Australie

Qtl, Quantitative trait loci

Rflp, Restriction fragment length polymorphism

Rifav, Research Institute on Fruits and Vegetables, Vietnam Rivm, Rijksinstituut voor Volksgezondheid en Milieu, Pays-Bas

Roselt, Réseau d'observatoires de surveillance écologique à long terme

Rrit, Rubber Research Institute of Thailand, Thaïlande

Sbl, Société des bois de Lastourville, Gabon

Sig, Système d'information géographique

Siupa, Initiative stratégique pour l'agriculture urbaine et périurbaine

Sodecoton, Société de développement du coton, Cameroun

Tansao, réseau régional d'amélioration du taro pour l'Asie du Sud-Est et l'Océanie

Ucad, Université Cheikh Anta Diop, Dakar, Sénégal

Unicamp, Universidade Estadual de Campinas, Brésil

Usp, Universidade de São Pãolo, Brésil

Utc, Université de technologie de Compiègne, France

Vasi, Institut des sciences agronomiques, Vietnam 


\section{Illustration de couverture}

Copyright réservé

\section{Photographies}

Page 9 : Cirad, A. Ferment, A. Miquel, H. Planton ;

page 10 : I. Duriez, M. Raunet, R. Pirot, A. Rival ;

page 11 : P.-Y. Le Gal, D. Snoeck, G. Trébuil, G. Trébuil.

Production, maquette, illustrations et fabrication

Délégation à l'information scientifique et technique

Service des éditions et du multimédia

Louma productions, 34 Aniane

Avec la participation du pôle images du Cirad et du service de communication du Cirad-tera

\section{Photogravure}

Flash Espace, 34 Montpellier

Impression

Basic Color, 30 Nîmes

Dépôt légal $3^{\mathrm{e}}$ trimestre 2002

Cet ouvrage est également publié en anglais 



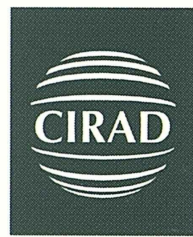

\section{Centre}

de coopération internationale en recherche agronomique pour le développement

42, rue Scheffer 75116 Paris

France

www.cirad.fr

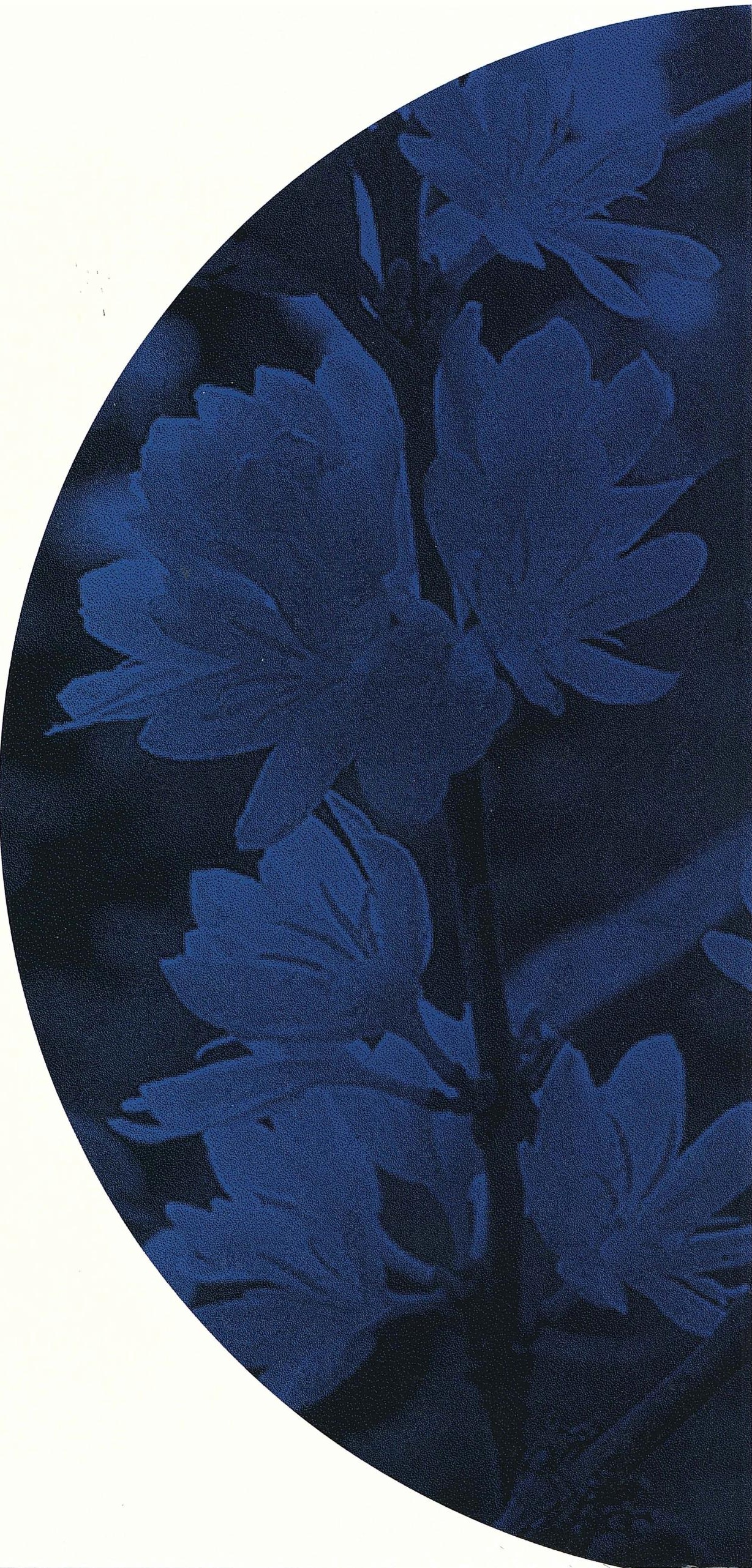

